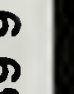
n 
Digitized by the Internet Archive in 2008 with funding from Microsoft Corporation 


\section{.}





\title{
THE WATER-RELATION BETWEEN PLANT AND SOIL
}

BY

\author{
BURTON E. LIVINGSTON AND LON A. HAWKINS
}

\section{THE WATER-SUPPLYING POWER OF THE SOIL AS INDICATED BY OSMOMETERS}

BY

HOWARD E. PULLING AND BURTON E. LIVINGSTON

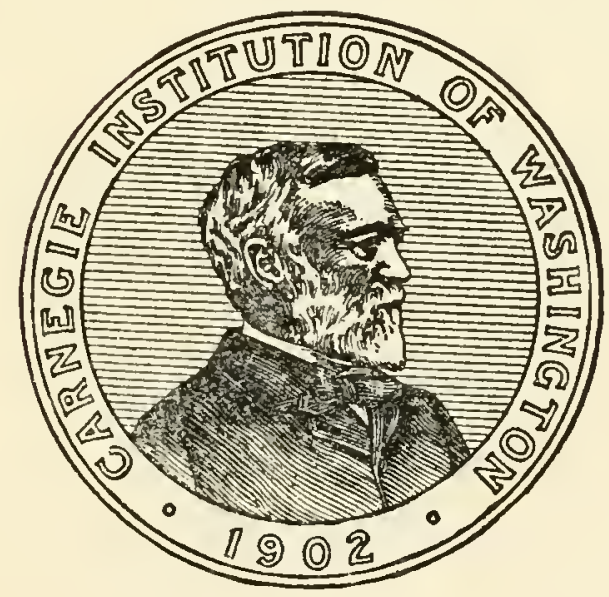

WASHINGTON, D. C.

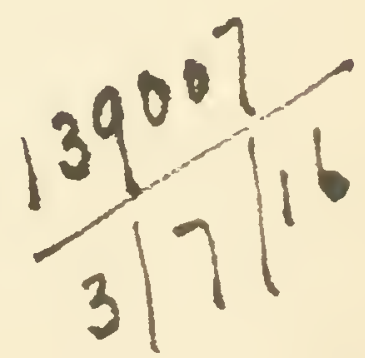

Published by the Carnegie Institution of: Washington 


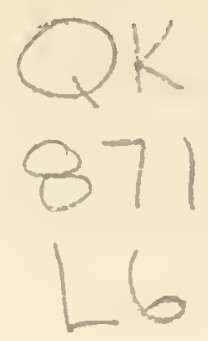

CARNEGIE INSTITUTION OF WASHINGTON

Publication No. 204

Botanical Contributions from the Johns Hopkins University, Nos. 38 and 39.

Copres of this Book

wore first issued

MAR 101915

TRESG OF GIBSON BROTHERS

WASHINGTON, D. C. 
THE WATER-RELATION BETWEEN PLANT AND SOIL

BY

BURTON E. LIVINGSTON AND LON A. HAWKINS 



\section{THE WATER-RELATION BETWEEN PLANT ANI) SOIL.}

\section{INTRODUCTION.}

The work of Dixon ${ }^{1}$ and his colleagues, and that of Renner, ${ }^{2}$ of Overton, ${ }^{3}$ and others have at length placed upon what appears to be a rational physical basis the long-vexed question of the dynamics of the ascent of water in plants, and recent studies of the relation of the evaporating power of the air ${ }^{4}$ and that of sunshine ${ }^{5}$ to plant transpiration have made it possible at least to begin to consider the problems of the aerial water relation of plants as involving measurable forces or powers. Our knowledge of the subterranean water-relation of plants remains, however, in an exceedingly primitive condition, although the a priori analysis of the problem here involved may be carried forward beyond the ability of present methods to furnish experimental data.

Livingston ${ }^{6}$ has insisted that the power of the soil to deliver water to root surfaces is the prime external condition determining the moisture supply to plants in non-saline and non-toxic soils, and the same writer has emphasized the need of some adequate method for determining this water-supplying power of the soil. Such a method is not yet at hand, though encouraging progress toward its attainment has recently

${ }^{1}$ Dixon, H. H., Transpiration and the ascent of sap. Prog. Rei Bot. 3: 1-66. 1909.

${ }^{2}$ Renner, O., Beiträge zur Physik der Transpiration. Flora 100: 451-547. 1910.

—- Experimentelle Beiträge zur Kenntnis der Wasserbewegung. Flora 103: 171-247. 1911.

${ }^{3}$ Overton, J. B., Studies on the relation of the living cells to the transpiration and sap-flow in Cyperus. Bot. Gaz. 51: 28-63, 102-20. 1911.

${ }^{4}$ Livingston, B. E., The relation of desert plants to soil moisture and to evaporation. Carnegie Inst. Wash. Pub. 50. Washington. 1906.

, Relative transpiration in cacti. Plant World 10: 110-14. 1907.

- A rain-correcting atmometer for ecological instrumentation. Plant World 13: 79-82. 1910.

- The resistance offered by leaves to transpirational water loss. Plant World 16: 1-35. 1913.

Harvey, E. M., The action of the rain-correcting atmometer. Plant World 16: 89-93. 1913.

${ }^{6}$ Livingston, B. E., A radio-atmometer for measuring light intensity. Plant World 14: 96-9. 1911.

- Light intensity and transpiration. Bot. Gaz. 52: 418-38. 1911.

${ }^{6}$ Livingston, B. E., 1906, page 19 el seq.

- Roles of the soil in limiting plant activities. Plant World 12: 49-53. 1909.

, The relation of the osmotic pressure of the cell sap in plants to arid habitats. Plant World 14: 153-64. 1911.

—. Present problems of physiological plant ecology. Amer. Nat. 43: 369-77. 1909. [The essentials of this paper appeared also, with same title, in Plant World 12: 41-6. 1909.] -, Present problcms in soil physics as related to plant activities. Amer. Nat. 46: 294-301. 1912.

_. Osmotic pressure and related forces as environmental factors. Plant World 16: 165-76. 1913.

Free, E. E., Studies in soil physics. Plant World 14: 29-39, 59-66, 110-19, 164-76, 186-90. 1911. Also reprinted, repaged. Tucson. 1912. 
been announced. ${ }^{1}$ It is clear that this soil property must be expressed as a rate; it is a dynamic rather than a static concept. It should be properly expressed as a number of weight units of water possibly delivered to (or through) unit cross-sectional area of the soil, per unit time. Such a water-supplying power of the soil should take a place in studies of subterranean plant environment, corresponding to that occupied by atmometrical measurements in the characterization of the water-extracting power of aerial environments.

While the dynamic aspect of the subterranean water-relation of plants has thus begun to attract attention, the static properties of soils have received more or less continued study for a long time and it seems probable that, under certain more or less limited conditions, the water-supplying power of a soil may eventually be derived from the proper ones of its static properties. Such an outcome is still very far from attainment, however, and the latter properties remain merely as terms in the description of soils as such rather than as environmental complexes influencing plant phenomena.

The relative proportions of differently sized particles in the soil are now to be determined with comparatively great precision. ${ }^{2}$ The moisture-content of soils is determined by the method of weighing, drying, and reweighing. The water-holding power is apparently best found by the use of a one-centimeter column ${ }^{3}$ of soil in a suitable container. Briggs and McLane ${ }^{4}$ have recently introduced the so-called moisture equivalent in place of the water-holding power and the former appears more useful than the latter in some ways. ${ }^{5}$ This is the waterholding power of the soil when subjected to a water-removing, centrifugal force equal to a thousand times that of gravitation. The aggregate surface of the soil particles can be measured in several ways, the most satisfactory being that of Mitscherlich, ${ }^{6}$ which determines calorimetrically the "heat of wetting."

Another physical constant of the soil has been brought forward by Cameron and Gallagher, " the "critical moisture content," which bids

${ }^{1}$ MacDougal, D. T., Department of Botanical Rescarch. Carnegic Inst. Wash. Year Book 12: 78. 1913. [ $\Lambda$ report of this work, by Pulling and Livingston, appears as the second paper in the present publication.]

${ }^{2} \mathrm{On}$ the mechanical analysis of soils, as well as on the determination of other static eharacters, see treatises on soil physies, such as the following:

Hilgard, E. W. Soils, their formation, properties, composition, and relations to climate and plant growth in the humid and arid regions. New York and London. 1912.

Mayer, Adolf, Dic Bodenkunde. Heidelberg. 1905.

Mitscherlich, Eilh. Alfred, Bodenkunde für Land- und Forstwirte. Berlin. 1905.

Wahnschaffe, F., Wissenschaftliche Bodenuntersuchung. Berlin. 1903.

Also see: Briggs, L. J., F. O. Martin, and J. R. Pearce, The centrifugal method of mechanieal soil analysis. U. S. Dept. Agric., Bur. Soils Bull. 24. 1904.

${ }^{3}$ Hilgard, 1912., page 209. Also, Wahnschaffe, 1903, page 160 el seq.

${ }^{4}$ Briggs, L. J., and J. W. McLane, The moisture equivalents of soils. U. S. Dept. Agric., Bur. Soils Bull. 45. 1907.

${ }^{5}$ For some bricf but clear remarks in this eonnection, sec Free, 1912.

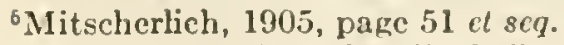

${ }^{7}$ Cameron, F. K., and F. E. Gallagher, Moisture content and ply'sical condition of soils. U.S. Dept. Agric., Bur. Soils Bull. 50. 1908. 
fair to become of considerable use in soil studies. This is a moisture content at which penetrability is least, and its value is nearly the same as that of Briggs's and McLane's moisture equivalent. There are at present, however, rather grave difficulties in its direct experimental determination.

Another newly studied physical soil characteristic which, under certain conditions, may have great value in connection with ecological (including agricultural) inquiries is brought forward by the work of Briggs and Shantz. ${ }^{1}$ This is the "wilting coefficient" or the moisture residuum left in the soil when wilting of the plant has so far progressed that recovery can not be attained in a water-saturated atmosphere, without increase in the soil-moisture content. Under some conditions it appears that this is truly a soil constant, uninfluenced by the plant or the aerial conditions, but the work of Caldwell ${ }^{2}$ and that of Shive and Livingston ${ }^{3}$ bring out the apparent fact that, for most atmospheric conditional complexes encountered in nature, the aerial conditions are decidedly not without influence upon the soil-moisture residuum here dealt with. It appears, in any event, as though this character might be very useful if its value be accompanied by atmometric data. The coefficients obtained by Briggs and Shantz are shown by them to be mathematically deducible from other soil constants, at least under certain conditions. For the present this whole matter must be left in abeyance until investigation may be carried further. In the meantime, it is worthy of special note that Briggs and Shantz have made the first logical attempt to express as a single magnitude the several variables which are determined in the mechanical analysis of soils. This appears to be a definite advance in soil physics.

Still another newly advocated function of certain physical properties of the soil has been shown to be of value in considerations of the waterrelations between some soil types and the plants naturally occurring thereon. This is Crump's "coefficient of soil humidity," which is the ratio of the water content to the humus content, both expressed as percentage of the dry weight of the soil. This constant is apparently of value with soils of considerable humus content, but is only a directly empirical one at best, and can not be expected to prove generally useful, as is indeed pointed out by its author.

${ }^{B}$ Briggs, L. J., and H. L. Shantz, A wax seal method for determining the lower limit of available soil moisture. Bot. Gaz. 51: 210-19. 1911.

_- Application of wilting coefficient determinations in agronomic investigations. Proc. Amer. Soc. Agron. 3: 250-60. 1912.

- The wilting coefficient and its indirect determination. Bot. Gaz. 53: 20-37. 1912.

_-, The relative wilting coefficients for different plants. Bot. Gaz. 53: 229-35. 1912.

- The wilting coefficient for different plants and its indirect determination. U.S. Dept. Agric., Bur. Plant Ind. Bull. 230. 1912.

- Die relativen Welkungskoefizienten verschiedener Pflanzen. Flora 105: 224-40. 1913.

${ }^{2}$ Caldwell, J. S., The relation of environmental conditions to the phenomenon of permanent wilting in plants. Physiol. Res. 1: 1-56. 1913.

${ }^{3}$ Shive, J. W, and B. E. Livingston, The relation of atmospheric evaporating power to soilmoisture content at permanent wilting in plants. Plant World 17: 81-121. 1914.

${ }^{4}$ Crump, W. B., Notes on water content and the wilting point. Jour. Ecol. 1: 96-100. 1913. 
It is readily recognized that the physical properties of the soil, as this term is usualiy employed, depend in great measure on the state of aggregation of the ultimate soil units. Only when these units alone are dealt with is the mechanical analysis of any value in defining a soil. The state of aggregation, or of packing, is clearly of profound importance in determining such properties as water-holding power, and the state of packing becomes frequently the prime controlling condition in the determination of the optimum or critical water content of Cameron and Gallagher. The moisture content of the soil, on the other hand, is a property that fluctuates with climatic and drainage conditions, and, within rather widely separated limits, bears no direct relation to the nature and size of the soil particles. Thus, it must be necessary to measure at least two physical properties (one of which is the moisture content) before the water-supplying power of the soil may possibly be determined indirectly. Such indirect determination is of course quite impossible at present, and the only means so far proposed for comparing water-supplying powers of different soils, or of the same soil at different times, depends upon direct measurement. Two such methods have been suggested. One proposes to measure the highest possible rate of evaporation attainable from unit surface of the soil. ${ }^{1}$ The other proposes to determine the highest possible rate at which an osmometer may withdraw moisture from the soil, per unit of surface. ${ }^{2}$ Neither of these methods appears as yet to have been subjected to an actual working test under field conditions. Nor does the "artificial root-hair" of Briggs and McCall, ${ }^{3}$ by which water is removed from the soil through a porous clay filter-candle attached to a vacuum bottle, seem to have received the attention, in this connection, which it apparently deserves.

The water-supplying power of the soil (which, as has been pointed out, is the time rate of possible water delivery at unit cross-sectional area in the soil) depends, obviously, upon the resistance to water absorption offered by the soil layer adjacent to the absorbing surface. This, in turn, is a function (1) of the nature and arrangement of the soil particles in this active layer, and (2) of the water content of the latter. The nature and arrangement of the soil particles may be assumed to remain practically constant in this layer after the soil mass as a whole has once settled into an approximate static equilibrium, but root absorption itself necessarily decreases (or tends to decrease) the water content of the soil from which water is removed. Whatever

\footnotetext{
${ }^{1}$ Livingston, 1906, page 37.

${ }^{2}$ Whitney, M., and F. K. Cameron, The chemistry of the soil as related to crop production. U. S. Dept. Agric., Bur. Soils Bull. 22. 1903.

Livingston, 1906, page 20 et seq.

MacDougal, 1914, page 78.

Pulling and Livingston, the second paper of the present publication.

${ }^{3}$ Briggs, L. J., and A. G. McCall, An artificial root for indueing capillary movement of soil moisture. Science N. S. 20: 566-9. 1904.
} 
may be the nature of the forces producing the migration of water from soil to plant (it seems that osmotic pressure does not play a prime and direct role in this movement, though the opposite has been frequently supposed), ${ }^{1}$ any decrease in the water content of the soil layer adjacent to the absorbing surface must result in an increased attraction of this layer for water. The more water is removed the thinner must be the water films about and between the soil grains. Concomitant with this increased attraction must occur an increased resistance to water movement from soil to plant and, at the same time, must also occur an increased tendency for water to move into the layer in question from more distant soil layers. If the rate of this latter movement equals the rate of removal of water at the absorbing surface, the increase in resistance to absorption just postulated can not occur and the absorbing surface is then drawing moisture from the more distant layers. On the other hand, as soon as the rate of migration of water from more distant soil to the active layer adjacent to the roots becomes less than that of water entrance into the absorbing surfaces, then the active soil layer (next to the root surfaces) must become drier and an increased resistance to absorption must develop. Thus the power of the soil to supply moisture to roots, depending directly upon the waterattracting power of the adjacent soil layer, must depend indirectly upon the resistance offered by more distant layers to the replacement of the water which has been absorbed. Of course, the latter resistance is a function of the nature and arrangement of these more distant portions of the soil and of their moisture content. It is not to be forgotten that the moisture content of the soil layer adjacent to the absorbing surfaces is largely dependent, at any given time, upon the rate of absorption itself during past time periods. It should also be mentioned here that the tendency of the roots to absorb water and that of the air above the soil to remove water by evaporation may create a tension in the capillary water films for considerable distances through the soil, and this tension acts to retard root absorption, without appreciable drying of the soil.

It is universally patent that transpiration accounts for practically all of the water requirement of ordinary plants in their vegetative phases and it is no less well known that the transpiration rate varies in magnitude from a minimum in the night to a much greater maximum in the day. It follows, then, as is also well known, that the water requirement of the plant as a whole varies through a similar range of magnitudes.

\footnotetext{
${ }^{1}$ For brief reference to this matter, which should some time be investigated, see:

Dixon, 1909.

Renner, O., Versuche zur Mechanik der Wasserversorgung. 2. Ueber Wurzeltätigkeit (Vorläufige Mitteilung). Ber. deutsch. Bot. Ges. 30: 642-8. 1912.

Livingston, 1906, page 21.

Also see: Livingston, B. E., The relation of the cell sap in plants to arid habitats. Plant World 14: 159 et seq. 1911.
} 
Renner (1911), and Livingston and Brown ${ }^{1}$ have shown that the saturation deficit in the plant varies with the transpiration rate, and the last-named writers have shown that the moisture content of foliage leaves is relatively low in the latter part of the day (at least in a somewhat arid climate) and very much higher in the later hours of the night. The same has been shown by Lloyd. ${ }^{2}$ Caldwell (1913) appears to be quite correct in supposing that the state of incipient drying must progress from the leaves toward the roots with the advance of the day, and it follows from this that the highest magnitude of the water requirement at the root surfaces should occur at a time somewhat later in the day than that at which occurs the highest transpiration rate. The lag thus postulated for the "Saugungswelle," or suction wave as Renner has termed it, as the latter progresses from leaves to roots, has been suggested by many studies of transpiration and absorption in the case of cut shoots absorbing from potometers. Edith B. Shreve ${ }^{3}$ has found incipient drying in the branches of a desert tree, similar to that found by Livingston and Brown and by Lloyd in leaves. So far as we are aware, however, Renner is the only writer who has thus far actually dealt experimentally with the forces involved in the absorption of water by roots and their relation to water movement within the plant and water loss therefrom. In the first place, Renner'st very ingenious experimental studies on water tension existing in ordinary plants showed that the magnitude of this tension frequently surpasses that of an atmosphere, even for low plants rooted in unusually wet soil and exposed to the air of a rainy summer in Munich. Furthermore, the same writer ${ }^{5}$ was able to demonstrate, not only that this tension is transmitted to the roots, but also that comparatively small alterations in its magnitude (resulting from changes in the transpiration rate or in the resistance to water absorption) are so propagated. His experiments lead Renner to the conclusion that the absorptive power of the roots is due to tension thus transmitted from the transpiring parts. This is exactly what should be expected from the existence of tension in the water mass of the plant body (arising from whatever cause and in whatever region) and from the consideration that such tension in a liquid should be transmitted equally in all directions, as far as the liquid extends. It seems to the present writers that Renner's conclusions in regard to the general mechanics of water

\footnotetext{
${ }^{1}$ Livingston, B. E., and W. H. Brown, Relation of the daily mareh of transpiration to variations in the water content of foliage leaves. Bot. Ga\%. 53: 311-30. 1912.

${ }^{2}$ Lloyd, F. E., The relation of transpiration and stomatal movements to the water content of the leaves of Fouquicria splendens. Plant World 15: 1-1.1. 1912.

${ }^{3}$ Shreve, Edith 13., The daily march of transpiration in a desert perennial. Carnegic Inst. Wash. Pub. 194. Washington. 1914.

${ }^{4}$ Renner, O., Versuche zur Mechanik der Wasserversorgung. 1. Der Druck in den Leitungsbahnen von Frielandpflanzen (Vorlïufige Mitteilung). Ber. deutsch. Bot. Ges. 30 : 576-80. 1912.

${ }^{5}$ Renner, $1912(2)$.
} 
absorption are entirely sound. It may well develop, however, that the propagation of the "suction wave" from leaves to roots may not always be so nearly instantaneous as the experiments of the lastmentioned writer indicate, for it is well known that there are gasbubbles in some vessels of stems and roots.

Certain phases of the general problem of plant water-relations have been considered by Dachnowski, ${ }^{1}$ whose paper should be read in this connection.

The present paper deals with a first attempt to study the relation between the diurnal march of the transpiration rate and the corresponding march of the water-attracting power of the soil, in the case of potted plants. The method employed is new and will require a somewhat full description.

METHOD.

\section{APPARATUS AND MANIPULATION.}

The auto-irrigator, devised by Livingston ${ }^{2}$ for the maintenance of an approximately constant soil-moisture content, especially in the case of plants growing in pots or boxes, was here employed. The device consists of a porous clay cup, such as is now widely used in atmometry, tightly stoppered and joined by a tube to a water reservoir at a lower level, tube and cup being filled with water and the free end of the former dipping below the water surface in the reservoir. The forces of adhesion, cohesion, and surface tension (capillarity) draw water from the cavity of the cup into its porous walls, in a manner exactly similar to that involved in the original wetting of the cup walls in the porous cup atmometer. ${ }^{3}$ If water is externally removed from the cup walls more enters from within, the cavity of the cup being kept filled with water by atmospheric pressure on the free water surface in the reservoir; air does not pass the wet walls, excepting, of course, as it dissolves in the contained water. In the porous cup atmometer

${ }^{1}$ Dachuowski, A., Transpiration in relation to growth and to the successional and geographic distribution of plants. Ohio Naturalist 14: 241-51. 1914.

${ }^{2}$ Livingston, B. E., A method for controlling plant moisture. Plant World 11: 39-40. 1908.

Hawkins, Lon A., The porous clay cup for the automatic watering of plants. Plant World 13: $220-27.1910$.

Transeau, E. N., Apparatus for the study of comparative transpiration. Bot. Gaz. 52:54-60. 1911.

${ }^{3}$ Babinet, J., Note sur un atmidoscope. Compt. Rend. 27: 529-30. 1848.

Marié-Davy, H., Atmidomètre à vase poreux de Babinet. Nouv. Mét. 2: 253-4. 1869.

Mitscherlich, E. A., Ein Verdunstungsmesser. Landw. Versuchsst. 60: 63-72. 1904.

Livingston, 1906, page 24 et seq.

, Operation of the porous cup atmometer. Plant World 13: 111-S. 1910. [This paper gives a list of literature references, to which additions are made in the following two citations.]

, A rotating table for standardizing porous cup atmometers. Plant World 15: 157-62. 1912.

- Atmometry and the porous cup atmometer. In press. Plant World. 1915.

Harvey, 1913. 
evaporation removes water from the system. In the auto-irrigator the "capillary" attraction of the surrounding soil brings about the same result. As water passes from cup to soil it automatically distributes itself so as to tend toward equilibrium throughout the soil mass. With a given soil mass and a given length of water column in the tube, static equilibrium is attained with a certain, definite average moisture content of this mass. A very thin layer of soil adjacent to the cup maintains for a long time a water content somewhat higher than that of the remaining soil, but this layer is only a millimeter or two in thickness. Beyond this layer there is but slight fall in soil-moisture content from the cup outward. Hawkins (1910) has shown that the auto-irrigator furnishes to potted plants a soil-moisture content that never fluctuates very markedly, that plants thus grown develop more rapidly and to a greater size than those spasmodically watered in the ordinary way, and that the root systems of such plants are much more uniformly distributed through the soil mass than is ordinarily the case.

Preliminary experiments showed that the variation in soil-moisture content of pot cultures provided with the auto-irrigator and sealed to prevent water loss excepting through the plant, is exceedingly small, after the system has once attained approximate equilibrium. (This matter will receive special attention presently.) From this it appeared highly probable that, with this apparatus, the rate of entrance of water from porous cup to soil may vary approximately (but with more or less pronounced lag) with the water-attracting power of the general soil mass. This power should be proportional to the mean resistance offered by the soil to root absorption, and this should depend, in any given culture, upon the rate at which root absorption actually has been occurring. As has been emphasized, the latter rate should vary (a lag being here also to be expected) with that of transpirational water loss from the aerially exposed plant surfaces. It was thus suggested that measurements showing the daily march of the rate of removal of water from the irrigator reservoir might throw light upon soil conditions as related to air conditions, and upon the variations in transpiration rate as related to the corresponding march of the rate of water absorption by plant roots.

The plants of these experiments were grown in a heavy loam soil, in tinned sheet-iron cylinders $15 \mathrm{~cm}$. high and $12.5 \mathrm{~cm}$. in diameter, the top of the soil mass being sealed over with plastiline after the first few days. Each cylinder was provided with a single irrigator cup joined by means of a rather long, flexible rubber tube to a bottle which served as reservoir. Each rubber tube bore a mark in a suitable position so that it might be fixed in a clamp support at that point, always leaving the same length of tubing free and hanging loosely between clamp and pot. Thus it was possible to place the cylinder 
upon a balance and make weighings, as frequently as might be requisite, to determine variations in the weight of the entire system-plant, soil, irrigator, and pot. The water loss from the irrigator reservoir was read by filling to a file-mark on the bottle neck, from a burette. For any relatively short period of time the loss by transpiration may be taken as equal to the loss in weight for that period plus the corresponding loss from the bottle. Slight alterations in weight caused by respiration and photosynthesis are neglected, as are also the errors introduced by thermometer effects, in the cup tube and bottle, due to temperature influence on the contained water. As will appear later, the variation in weight was not always manifested as a loss, in which case the transpirational water loss is of course the bottle loss minus the corresponding gain in weight.

These experiments were carried out in one of the experiment houses of the Laboratory of Plant Physiology of the Johns Hopkins University. The cultures were sealed January 24, 1913. At this time there were nine cylinders in the series. Three cylinders contained each three healthy plants of Vicia faba about $15 \mathrm{~cm}$. high, grown from seed planted in the cylinders January 2. Three cylinders contained each three healthy plants of Coleus blumei (a pale green variety) about 10 $\mathrm{cm}$. high. These were from rooted cuttings, planted in the cylinders January 10 . The remaining three cylinders each contained three plants of Pelargonium hybridum, about $10 \mathrm{~cm}$. high. The bottom of the irrigator cup was, in all cases, $50 \mathrm{~cm}$. above the water surface in the reservoir; the cup itself was about $12 \mathrm{~cm}$. high. Thus, all water entering the soil was removed from the cup against a pressure of from 50 to $62 \mathrm{~cm}$. of water. An ordinary standardized porous cup atmometer, mounted to draw from a burette, was operated alongside the cultures to give integrated measures of the evaporating power of the air for the various periods.

The plants were allowed to grow and weighings and irrigator and atmometer readings were frequently made, until February 23. Beginning with the ninth hour on this day and continuing to include the tenth hour on the following day, hourly observations were obtained. All the plants were in a flourishing condition at this time, and no wilting occurred during this day.

After the completion of this 25-hour series of measurements the plants were allowed to grow for a month, generally with daily readings and weighings. On February 26 , however, the heights of the supplying water columns were altered, being changed from 50 to $100 \mathrm{~cm}$., for the Coleus and Pelargonium plants, and from 50 to $5 \mathrm{~cm}$. for those of Vicia.

Beginning with the ninth hour, March 23, and continuing through the eighteenth hour of the following day, a second series of hourly measurements was carried out. The plants of Vicia showed pronounced wilting during the hottest hours of this day. After the com- 
pletion of this series the cultures were continued, generally with daily determinations, till April 29, after which date weighings and readings were discontinued.

During the latter part of the period following the second series of hourly measurements, the plants were considerably injured by inadequate supply of water. If such cultures are to be operated with such intense evaporation as was experienced by these plants in April, it appears desirable to decrease the resistance to water absorption by the plants. Probably this might be accomplished by employing more than one auto-irrigator cup per culture. A shorter water column would have some influence in this direction when lighter soils were employed, and a lighter (more sandy) soil would in itself be effective in the same direction. The Pelargonium plants appeared to withstand the conditions generally better than those of the other forms. In spite of obvious conditions of drought, however, several perfect seeds were finally harvested from the Vicia plants and the others made very satisfactory growth. It should be noted here that the roots of the Coleus plants were found, at the end of the experiments, to be badly infested with nematodes.

\section{FLUCTUATION IN SOIL-MOISTURE CONTENT WHEN THE AUTO- IRRIGATOR IS EMPLOYED.}

The value of the auto-irrigator in maintaining soil-moisture content with but small fluctuations has been emphasized in earlier papers, ${ }^{1}$ but we are not aware of any published data upon the actual degree of fluctuation which is to be expected in cultures equipped with the device. Our data furnish considerable evidence in this connection, and we digress here in order to present this evidence.

There were but two possible causes for considerable alteration in the weight of our cultures: variation in soil-moisture content and variation in plant weight. No means is yet at hand for distinguishing the effects of these two possible variations, and it is assumed in our calculations that the weight of the plants did not vary. We shall deal here only with the two periods of hourly observation, each period extending over about a day, so that fluctuation in the amount of non-aqueous material within the plants is easily negligible. Fluctuation in the water content of the plants of a culture during 24 hours is surely not so insignificant, but lack of methods for its separate study has forced us to the assumption just stated. Moreover, the plant weight employed in our calculations is, in each case, not the actual weight of the plants concerned, either at the beginning or end of the day period in question, as ought to be the case, but it is the weight exhibited by the plants at the end of the whole series of observations, when the cultures were discontinued.

${ }^{1}$ Livingston, 1908; Hawkins, 1910; Transeau, 1911, as previously cited. 
The dry weights of the plants were probably somewhat greater at this time than at either of the day series. As to probabilities in relation to the plant water content and its variation, nothing can be said, but it will be seen directly that the errors thus introduced must have been very small.

When the cultures were discontinued the general tare was determined for each, including the weight of the cylinder and seal, of the irrigator cup, stopper, and glass tube (all filled with water, as in operation), and of that portion of the rubber tubing connection (also filled) which had been supported by the balance in the regular weighings of the cultures. The roots were removed from the soil as far as possible and their green weight, together with that of the corresponding tops, were regarded as the plant weight above mentioned, and this was also added as part of the general tare. The dry weight of the soil was also determined for each culture. From the total weight of the culture for any observation was subtracted the general tare plus the dry weight of the soil, and the remainder was assumed to be the weight of the soil moisture.

If the dry weight of the plant varied, the error thus involved should introduce a relatively very small error in the magnitude of the dry weight of the soil, the latter weight being very large in relation to the former. When the water content of the plant was high our calculated soil-moisture content must have been too great; when the plant contained less water the calculated content of the soil must have been too small. The dry weight of the soil ranged from 1,875 grams to 1,977 grams in the various cultures, and it is readily seen that no considerable error was introduced in this connection. The water content of this soil mass had a value ranging from about 150 grams to about 375 grams. Thus possible fluctuation in water content of the relatively small plants could account for but a small error in any case.

In the actual calculations, the results of which are about to be presented, the average weight of the moist soil during each of the two 24-hour periods was determined for each culture. From this was subtracted the corresponding dry-soil weight, the resulting difference being the average weight of the contained water for the period in question. This was divided by the dry-soil weight and the quotient multiplied by 100 to give the average soil-moisture content, in percentage on the basis of the dry weight. The greatest plus and minus variations from the average weight of the culture are considered as the maximum variations in water content, stated in grams. These quantities, divided by the corresponding dry-soil weight, and the quotient multiplied by 100 , in each case, furnish the maximum plus and minus variations, expressed as percentage on the basis of dry-soil weight. The maximum plus and minus percentage variations in soil-moisture content, divided by a hundredth of the corresponding average per- 
centage moisture content for the given day, show the percentage variations in moisture content on the basis of the average.

Since the same soil was employed in all of our cultures, it follows that the data of moisture content are here comparable, when thus calculated to the dry weight of the soil as basis, although it is of course evident that such values would not be comparable if different soils were involved.

The essential data in this connection, for two cultures of each of the three species used, are given in table 1.

TABLE 1.-Maximum plus and minus variations in soil-moisture content for a period of 24 hours, of cylinders of soil with plants, the free soil surface sealed, provided with automatic water supply through aulo-irrigators.

\begin{tabular}{|c|c|c|c|c|c|c|c|c|c|c|}
\hline \multirow{3}{*}{ Plant. } & \multicolumn{5}{|c|}{ Series of February 23-24. } & \multicolumn{5}{|c|}{ Series of March 23-24. } \\
\hline & \multirow{2}{*}{ 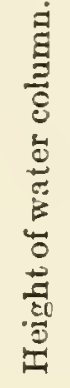 } & \multirow{2}{*}{ 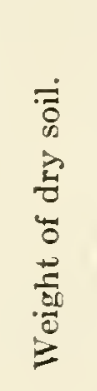 } & \multirow{2}{*}{ 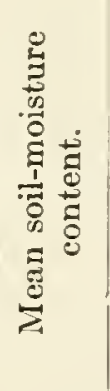 } & \multicolumn{2}{|c|}{$\begin{array}{c}\text { Maximum } \\
\text { plus and minus } \\
\text { variation from } \\
\text { mean. }\end{array}$} & \multirow{2}{*}{ 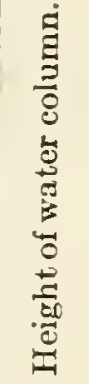 } & \multirow{2}{*}{ 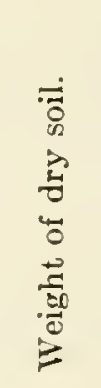 } & \multirow{2}{*}{ 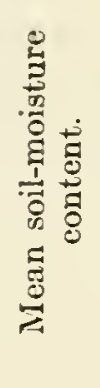 } & \multicolumn{2}{|c|}{$\begin{array}{l}\text { Maximum } \\
\text { plus and minus } \\
\text { variation from } \\
\text { mean. }\end{array}$} \\
\hline & & & & $\begin{array}{l}\text { On basis } \\
\text { of dry } \\
\text { weight } \\
\text { of soil. }\end{array}$ & $\begin{array}{l}\text { On basis } \\
\text { of mean } \\
\text { moisture } \\
\text { content } \\
\text { of soil. }\end{array}$ & & & & $\begin{array}{l}\text { On basis } \\
\text { of dry } \\
\text { weight } \\
\text { of soil. }\end{array}$ & $\begin{array}{l}\text { On basis } \\
\text { of mean } \\
\text { moisture } \\
\text { content } \\
\text { of soil. }\end{array}$ \\
\hline \multirow{7}{*}{$\begin{array}{l}\text { Coleus.... \{ }\left\{\begin{array}{l}A \\
B\end{array}\right. \\
\text { Vicia...... \{ } \begin{array}{l}A \\
B\end{array} \\
\text { Pelargonium }\left\{\begin{array}{l}A \\
B\end{array}\right.\end{array}$} & $\mathrm{cm}$. & gms. & p. $c t .{ }^{1}$ & p. ct. & p. ct. & $\mathrm{cm}$. & gins. & p. $c t .^{1}$ & p. $c t$. & p. $c t$. \\
\hline & 50 & 1901 & 16.6 & 0.68 & 4.1 & 100 & 1901 & 15.8 & 0.45 & 2.8 \\
\hline & 50 & 1922 & 18.9 & 0.83 & 4.4 & 100 & 1922 & 16.2 & 0.75 & 4.6 \\
\hline & 50 & 1879 & 17.8 & 0.77 & 4.3 & 5 & 1879 & 15.1 & 0.50 & 3.3 \\
\hline & 50 & 1977 & 16.0 & 0.63 & 3.9 & 5 & 1977 & 16.5 & 0.66 & 4.0 \\
\hline & 50 & 1893 & 10.9 & 0.29 & 2.7 & 100 & 1893 & 7.3 & 0.21 & 2.9 \\
\hline & 50 & 1875 & 15.5 & 0.72 & 4.6 & 100 & 1875 & 9.1 & 0.28 & 3.1 \\
\hline
\end{tabular}

${ }^{1}$ On basis of weight of dry soil.

From the data of table 1 it appears that the maximum plus and minus variation from the mean soil-moisture content did not attain the magnitude of 1 per cent of the dry weight of the soil mass for either of the two 24-hour periods during which hourly observations were taken.

Inspection of table 1 shows that the soil-moisture contents of the different cultures altered during the month that intervened between the two 24-hour periods. 'There was a decrease in all cases, excepting alone that of Vicia B, which exhibited a slight inerease of soil moisture, from 16.0 to 16.5 per cent. This might have been expected from the fact that the water column was very much shorter for the second period than for the first, but Vicia A altered in the opposite direction, from 17.8 to 15.1 per cent. No information is at hand for explaining this occurrence.

In the Coleus and Pelargonium cultures, where the water column was twice as long for the second period as for the first, the decrease in soil moisture was from 16.6 and 18.9 to 15.8 and 16.2 per cent for the 
two Coleus cultures, and from 10.9 and 15.5 to 7.3 and 9.1 for the two Pelargonium cultures. Why the last-named pair of cultures should have altered so markedly is not yet explainable, but it appears as though the absorption rate of the plant must have exerted an influence. Probably a larger number of irrigator cups (a larger irrigating surface per unit of soil volume) would prevent this sort of occurrence.

With such cultures, each supplied with a single irrigator cup and grown under such temperature and light conditions as ours, it is safe to suppose (see tables 2,3 , and 4 ): that the soil-moisture content will be found to be greater in the late night and early morning, and less in the late afternoon and early evening; that the actual moisture content will very closely approximate the mean for the entire day at two short periods, one occurring before the maximum of water content and the other after it; and that, for any day, the value of the maximum will surpass that of the minimum by not over 2 per cent, the dry weight of the soil being the basis for calculating the percentage of water content.

This statement, that the plus and minus fluctuation in the soilmoisture content of our cultures was always considerably less than 1 per cent of the dry weight of the soil, may be misleading, for the relative magnitudes of such variations depend upon the actual mean water content. It is therefore better to employ this mean as a basis for calculating the percentage values. From the data thus derived (also given in table 1), it appears that the moisture content of our soils varied less than 5 per cent above and below the mean.

In plant cultures where the maintenance of an approximately constant soil-moisture content is requisite, this range of variation from the mean of this condition, as here brought out, is probably practically negligible. There is no doubt that the auto-irrigator does maintain soil-moisture conditions far more nearly constant than does any other method of watering (aside from the growing of plants in saturated soil or in water culture). Especially is this control of soil moisture satisfactory when it is remembered what a short way has thus far been traversed toward the control, or even measurement, of other environmental conditions and of plant phenomena themselves. When plant physiology and ecology become somewhat refined and when research in these lines becomes consciously and aggressively directed toward permanent progress in scientific interpretation, then cultures may need to be grown under more rigid control of soil moisture than that furnished by the arrangement of the auto-irrigator as we have employed it. For the present state of our science the accuracy of such an arrangement is highly satisfactory.

The nature of the device here under discussion makes it obvious that it is susceptible of much greater refinement than has ever been put into practice. There seems to be no doubt, for example, that our soil masses would have been maintained much more constant in their water- 
content if two or more irrigator cups had been used instead of a single one. It is in this direction that first progress toward a still more sensitive instrument may be expected. The device may be improved in many other ways.

It will have been noted that we have tacitly assumed the watercontent of our soils to be uniformly distributed throughout the soil mass. As has been stated, however, the moisture content may always be expected to be somewhat greater in the near vicinity of the supplying surface than elsewhere, and it is also clear that it must be exceptionally low in the near vicinity of absorbing surfaces, such as those of plant roots. It follows that the fluctuations shown above do not really apply to the entire soil mass in question, but that they are merely like mathematically derived averages, which may find no actual physical expression in any case. There seems no ground for questioning the supposition that the first few layers of soil particles adjacent to the absorbing root hairs of our experiments must have undergone far greater fluctuations in moisture content than those indicated above. The problems of water movement through soils and those of root absorption, when the latter shall be seriously attacked, require to be approached from the point of view suggested by the question just raised, but nothing has so far been done to furnish the lind of information here needed; yet this whole matter is surely approachable along relatively simple lines of physical study.

\section{PRELIMINARY ANALYSIS OF THE PROBLEM.}

The numerical results of our two series of measurements are shortly to be presented, but since the important features of the tabulations and graphs involve arithmetical manipulation of the observational data, it will be expedient first to set forth the general interpretation which we have attempted.

As in all profitable physiological analysis, the organism and its surroundings should here be treated as a dynamic system. The movement of water from plant to air represents work, in the physieal sense, and the complex of conditions determining the time rate of doing this work is to be measured as a power-the desiccating power of the aerial environment (see Livingston, 1911). This power operates against a resistance in accomplishing the work done, which is the resistance afforded by the plant surfaces to transpirational water loss (see livingston, 1913). Loss of water by transpiration must, in ordinary plants, be balanced by entrance of water through root surfaces and the water efficiency of a plant, under any set of environmental conditions, is dependent upon the relation of entrance to outgo. If $A$ denote the rate of absorption and $T$ the rate of transpiration, then the plant body gains in water content for any period when $A$ is greater than $T$. 
It loses in water content when $T$ is greater than $A$, and the condition that growth and other water-consuming processes may go forward is that $A$ must be somewhat greater than $T$, in general.

The movement of water from soil films into plant roots is dependent upon a complex of internal conditions which may be taken together as the absorptive power of the root system. This power operates, again, against external resistance, the resistance offered by the soil to water absorption by roots. The absorptive power of roots is in large part ultimately dependent upon transpiration, through the rate at which water is removed from the roots upward; the water columns are considered as continuous (though interrupted, in a sense, by imbibed cell walls) from root periphery to leaf periphery and as capable of bearing great strain. ${ }^{1}$ Root-absorbing power may also vary, however, because of changes originating in the roots themselves. Such changes have not been quantitatively studied as yet, no method being so far available for this sort of investigation. Nevertheless, there can be no question that the extent of root surfaces, ceteris paribus, is a very important factor in determining the absorptive power of a root system for water, just as the extent of foliar surfaces has great influence in the control of the plant's general transpiring power. Furthermore, Livingston ${ }^{2}$ has suggested that plants growing in certain toxic soils and having the cortical cells of the roots greatly swollen may be injured in their aerial parts primarily through low water-absorbing power of the roots. Also, Caldwell (1913) has pointed out that permanent wilting with low evaporation rates, causing the death of root hairs, markedly decreases the root absorbing power, apparently through the breaking of the film continuity between plant water and soil water. The resistance offered by the soil to water entrance into roots, that is, the attraction of the soil for water, should of course be proportional to the reciprocal of the power of the soil to deliver water to absorptive surfaces.

If we wish to compare the diurnal marches of all these various powers, we need first to measure them in some adequate way and with suitable time intervals, and next to reduce each series of values obtained to a uniform basis, considering the value for some particular hour as unity. The same hour is of course to be employed in every case, thus presenting the complex data in a form such that the relative rates of change of the different powers dealt with may be directly comparable.

In our attempt in this direction, the desiccating power of the aerial environment is considered as the evaporating power of the air, neglecting the effect of radiant energy, as far as the absorption of the latter by the plant foliage is more pronounced than its absorption by the white porous cup of the atmometer. It would probably have been better if a

${ }^{1}$ Dixon, 1909.

${ }^{2}$ Livingston, B. E., Note on the relation between growth of roots and of tops in wheat. Bot. Gaz. 41: 139-43. 1906. 
radio-atmometer ${ }^{1}$ had been employed, but it was not. We may term this desiccating power $d_{a}$ and the atmometric reading $E$, so that $d_{a}$ is taken as equivalent to $E$ for any time period in these experiments.

The transpiring power of the plants was taken as the relative transpiration ratio (Livingston, 1906, 1913), which is the absolute transpiration rate, for a given period, divided by the evaporation rate for the same period, the latter from a standardized atmometer exposed with the plants. For our present purpose the area of the plant surface need not enter into the discussion; area may be regarded as one of the internal conditions determining general transpiring power. If transpiring power is represented by $d_{b}$, and if $T$ represents (as above) the actual transpirational water loss for the time period in question, then we have $d_{l}=\frac{T}{E}$.

The absorptive power of the roots was not measured, as we have said, but it is probably safe to suppose that it does not independently vary in magnitude from hour to hour, in any great degree; at least it can exhibit no such marked and regular fluctuations as does foliar transpiring power, for the roots of our plants were never subjected to great changes in their water surroundings, and roots in general have never been shown to exhibit anything parallel to stomatal movement.

If it were possible to measure actual absorption as absolute transpiration may be measured, it should then be easy to determine the absorbing power of the root system. The treatment would be quite parallel to that resorted to by Livingston (1906) in deriving the transpiring power. In the latter case, as we have seen, the absolute transpiration rate is divided by the evaporation rate from a standard physical surface; $\frac{T}{E}$, the relative transpiration ratio, is the measure of transpiring power. In the case of subterranean conditions we should divide the absolute absorption rate by the power of the soil to deliver water to the roots, thus obtaining what might be termed the relative absorption rate, or absorbing power. We suppose here that the rate of water loss from the irrigator is reciprocally proportional to the water-supplying power of the soil; for if a soil has at one time a water-supplying power two (or three, etc.) times as great as at an earlier period, then its resistance to root absorption must be one-half (one-third, etc.) as great as this resistance was before. If, then, the rate of loss from the irrigator be taken as $I$, then $\frac{1}{I}$ is the supplying power sought. Hence, if $A$ represents the absolute absorption rate, then the rate of relative absorption (or the absorbing power of the root system) should be the ratio $\frac{A}{1}=A I$, which corresponds to the relative transpiration ratio $\frac{T}{E}$. I

${ }^{1}$ Livingston, 1911 ( 1 and 2). 
Although not experimentally dealt with here, we may, for the purpose of the general theory, let the symbol $d_{r}$ denote the reciprocal of root absorbing power $(A I)$; that is, the power effective at root surfaces to retard water entrance. Thus $d_{r}=\frac{1}{A I}$, with the notation given above.

The resistance offered by the soil to water absorption was considered proportional to the water-absorbing power of the soil, as shown by its rate of removal of water from the unchanging surface of the auto-irrigator. This may be denoted by $d_{s}$, the effective power in the soil, tending to cause water loss from the roots or retardation of water entrance, and may be termed the water-attracting power of the soil.

The whole environment, subterranean and aerial, may be considered as a machine always tending to remove water from the plant, and the plant may be similarly regarded as a machine tending to give off water to the environment. We may express this water-removing tendency of the total environment as its desiccating power, $D_{e}$, which should be proportional to the product of the desiccating power of the aerial surroundings $\left(d_{a}\right)$ and the water-attracting power of the soil $\left(d_{s}\right)$. Thus, $D_{e}=d_{a} \times d_{s}$, which means that if $d_{a}$ is $m$ times as great at hour 2 as at hour 1 , and if $d_{s}$ is similarly $n$ times as great, then $D_{e}$ is $m n$ times as great for the second period as for the first. We may also say that $D_{e}$, for any hour, is a measure of the aridity of the environment as a whole, expressed in terms of its aridity for some other hour taken as unity. It appears that we may possibly have here what at least may approach being a single-term measure of all that ecologists connote by environmental conditions, as far as water is concerned, and for our particular cultures. The application of this method of reasoning to plants under other conditions than the ones here employed, as in the open ground, will of course involve new difficulties; this is a matter for future dynamic studies on plant water-relations. A beginning is perhaps well made by carrying out an investigation of these features for a few individual potted plants, and this, in a crude and preliminary way, is all that is here to be attempted.

It has been remarked that the water efficiency of a plant $(i . e$. , its power to maintain water in its tissues sufficient for the usual physiological processes) is not dependent alone upon the surroundings, but is also a function of internal conditions, of foliar transpiring power and of root absorbing power. These two powers are operative in opposite directions; the former tends to accelerate desiccation, the latter to retard it. If the root absorbing power were brought into our argument as it now stands, we should have to use its reciprocal, as has been noted.

Attempting to state in a single term the effectiveness of the internal conditions tending to promote desiccation, as we have just done for the external ones, we obtain an equation like the following: $D_{i}=d_{l} \times d_{r}$. 
In this equation $D_{\mathbf{s}}$ represents the total tendency of the internal complex of conditions to give up water to the surroundings, $d_{l}$ denotes the factor of this tendency due to transpiring power, and $d_{r}$ stands for the factor due to the ease with which roots might part with water. But transpiring power $\left(d_{l}\right)$ may be measured by the ratio $\frac{T}{E}$, and the reciprocal of absorbing power $\left(d_{r}\right)$ may be represented by $\frac{1}{A I}$. Therefore, $D_{1}=\frac{T}{E} \times \frac{1}{A I}=\frac{T}{A} \times \frac{1}{E I}$. In words, the tendency of the plant body to part with water during any time period, as related to this tendeney for any other period, is the ratio of absolute transpiration to absolute absorption for the second period (these being stated in terms of the corresponding rates for the first period) multiplied by the reciprocal of the product of the atmometric and irrigator losses for the second period (these latter being also stated in terms of the corresponding losses for the first period). It is to be emphasized that such a statement rests on the assumptions that the rate of water loss from the irrigator is a measure of the power of the soil to retard water absorption by the root system, that its reciprocal is proportional to the watersupplying power of the soil, and that the atmometric loss is a measure of the desiceating power of the aerial surroundings. Furthermore, this statement is of no great practical value at the present time, on account of the fact that no method is yet available for approximating absorption rates.

If the reasoning of the last paragraphs be correct, then the tendency of any plant to lose water, with any given set of surroundings (which tendeney may be represented by $D$ ), should be proportional to the product, $D_{e} \times \mathrm{D}_{i}$, the product of the internal and external tendencies toward plant desiccation. This product may be regarded as a relative measure of the effective environmental desiccating power or effective aridity; it is the power of the environment tending toward plant desiccation, as far as this power is influential when operating in conjunction with the given internal conditions.

We may thus write: $D=D_{c} \times D_{i}=d_{a} \times d_{s} \times d_{l} \times d_{r}$ or, for our tests, $D=E \times I \times \frac{T}{A} \times \frac{1}{E I}$, which finally becomes, $D=\frac{T}{A}$. The ratio $\frac{T}{A}$ is, then, a relative measure of the tendency of the plant (with its internal conditions as they may happen to be) during any time period to lose water to the surroundings (with whatever eomplex of conditions the surroundings may present). This is exactly the proposition with which we started. If this ratio is greater than unity the environment is not well adapted to the plant, or the plant is not well adapted to its surroundings, as far as the water-relation is concerned, and, if such a state of affairs be continued, growth must cease and finally death or 
at least dormancy of many vital processes must occur. If the ratio is somewhat less than unity, then at least some growth should be possible, assuming that a surplus of water is necessary for growth processes. It seems possible that the critical value of the ratio here considered, at which growth or other vital activity may be definitely affected, may eventually become a valuable physiological and ecological constant, by which some of the over-discussed "adaptations" of plants may be quantitatively stated, at least in an approximate way. Without means for evaluating $A$ (absorption rate), this statement is mainly valuable in the planning of researches.

It is to be remarked here that it would be quite as logical, and perhaps more in accordance with usual ways of thinking, to deal with the reciprocals of all the quantities named above, thus deriving the power of the environment to supply water to the plant (environmental hydrating power, $H_{e}$, perhaps) and the general tendency of the whole system (plant and environment together) to maintain in the tissues moisture adequate to growth, etc. $(H$, say). The latter concept coincides with our idea of the water efficiency of the plant in any given environment and may eventually give rise to a practical measure of the tendency toward success or failure of any plant when growing under any set of conditions. Here it is merely to be emphasized that it is quite immaterial at present whether we deal with $D, D_{e}$, and $D_{i}$ or with $H, H_{e}$, and $H_{i}$, since $H=\frac{1}{D}$, etc.

It is already clear that the water-relations of a given plant, and their march through its life, can not be understood until there becomes available some method by which the rate of water absorption by roots or the absorbing power of these organs may be approximated, at least in relative terms. Thus, the only value to be attached to the latter portion of our discussion lies in the manner in which it emphasizes this physiological characteristic of the organism. We have assuredly reasoned in a circle and "come out where in we went," but our peregrinations seem to show clearly just where constructive research is most needed, as far as plant water-relations are concerned.

It is but trite to remark that no real knowledge of the dynamics of plant water-relations can be attained without measurements of both internal and external conditions, but the study of these relations has thus far contented itself so thoroughly with statics that insistance upon this axiom may be pardonable at the present time. If our suggested means for the study of the soil-moisture conditions proves of value, the environment may be said to be tentatively comparatively well cared for, for the desiccating power of the aerial environment may be rather readily determined. Of the internal conditions we can approximate only the transpiring power, which is easy, because absolute transpiration rates may be directly measured. Of the other internal 
conditions almost nothing is known, excepting that they are often apparently very important.

It may not be out of place here to consider a little more deeply the general nature and relations of these quantitatively unknown internal conditions. We may begin with the aerial periphery of the plant and progress downward. Transpiring power, which has now been studied to some extent, resides only at the surfaces of exposed membranes of leaves, etc. It is commonly granted to vary with the extent of these membranes, which extent varies with the increase and decrease of general transpiring surface (as with the formation of new leaves and the falling away of old ones). It also varies with the effective exposure of the moist membranes of any single leaf during any single day, which fluctuates with stomatal movements wherever these occur; the closing of each stoma removes from effective contact with the exterior a certain amount of moist cell-wall surface. Beyond this, transpiring power depends upon the attraction exerted between the gel-colloidal walls of the transpiring cells and their imbibed water. This attraction is clearly a function of the nature of the wall and of its water content; with a given wall, the more nearly it approaches saturation with water the more nearly must its transpiring power approach a maximum. The sort of fluctuation suggested by the last clause has been emphasized by Livingston, Renner, Caldwell, and Edith B. Shreve as incipient drying or saturation deficit, which appears to be a condition in the control of certain important fluctuations in transpiring power. It is more commonly emphasized, at least in a general way, that alteration in the nature of exposed cell walls is frequently accompanied by profound changes in transpiring power; the power of foliar epidermis, for example, to give off water vapor, is well known to vary through cutinization and through impregnation with wax-like and other non-water-attracting substances. Foliar surfaces often alter markedly in this way, as leaves pass through progressive developmental phases. Much more is known of the sequence and nature of these wall changes, however, than of their effects upon transpiring power. ${ }^{1}$ Such changes are usually permanent and not readily reversible, unlike stomatal changes and the phenomena of incipient drying.

\footnotetext{
'These changes in the nature of cell walls aro apparently more or less controlled by internal conditions, sequences of metabolic processes and all the maze of as yet uninvestigated conditions suggested by the words ontogeny and devclopment. But they seem to be frequently determined, in large measure, by external conditions, the whole problem being made very complex by the faet, for instance, that transpiration rate appears to condition cutinization, while the degree of cutinization is an important condition controlling transpiration. It is such retroactive causal relations that make natural phenomena appear purposeful, to many minds, until they have been analyzed to a degree. l'feffer made a remark which suggests problems for inuch constructive study in relation to transpiring power when he wrote: "The infucnco of tranepiration in favoring the development of the cuticle and of the conclueting ehanuels seems to be direetly connected with the movements of water it iuduees." (Pfeffer, W., Physiology of plants, translated by A. J. Ewart 2 : 121. Oxford. 1903.) This apparent direct connection may perhaps come about through the phenomenon of incipicut rrying.
} 
Passing back into the plant body, incipient drying of peripheral walls is surely dependent, under continuous external conditions, upon the rate of water movement from deeper lying parts toward the walls concerned. This rate is obviously a function of the internal resistance offered to such water movement. Among many conditions surely influencing this resistance only two may bementioned here-the general water-conducting power of the plant body and the water-supplying power of the subterranean periphery. Little has been done in a dynamic way toward a knowledge of how different plants may differ in regard to their conducting power.

The water-absorbing power of subterranean surfaces of the plant is of course largely dependent upon the actual rate of upward conduction of water, which depends, indirectly, upon the actual transpiration rate and upon internal factors. Nevertheless, as we have already emphasized, the extent, nature, etc., of the exposed cell membranes of roots must frequently furnish the limiting condition of absorbing power. It is obvious that the rate of upward conduction of water may sometimes be determined by this absorbing power; indeed, transpiring power, conducting power, and absorbing power are probably very closely connected in many cases. A knowledge of the water-absorbing process, in its relation to the general well-being of the plant, is thus seen to be deeply involved with an appreciation of the dynamics of water conduction and transpiration.

From the last paragraphs it emerges that what we have called waterabsorbing power of the root system and designated by $A I$ really refers to much more than the specific properties or characteristics of the roots themselves. It also appears that transpiring power $\frac{T}{E}$ involves many features resident only at a distance from the exposed foliar membranes.

An additional consideration is required here, to prevent our suggestions on the measurement of environmental aridity from being misleading. From our deductions and assumptions, as thus far set forth, this aridity seems to become nil when either $I$ or $E$, as here employed, becomes zero; for $D_{e}=E I$. I should become zero when the entire water-absorbing surface of the plant is bathed in free liquid water, as in the case of water cultures. Similarly, $E$ should vanish when there is no evaporation, as when the entire transpiring surface is covered with a water film thick enough so that variations in the evaporation rate from the exposed film surface have no influence upon the water conditions of the plant tissues thus covered. A plant completely submerged in pure water should be subject to no external resistance to absorption and to no external acceleration of water loss. (We ignore the usually negligible phenomena of guttation and external secretion of liquid water.) In all three of these cases $D$ appears to become nil, according to our equation. 
Nevertheless, it is obvious enough that the water-extracting power of the environment as a whole can not be considered as completely vanishing when only one of its component factors, as here expressed, becomes zero; wilting and death of leaves may surely be produced by high transpiration rates, even in plants rooted in water. In such a case the resistance offered by the plant itself to water movement takes the place of the soil resistance that has vanished. From this it is clear that the resistance offered by the soil to root absorption can be a limiting condition for plants only when its magnitude is greater than the internal resistance to absorption and conduction. If this internal resistance is such that, under a given set of other conditions, water can move from roots to leaves no faster than with a certain rate, then it is quite immaterial at what rate water may be supplied to the root surfaces, so long as the latter rate is equal to or greater than the possible internal movement.

It thus appears that the statement $D_{e}=E I$ may be expected to express the approximate truth only when the internal resistance to water movement is less than the value $I$. We may denote the internal resistance here in question by $R$. Then, so far as we have gone, $D_{e}=E I$ when $R<I$. But, even within the limits set by this condition, our general statement can not uniformly hold; for $R$ may be less than $I$ and at the same time $E$ may be nil, in which case $D$ should again vanish, which we know it does not. Under such conditions there is no water-extracting power exerted by the aerial surroundings, and the only desiccating power effective to tend to remove water from the plant is $I$, the attraction of the soil for water. As long as $R<I, R$ does not play a controlling part in this relation, and our expression becomes simply $D_{e}=I$.

A consideration of all the logical possibilities in this connection would lead farther afield than it is requisite to go at present. It simply needs emphasis here that the statement $D_{e}=E I$ is to be regarded as approximately true only within the limits set by the conditions, $R<I$ and $E>0$. As to the possible values which $R$ may assume, it is clear that there must always be some resistance to water movement from absorbing to transpiring periphery. It therefore follows that $R$ may be supposed to have any value greater than zero. Hence, when $R<I$ and $R>0$, then $I>0$.

Thus the conditions under which the environmental desiccating power may be taken as proportional to the product EI are: (1) that the internal resistance to water movement is less than the attraction of the soil for water $(R<I)$; $(2)$ that the latter atiraction is always positive $(I>0)$; and (3) that there is some tendency for evaporation to occur from aerial surfaces $(E>0)$. We venture the conviction that these conditions are fulfilled in the vast majority of cases involving ordinary plants, with roots in soil and stems and leaves in air. This 
is assumed for the cases to be dealt with below, although the value of $R$ is there quite unknown. The logical analysis, along the lines just followed, may be carried farther when need arises.

In our actual employment of the various powers above mentioned we shall not attempt any adequate treatment of the internal conditions; as has been stated, root absorbing power and the conducting power of the plant as a whole have not yet been brought under experimental observation, so that the experimental approximation of effective environmental aridity (involving these as well as transpiring power) is not now possible. We shall confine attention to the external conditions $I$ and $E$ and to the single internal one, transpiring power $\frac{T}{E}$, and the main interest of our study will lie in the daily marches of the relative magnitudes of these conditions, measured in terms of their respective values for some selected hour period.

\section{THE MEASUREMENTS.}

The numerical data derived from one of each of our pairs of duplicate experiments will now be presented. ${ }^{1}$ The other one of the pair showed results essentially similar, in all three cases. In this presentation we shall deal with the march of evaporation $(E)$, transpiration $(T)$, transpiring power $\left(\frac{T}{E}\right)$, attraction of the soil for water $(I)$, and environmental aridity $(E I)$. In tables 2,3 , and 4 , the hourly change in weight of plant and soil and the hourly loss of water from the irrigator and from the atmometer are the observed data. The corresponding absolute transpiration increments are obtained, as has been stated, by subtracting the change in weight from the irrigator loss. Columns 6,7 , and 8 of the tables, give the three values, irrigator loss $(I)$, absolute transpiration $(T)$, and atmometer loss $(E)$ for every hour of the two series of observations, reduced to a basis which considers the rate for one of the night hours of the first series as unity. Column 9 gives the relative transpiration ratios $\left(\frac{T}{E}\right)$, also reduced to the same uniform basis, and the last column shows the values of the product of irrigator loss and atmometer loss, also on that basis. These last values may be considered to represent environmental aridity (following our preceding discussion), relative to the value of this condition for the standard hour of the earlier series. Each table represents a single plant and includes the results from the two series of observations, one beginning February 23 and the other March 23.

Since the weighings lacked accuracy, owing largely to the crude method of suspending the looped rubber tube of the apparatus instead

\footnotetext{
'In the calculation and tabulation of the great mass of measurements resulting from this study the authors have been ably assisted by Mrs. Grace J. Livingston and Miss Aleita Hopping.
} 
TABLE 2.-Data for Coleus.

\begin{tabular}{|c|c|c|c|c|c|c|c|c|c|}
\hline \multirow{2}{*}{$\begin{array}{l}\text { Day } \\
\text { and } \\
\text { hour. }\end{array}$} & \multirow{2}{*}{$\begin{array}{l}\text { Change } \\
\text { of } \\
\text { weight. }\end{array}$} & \multicolumn{3}{|c|}{ Actual loss. } & \multicolumn{3}{|c|}{$\begin{array}{l}\text { Loss, relative to that of } \\
\text { hour } 3 \text {, Feb. } 23 \text {. }\end{array}$} & \multicolumn{2}{|c|}{$\begin{array}{l}\text { Derived values, } \\
\text { relative to hour } 3 \text {, } \\
\text { Feb. } 23 \text {. }\end{array}$} \\
\hline & & $\begin{array}{c}\text { Irriga- } \\
\text { tor.1 }\end{array}$ & $\begin{array}{c}\text { Trans- } \\
\text { piration. }\end{array}$ & $\begin{array}{c}\text { Atmom- } \\
\text { eter. }^{2}\end{array}$ & $\begin{array}{l}\text { Irrigator } \\
\quad(I) .\end{array}$ & $\begin{array}{c}\text { Trans- } \\
\text { piration } \\
(T) .\end{array}$ & $\begin{array}{c}\text { Atmom- } \\
\text { eter } \\
(E) .\end{array}$ & $\begin{array}{l}\text { Relative } \\
\text { transpi- } \\
\text { ration } \\
\left(\frac{T}{E}\right)\end{array}$ & $\begin{array}{l}\text { Environ- } \\
\text { mental } \\
\text { aridity } \\
(E I)\end{array}$ \\
\hline $\begin{array}{r}\text { Feb. } 23 \\
\text { Hour } \\
10 \\
10 \\
11 \\
12 \\
13 \\
14 \\
15 \\
16 \\
17 \\
18 \\
19 \\
20 \\
21 \\
22 \\
23 \\
24\end{array}$ & $\begin{array}{l}\text { grams } \\
0.0 \\
-4.0 \\
-5.0 \\
-7.0 \\
-6.0 \\
-6.0 \\
-2.0 \\
-1.0 \\
-1.0 \\
+4.0 \\
+3.5 \\
+2.5 \\
+3.0 \\
+1.5 \\
+0.5 \\
+3.0\end{array}$ & $\begin{array}{l}c . c . \\
1.6 \\
2.3 \\
2.2 \\
3.4 \\
5.1 \\
5.4 \\
5.7 \\
6.6 \\
6.0 \\
6.5 \\
4.9 \\
3.1 \\
3.0 \\
2.9 \\
2.1 \\
2.1\end{array}$ & $\begin{array}{r}\text { grams } \\
1.6 \\
6.3 \\
7.2 \\
10.4 \\
11.1 \\
11.4 \\
7.7 \\
7.6 \\
7.0 \\
2.5 \\
1.4 \\
0.6 \\
0.0 \\
1.4 \\
1.6 \\
-0.9\end{array}$ & $\begin{array}{l}c . c . \\
0.88 \\
0.96 \\
1.36 \\
1.36 \\
1.52 \\
1.20 \\
1.12 \\
1.12 \\
0.88 \\
0.72 \\
0.80 \\
0.56 \\
0.56 \\
0.64 \\
0.48 \\
0.48\end{array}$ & $\begin{array}{l}1.14 \\
1.64 \\
1.57 \\
2.43 \\
3.64 \\
3.86 \\
4.07 \\
4.72 \\
4.28 \\
4.64 \\
3.50 \\
2.21 \\
2.14 \\
2.07 \\
1.50 \\
1.50\end{array}$ & $\begin{array}{l}1.14 \\
4.50 \\
5.11 \\
7.43 \\
7.93 \\
8.14 \\
5.50 \\
5.43 \\
5.00 \\
1.79 \\
1.00 \\
0.43 \\
0.00 \\
1.00 \\
1.14 \\
0.00\end{array}$ & $\begin{array}{l}1.83 \\
2.00 \\
2.83 \\
2.83 \\
3.17 \\
2.50 \\
2.33 \\
2.33 \\
1.83 \\
1.50 \\
1.67 \\
1.17 \\
1.17 \\
1.33 \\
1.00 \\
1.00\end{array}$ & $\begin{array}{l}0.62 \\
2.75 \\
1.82 \\
2.64 \\
2.50 \\
\mathbf{3} .25 \\
2.36 \\
2.33 \\
2.73 \\
1.19 \\
0.60 \\
0.37 \\
0.00 \\
0.75 \\
1.14 \\
0.00\end{array}$ & $\begin{array}{r}2.09 \\
3.28 \\
4.44 \\
4.05 \\
11.54 \\
9.04 \\
9.48 \\
11.00 \\
7.84 \\
6.96 \\
5.85 \\
2.58 \\
2.51 \\
2.75 \\
1.50 \\
1.50\end{array}$ \\
\hline $\begin{array}{rr}\text { Feb. } 24 \\
\text { Hour } \\
1 \\
2 \\
3 \\
4 \\
5 \\
5 \\
6 \\
7 \\
8 \\
9 \\
10 \\
10\end{array}$ & $\begin{array}{r}0.0 \\
+2.0 \\
0.0 \\
+1.0 \\
0.0 \\
+2.0 \\
+0.5 \\
0.0 \\
-1.5 \\
-3.0\end{array}$ & $\begin{array}{l}2.1 \\
1.9 \\
1.4 \\
2.1 \\
1.4 \\
1.6 \\
1.4 \\
1.5 \\
1.4 \\
1.6\end{array}$ & $\begin{array}{r}2.1 \\
-0.1 \\
1.4 \\
1.1 \\
1.4 \\
-0.4 \\
0.9 \\
1.5 \\
2.9 \\
4.6\end{array}$ & $\begin{array}{l}0.56 \\
0.56 \\
0.48 \\
0.56 \\
0.48 \\
0.48 \\
0.52 \\
0.44 \\
0.52 \\
0.68\end{array}$ & $\begin{array}{l}1.50 \\
1.36 \\
1.00 \\
1.50 \\
1.00 \\
1.14 \\
1.00 \\
1.07 \\
1.00 \\
1.14\end{array}$ & $\begin{array}{l}1.50 \\
0.00 \\
1.00 \\
0.79 \\
1.00 \\
0.00 \\
0.64 \\
1.07 \\
2.07 \\
3.29\end{array}$ & $\begin{array}{l}1.17 \\
1.17 \\
1.00 \\
1.17 \\
1.00 \\
1.00 \\
1.08 \\
0.92 \\
1.08 \\
1.42\end{array}$ & $\begin{array}{l}1.28 \\
0.00 \\
1.00 \\
0.67 \\
1.00 \\
0.00 \\
0.60 \\
1.16 \\
1.92 \\
2.32\end{array}$ & $\begin{array}{l}1.76 \\
1.59 \\
1.00 \\
1.76 \\
1.00 \\
1.14 \\
1.08 \\
0.99 \\
1.08 \\
1.62\end{array}$ \\
\hline $\begin{array}{r}\text { Mar. } \\
\text { Hour } \\
11 \\
12 \\
13 \\
14 \\
15 \\
16 \\
17 \\
18 \\
19 \\
20 \\
21 \\
22 \\
23 \\
24\end{array}$ & $\begin{array}{r}-5.0 \\
-5.0 \\
-6.0 \\
-3.0 \\
-2.0 \\
0.0 \\
+4.0 \\
+2.0 \\
+2.5 \\
+2.0 \\
+2.5 \\
+2.0 \\
+2.0 \\
+2.0 \\
+2.0\end{array}$ & $\begin{array}{l}3.4 \\
4.1 \\
5.2 \\
6.4 \\
7.8 \\
6.6 \\
6.2 \\
4.0 \\
3.5 \\
2.8 \\
2.8 \\
2.3 \\
2.4 \\
1.9 \\
2.2\end{array}$ & $\begin{array}{r}8.4 \\
9.1 \\
11.2 \\
9.4 \\
9.8 \\
6.6 \\
2.2 \\
2.0 \\
1.0 \\
0.8 \\
0.3 \\
0.3 \\
0.4 \\
-0.1 \\
0.2\end{array}$ & $\begin{array}{l}1.46 \\
1.53 \\
1.53 \\
1.90 \\
1.75 \\
1.68 \\
1.46 \\
1.39 \\
1.10 \\
1.39 \\
0.51 \\
0.95 \\
0.80 \\
0.80 \\
0.73\end{array}$ & $\begin{array}{l}2.43 \\
2.93 \\
3.72 \\
4.57 \\
\mathbf{5} .54 \\
4.72 \\
4.43 \\
2.86 \\
2.50 \\
2.00 \\
2.00 \\
1.64 \\
1.71 \\
1.36 \\
1.57\end{array}$ & $\begin{array}{l}6.00 \\
6.50 \\
8.00 \\
6.72 \\
7.00 \\
4.71 \\
1.57 \\
1.43 \\
0.71 \\
0.57 \\
0.21 \\
0.21 \\
0.29 \\
0.00 \\
0.14\end{array}$ & $\begin{array}{l}3.04 \\
3.19 \\
3.19 \\
3.96 \\
3.65 \\
3.50 \\
3.04 \\
2.90 \\
2.29 \\
2.90 \\
1.06 \\
1.98 \\
1.67 \\
1.67 \\
1.52\end{array}$ & $\begin{array}{l}1.97 \\
2.01 \\
2.51 \\
1.70 \\
1.92 \\
1.35 \\
0.52 \\
0.49 \\
0.31 \\
0.20 \\
0.20 \\
0.11 \\
0.17 \\
0.00 \\
0.09\end{array}$ & $\begin{array}{r}7.39 \\
9.35 \\
11.87 \\
18.10 \\
20.22 \\
16.52 \\
13.47 \\
8.29 \\
5.73 \\
5.80 \\
2.12 \\
3.25 \\
2.86 \\
2.27 \\
2.39\end{array}$ \\
\hline $\begin{array}{r}\text { Mar. } 24 \\
\text { Hour } \\
1 \\
2 \\
3 \\
4 \\
5 \\
6 \\
7 \\
8 \\
9 \\
9 \\
10 \\
11 \\
12 \\
13 \\
14 \\
15 \\
16 \\
17 \\
18\end{array}$ & $\begin{array}{r}+1.0 \\
+1.0 \\
+0.5 \\
+1.5 \\
+1.0 \\
0.0 \\
-1.0 \\
-3.0 \\
-3.0 \\
-4.0 \\
-4.0 \\
-6.0 \\
-5.0 \\
-3.0 \\
0.0 \\
+4.0 \\
+4.0 \\
+2.0\end{array}$ & $\begin{array}{l}1.5 \\
1.8 \\
1.6 \\
1.7 \\
1.3 \\
1.7 \\
1.8 \\
2.4 \\
3.2 \\
4.0 \\
4.7 \\
5.5 \\
6.7 \\
7.5 \\
7.6 \\
6.2 \\
4.0 \\
3.7\end{array}$ & $\begin{array}{r}0.5 \\
0.8 \\
1.1 \\
0.2 \\
0.3 \\
1.7 \\
2.8 \\
5.4 \\
6.2 \\
8.0 \\
8.7 \\
11.5 \\
11.7 \\
10.5 \\
7.6 \\
2.2 \\
0.0 \\
1.7\end{array}$ & $\begin{array}{l}0.73 \\
0.58 \\
0.73 \\
0.66 \\
0.73 \\
0.58 \\
0.66 \\
0.80 \\
0.95 \\
1.17 \\
1.02 \\
0.95 \\
1.24 \\
1.61 \\
1.31 \\
1.17 \\
1.17 \\
0.58\end{array}$ & $\begin{array}{l}1.07 \\
1.29 \\
1.14 \\
1.21 \\
0.93 \\
1.21 \\
1.29 \\
1.71 \\
2.19 \\
2.86 \\
3.36 \\
3.93 \\
4.79 \\
5.36 \\
5.50 \\
4.43 \\
2.86 \\
2.64\end{array}$ & $\begin{array}{l}0.36 \\
0.57 \\
0.79 \\
0.14 \\
0.21 \\
1.21 \\
2.00 \\
3.66 \\
4.43 \\
5.72 \\
6.22 \\
8.22 \\
8.36 \\
7.50 \\
5.50 \\
1.57 \\
0.00 \\
1.21\end{array}$ & $\begin{array}{l}1.52 \\
1.22 \\
1.52 \\
1.37 \\
1.52 \\
1.22 \\
1.37 \\
1.67 \\
1.98 \\
2.44 \\
2.12 \\
1.98 \\
2.58 \\
3.35 \\
2.73 \\
2.44 \\
2.44 \\
1.83\end{array}$ & $\begin{array}{l}0.24 \\
0.47 \\
0.52 \\
0.10 \\
0.14 \\
0.99 \\
1.46 \\
2.19 \\
2.24 \\
2.34 \\
2.93 \\
4.15 \\
3.24 \\
2.2 .1 \\
2.01 \\
0.64 \\
0.00 \\
0.66\end{array}$ & $\begin{array}{r}1.63 \\
1.57 \\
1.73 \\
1.66 \\
1.41 \\
1.48 \\
1.77 \\
2.86 \\
4.34 \\
6.98 \\
7.12 \\
7.78 \\
12.36 \\
17.96 \\
15.02 \\
10.81 \\
6.98 \\
4.83\end{array}$ \\
\hline \multicolumn{5}{|c|}{ 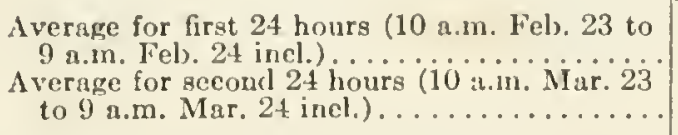 } & $\begin{array}{l}2.26 \\
2.36\end{array}$ & $\begin{array}{l}2.60 \\
2.39\end{array}$ & $\begin{array}{l}1.59 \\
2.21\end{array}$ & $\begin{array}{l}1.33 \\
0.91\end{array}$ & $\begin{array}{l}4.04 \\
6.17\end{array}$ \\
\hline
\end{tabular}

1Irrigator column $50 \mathrm{~cm}$. high in first series, $100 \mathrm{~cm}$. in second.

${ }^{2}$ Atmometer readings have been eorreeted to the Livingston standard atmometer and are thus comparable to other published readings obtained with his standardized eylindrical instrument. 
TABLe 3.-Data for Vicia.

\begin{tabular}{|c|c|c|c|c|c|c|c|c|c|}
\hline \multirow[b]{2}{*}{$\begin{array}{l}\text { Day } \\
\text { and } \\
\text { hour. }\end{array}$} & \multirow[b]{2}{*}{$\begin{array}{l}\text { Change } \\
\text { of } \\
\text { weight. }\end{array}$} & \multicolumn{3}{|c|}{ Actual loss. } & \multicolumn{3}{|c|}{$\begin{array}{l}\text { Loss, relative to that of } \\
\text { hour } 3, \text { Feb. } 23 \text {. }\end{array}$} & \multicolumn{2}{|c|}{$\begin{array}{l}\text { Derived values, } \\
\text { relative to hour } 3 \text {, } \\
\text { Feb. } 23 \text {. }\end{array}$} \\
\hline & & $\begin{array}{l}\text { Irriga- } \\
\text { tor.1 }\end{array}$ & $\begin{array}{l}\text { Trans- } \\
\text { piration. }\end{array}$ & $\underset{\text { eter. }}{2}$ & $\begin{array}{l}\text { Irrigator } \\
(I) .\end{array}$ & $\begin{array}{l}\text { Trans- } \\
\text { piration } \\
(T) .\end{array}$ & $\begin{array}{c}\text { Atmom- } \\
\text { eter } \\
(E) .\end{array}$ & $\begin{array}{c}\text { Relative } \\
\text { transpi- } \\
\text { ration } \\
\left(\frac{T}{E}\right) .\end{array}$ & $\begin{array}{l}\text { Environ- } \\
\text { mental } \\
\text { aridity } \\
(E I) .{ }^{3}\end{array}$ \\
\hline $\begin{array}{rr}\text { Feb. } 23 \\
\text { Hour } & 9 \\
10 \\
11 \\
12 \\
13 \\
14 \\
15 \\
16 \\
17 \\
18 \\
19 \\
20 \\
21 \\
22 \\
23 \\
24 \\
20\end{array}$ & $\begin{array}{l}\text { grams } \\
-1.0 \\
-6.0 \\
-9.0 \\
-7.0 \\
-3.0 \\
-3.0 \\
+1.0 \\
+1.0 \\
+4.0 \\
+2.0 \\
+6.0 \\
+1.0 \\
+5.0 \\
+0.5 \\
+0.5 \\
+1.0\end{array}$ & $\begin{array}{r}c . c . \\
4.6 \\
6.6 \\
9.2 \\
9.5 \\
13.3 \\
11.8 \\
12.6 \\
11.8 \\
11.1 \\
7.0 \\
5.6 \\
4.0 \\
3.5 \\
3.0 \\
2.2 \\
2.3\end{array}$ & $\begin{array}{r}\text { grams } \\
5.6 \\
12.6 \\
18.2 \\
16.5 \\
16.3 \\
14.8 \\
11.6 \\
10.8 \\
7.1 \\
5.0 \\
-0.4 \\
3.0 \\
-1.5 \\
2.5 \\
1.7 \\
1.3\end{array}$ & $\begin{array}{l}c . c . \\
0.88 \\
0.96 \\
1.36 \\
1.36 \\
\mathbf{1 . 5 2} \\
1.20 \\
1.12 \\
1.12 \\
0.88 \\
0.72 \\
0.80 \\
0.56 \\
0.56 \\
0.64 \\
0.48 \\
0.48\end{array}$ & $\begin{array}{l}2.30 \\
3.30 \\
4.60 \\
4.75 \\
6.65 \\
5.90 \\
6.30 \\
5.90 \\
5.55 \\
3.50 \\
2.80 \\
2.00 \\
1.75 \\
1.50 \\
1.10 \\
1.15\end{array}$ & $\begin{array}{l}2.80 \\
6.30 \\
9.10 \\
8.25 \\
8.15 \\
7.40 \\
5.80 \\
5.40 \\
3.55 \\
2.50 \\
0.00 \\
1.50 \\
0.00 \\
1.25 \\
0.85 \\
0.65\end{array}$ & $\begin{array}{l}1.83 \\
2.00 \\
2.83 \\
2.83 \\
3.17 \\
2.50 \\
2.33 \\
2.33 \\
1.83 \\
1.50 \\
1.67 \\
1.17 \\
1.17 \\
1.33 \\
1.00 \\
1.00\end{array}$ & $\begin{array}{l}1.53 \\
3.15 \\
3.22 \\
2.92 \\
2.57 \\
2.96 \\
2.49 \\
2.32 \\
1.94 \\
1.67 \\
0.00 \\
1.28 \\
0.00 \\
0.94 \\
0.85 \\
0.65\end{array}$ & $\begin{array}{c}4.21 \\
6.60 \\
13.02 \\
13.44 \\
21.08 \mathrm{~W} \\
14.75 \mathrm{~W} \\
14.68 \mathrm{~W} \\
13.75 \\
10.16 \\
5.25 \\
4.68 \\
2.34 \\
2.05 \\
2.00 \\
1.10 \\
1.15\end{array}$ \\
\hline $\begin{array}{r}\text { Hour } \quad 1 \\
2 \\
2 \\
3 \\
4 \\
5 \\
6 \\
7 \\
8 \\
8 \\
9 \\
10\end{array}$ & $\begin{array}{r}+2.0 \\
0.0 \\
0.0 \\
+1.0 \\
+1.0 \\
+2.0 \\
+0.5 \\
-0.5 \\
-2.0 \\
-3.0\end{array}$ & $\begin{array}{l}2.1 \\
2.4 \\
2.0 \\
2.9 \\
2.3 \\
2.3 \\
2.8 \\
3.4 \\
3.5 \\
4.8\end{array}$ & $\begin{array}{l}0.1 \\
2.4 \\
2.0 \\
1.9 \\
1.3 \\
0.3 \\
2.3 \\
3.9 \\
5.5 \\
7.8\end{array}$ & $\begin{array}{l}0.56 \\
0.56 \\
0.48 \\
0.56 \\
0.48 \\
0.48 \\
0.52 \\
0.44 \\
0.52 \\
0.68\end{array}$ & $\begin{array}{l}1.05 \\
1.20 \\
1.00 \\
1.45 \\
1.15 \\
1.15 \\
1.40 \\
1.70 \\
1.75 \\
2.40\end{array}$ & $\begin{array}{l}0.05 \\
1.20 \\
1.00 \\
0.95 \\
0.65 \\
0.15 \\
1.15 \\
1.95 \\
2.75 \\
3.90\end{array}$ & $\begin{array}{l}1.17 \\
1.17 \\
1.00 \\
1.17 \\
1.00 \\
1.00 \\
1.08 \\
0.92 \\
1.08 \\
1.42\end{array}$ & $\begin{array}{l}0.43 \\
1.03 \\
1.00 \\
0.81 \\
0.65 \\
0.15 \\
1.06 \\
2.12 \\
2.55 \\
2.75\end{array}$ & $\begin{array}{l}1.23 \\
1.40 \\
1.00 \\
1.70 \\
1.15 \\
1.15 \\
1.51 \\
1.56 \\
1.89 \\
3.41\end{array}$ \\
\hline $\begin{array}{r}\text { Mour } 10 \\
11 \\
12 \\
13 \\
14 \\
15 \\
16 \\
17 \\
18 \\
19 \\
20 \\
21 \\
22 \\
23 \\
24\end{array}$ & $\begin{array}{r}-2.0 \\
-4.0 \\
-2.0 \\
-6.0 \\
+1.0 \\
0.0 \\
+2.0 \\
+2.0 \\
+3.0 \\
+2.0 \\
+1.0 \\
+1.0 \\
+1.0 \\
+2.0 \\
0.0\end{array}$ & $\begin{array}{l}6.3 \\
6.2 \\
8.2 \\
9.4 \\
9.5 \\
8.2 \\
7.6 \\
5.0 \\
5.1 \\
2.1 \\
2.5 \\
2.1 \\
2.2 \\
1.8 \\
2.0\end{array}$ & $\begin{array}{r}8.3 \\
10.2 \\
10.2 \\
\mathbf{1 5 . 4} \\
8.5 \\
8.2 \\
\mathbf{5} .6 \\
3.0 \\
2.1 \\
0.1 \\
1.5 \\
1.1 \\
1.2 \\
-0.2 \\
2.0\end{array}$ & $\begin{array}{l}1.46 \\
1.53 \\
1.53 \\
1.90 \\
1.75 \\
1.68 \\
1.46 \\
1.39 \\
1.10 \\
1.39 \\
0.51 \\
0.95 \\
0.80 \\
0.80 \\
0.73\end{array}$ & $\begin{array}{l}3.15 \\
3.10 \\
4.10 \\
4.70 \\
4.75 \\
4.10 \\
3.80 \\
2.50 \\
2.55 \\
1.05 \\
1.25 \\
1.05 \\
1.10 \\
0.90 \\
1.00\end{array}$ & $\begin{array}{l}4.15 \\
5.10 \\
5.10 \\
7.70 \\
4.25 \\
4.10 \\
2.80 \\
1.50 \\
1.05 \\
0.05 \\
0.75 \\
0.55 \\
0.60 \\
0.00 \\
1.00\end{array}$ & $\begin{array}{l}3.04 \\
3.19 \\
3.19 \\
3.96 \\
3.65 \\
3.50 \\
3.04 \\
2.90 \\
2.29 \\
2.90 \\
1.06 \\
1.98 \\
1.67 \\
1.67 \\
1.52\end{array}$ & $\begin{array}{l}1.37 \\
1.60 \\
1.60 \\
1.94 \\
1.16 \\
1.17 \\
0.92 \\
0.52 \\
0.46 \\
0.02 \\
0.71 \\
0.28 \\
0.36 \\
0.00 \\
0.66\end{array}$ & $\begin{array}{c}9.58 \\
9.89 \\
13.08 \mathrm{~W} \\
\mathbf{1 8 . 6 1} \mathrm{W} \\
17.34 \mathrm{~W} \\
14.35 \mathrm{~W} \\
11.55 \mathrm{~W} \\
7.25 \\
5.84 \\
3.05 \\
1.33 \\
2.08 \\
1.84 \\
1.50 \\
1.52\end{array}$ \\
\hline $\begin{array}{r}\text { Mar. } 24 \\
\text { Hour } \\
2 \\
3 \\
3 \\
4 \\
5 \\
6 \\
7 \\
8 \\
8 \\
9 \\
10 \\
11 \\
12 \\
13 \\
14 \\
15 \\
16 \\
17 \\
18\end{array}$ & $\begin{array}{r}+1.0 \\
+1.0 \\
0.0 \\
+1.0 \\
+0.5 \\
-0.5 \\
-2.0 \\
-3.0 \\
-5.0 \\
-1.0 \\
0.0 \\
-4.0 \\
-2.0 \\
-2.0 \\
+1.0 \\
+1.0 \\
+2.0 \\
+2.0\end{array}$ & $\begin{array}{l}1.9 \\
1.3 \\
1.9 \\
1.0 \\
1.6 \\
1.6 \\
2.6 \\
4.6 \\
5.7 \\
7.7 \\
6.7 \\
7.0 \\
7.7 \\
9.0 \\
9.0 \\
6.7 \\
5.7 \\
3.9\end{array}$ & $\begin{array}{r}0.9 \\
0.3 \\
1.9 \\
0.0 \\
1.1 \\
2.1 \\
4.6 \\
7.6 \\
10.7 \\
8.7 \\
6.7 \\
11.0 \\
9.7 \\
11.0 \\
8.0 \\
5.7 \\
3.7 \\
1.9\end{array}$ & $\begin{array}{l}0.73 \\
0.58 \\
0.73 \\
0.66 \\
0.73 \\
0.58 \\
0.66 \\
0.80 \\
0.95 \\
1.17 \\
1.02 \\
0.95 \\
1.24 \\
1.61 \\
1.31 \\
1.17 \\
1.17 \\
0.88\end{array}$ & $\begin{array}{l}0.95 \\
0.65 \\
0.95 \\
0.50 \\
0.80 \\
0.80 \\
1.30 \\
2.30 \\
2.85 \\
3.85 \\
3.35 \\
3.50 \\
3.85 \\
4.50 \\
4.50 \\
3.35 \\
2.85 \\
1.95\end{array}$ & $\begin{array}{l}0.45 \\
0.15 \\
0.95 \\
0.00 \\
0.55 \\
1.05 \\
2.30 \\
3.80 \\
5.35 \\
4.35 \\
3.35 \\
5.50 \\
4.85 \\
5.50 \\
4.00 \\
2.85 \\
1.85 \\
0.95\end{array}$ & $\begin{array}{l}1.52 \\
1.21 \\
1.52 \\
1.38 \\
1.52 \\
1.21 \\
1.38 \\
1.67 \\
1.98 \\
2.44 \\
2.13 \\
1.98 \\
2.58 \\
3.35 \\
2.73 \\
2.44 \\
2.44 \\
1.83\end{array}$ & $\begin{array}{l}0.30 \\
0.12 \\
0.63 \\
0.00 \\
0.36 \\
0.87 \\
1.67 \\
2.28 \\
2.70 \\
1.78 \\
1.57 \\
2.78 \\
1.88 \\
1.64 \\
1.47 \\
1.17 \\
0.76 \\
0.52\end{array}$ & $\begin{array}{c}1.44 \\
0.79 \\
1.44 \\
0.69 \\
1.22 \\
0.97 \\
1.79 \\
3.84 \\
5.64 \\
9.39 \\
7.14 \\
6.93 \\
9.93 \\
15.08 \mathrm{~W} \\
12.29 \mathrm{~W} \\
8.17 \mathrm{~W} \\
6.95 \\
3.57\end{array}$ \\
\hline $\begin{array}{c}\text { Average } \\
9 \text { a.m. } \\
\text { Average } \\
\text { to } 9 \mathrm{a} .\end{array}$ & $\begin{array}{l}\text { secon } \\
\text { Mar. }\end{array}$ & $\begin{array}{l}\text { hou } \\
\text { cl.) }\end{array}$ & $\begin{array}{l}08 \\
\cdots\end{array}$ & ir. 2 & $\begin{array}{l}2.86 \\
2.09\end{array}$ & $\begin{array}{l}2.94 \\
2.22\end{array}$ & $\begin{array}{l}1.59 \\
2.21\end{array}$ & $\begin{array}{l}1.53 \\
0.90\end{array}$ & $\begin{array}{l}5.78 \\
5.69\end{array}$ \\
\hline
\end{tabular}

Irrigator column $50 \mathrm{~cm}$. high in first series, $5 \mathrm{~cm}$. in second.

2 Atmometer readings have been corrected to the Livingston standard atmometer and are thus comparable to other published readings obtained with his standardized cylindrical instrument.

${ }^{8} \mathrm{~W}$ in this column denotes that wilting was evident. 
TABLE 4.-Data for Pelargonium.

\begin{tabular}{|c|c|c|c|c|c|c|c|c|c|}
\hline \multirow{2}{*}{$\begin{array}{l}\text { Day } \\
\text { and } \\
\text { hour. }\end{array}$} & \multirow{2}{*}{$\begin{array}{c}\text { Change } \\
\text { of } \\
\text { weight. }\end{array}$} & \multicolumn{3}{|c|}{ Actual loss. } & \multicolumn{3}{|c|}{$\begin{array}{l}\text { Loss, relative to that of } \\
\text { hour } 3, \text { Feb. } 23 \text {. }\end{array}$} & \multicolumn{2}{|c|}{$\begin{array}{c}\text { Derived values, } \\
\text { rclative to hour } 23, \\
\text { Feb. } 23 \text {. }\end{array}$} \\
\hline & & $\begin{array}{c}\text { Irriga- } \\
\text { tor. }{ }^{1}\end{array}$ & $\begin{array}{c}\text { Trans- } \\
\text { piration. }\end{array}$ & $\begin{array}{c}\text { Atmom- } \\
\text { eter. }{ }^{2}\end{array}$ & $\begin{array}{c}\text { Irrigator } \\
(I) .\end{array}$ & $\begin{array}{c}\text { Trans- } \\
\text { piration } \\
(T)\end{array}$ & $\begin{array}{l}\text { Atrmom- } \\
\text { eter } \\
(E)\end{array}$ & $\begin{array}{c}\text { Relative } \\
\text { transpi- } \\
\text { ration } \\
\left(\frac{T}{E}\right)\end{array}$ & $\begin{array}{l}\text { Environ- } \\
\text { mental } \\
\text { aridity } \\
(E I)\end{array}$ \\
\hline $\begin{array}{r}\text { Feb. } 23 \\
\text { Hour } 9 \\
10 \\
11 \\
12 \\
13 \\
14 \\
15 \\
16 \\
17 \\
18 \\
19 \\
20 \\
21 \\
22 \\
23 \\
24\end{array}$ & $\begin{array}{r}\text { grams } \\
0.0 \\
-3.0 \\
-5.0 \\
-5.0 \\
-5.0 \\
-5.0 \\
-3.0 \\
-2.0 \\
+1.0 \\
+2.0 \\
+1.5 \\
+2.5 \\
+0.5 \\
+0.5 \\
0.0 \\
+1.5\end{array}$ & $\begin{array}{l}c . c . \\
0.8 \\
1.5 \\
1.8 \\
2.5 \\
3.1 \\
3.2 \\
2.9 \\
3.6 \\
2.9 \\
2.9 \\
2.5 \\
2.0 \\
1.3 \\
1.7 \\
1.1 \\
1.1\end{array}$ & $\begin{array}{r}\text { grams } \\
0.8 \\
4.5 \\
6.8 \\
7.5 \\
8.1 \\
8.2 \\
5.9 \\
5.6 \\
1.9 \\
0.9 \\
1.0 \\
-0.5 \\
0.8 \\
1.2 \\
1.1 \\
-0.4\end{array}$ & $\begin{array}{l}c . c . \\
0.88 \\
0.96 \\
1.36 \\
1.36 \\
1.52 \\
1.20 \\
1.12 \\
1.12 \\
0.88 \\
0.72 \\
0.80 \\
0.56 \\
0.56 \\
0.64 \\
0.48 \\
0.48\end{array}$ & $\begin{array}{l}0.73 \\
1.36 \\
1.64 \\
2.27 \\
2.82 \\
2.91 \\
2.64 \\
3.27 \\
2.64 \\
2.64 \\
2.27 \\
1.82 \\
1.18 \\
1.55 \\
1.00 \\
1.00\end{array}$ & $\begin{array}{l}0.73 \\
4.09 \\
6.18 \\
6.82 \\
7.36 \\
7.45 \\
5.36 \\
5.09 \\
1.73 \\
0.82 \\
0.91 \\
0.00 \\
0.73 \\
1.09 \\
1.00 \\
0.00\end{array}$ & $\begin{array}{l}1.83 \\
2.00 \\
2.83 \\
2.83 \\
3.17 \\
2.50 \\
2.33 \\
2.33 \\
1.83 \\
1.50 \\
1.67 \\
1.17 \\
1.17 \\
1.33 \\
1.00 \\
1.00\end{array}$ & $\begin{array}{l}0.40 \\
2.05 \\
2.18 \\
2.41 \\
2.32 \\
2.98 \\
2.30 \\
2.18 \\
0.95 \\
0.55 \\
0.54 \\
0.00 \\
0.62 \\
0.82 \\
1.00 \\
0.00\end{array}$ & $\begin{array}{l}1.34 \\
2.72 \\
4.61 \\
6.42 \\
8.94 \\
7.28 \\
6.15 \\
7.62 \\
4.83 \\
3.96 \\
3.79 \\
2.13 \\
1.38 \\
2.06 \\
1.00 \\
1.00\end{array}$ \\
\hline $\begin{array}{r}\text { Feb. } 24 \\
\text { Hour } \\
1 \\
2 \\
3 \\
4 \\
5 \\
6 \\
7 \\
7 \\
8 \\
9 \\
10 \\
\end{array}$ & $\begin{array}{r}-0.5 \\
+1.0 \\
+1.0 \\
+1.0 \\
0.0 \\
+1.0 \\
+0.5 \\
0.0 \\
-0.5 \\
-2.0\end{array}$ & $\begin{array}{l}1.3 \\
0.8 \\
1.0 \\
1.1 \\
0.8 \\
1.0 \\
0.9 \\
1.5 \\
1.3 \\
1.4\end{array}$ & $\begin{array}{r}1.8 \\
-0.2 \\
0.0 \\
0.1 \\
0.8 \\
0.0 \\
0.4 \\
1.5 \\
1.8 \\
3.4\end{array}$ & $\begin{array}{l}0.56 \\
0.56 \\
0.48 \\
0.56 \\
0.48 \\
0.48 \\
0.52 \\
0.44 \\
0.52 \\
0.68\end{array}$ & $\begin{array}{l}1.18 \\
0.73 \\
0.91 \\
1.00 \\
0.73 \\
0.91 \\
0.82 \\
0.36 \\
1.18 \\
1.27\end{array}$ & $\begin{array}{l}1.64 \\
0.00 \\
0.00 \\
0.09 \\
0.73 \\
0.00 \\
0.36 \\
1.36 \\
1.64 \\
3.09\end{array}$ & $\begin{array}{l}1.17 \\
1.17 \\
1.00 \\
1.17 \\
1.00 \\
1.00 \\
1.08 \\
0.92 \\
1.08 \\
1.42\end{array}$ & $\begin{array}{l}1.40 \\
0.00 \\
0.00 \\
0.08 \\
0.07 \\
0.00 \\
0.33 \\
1.48 \\
1.52 \\
2.18\end{array}$ & $\begin{array}{l}1.38 \\
0.85 \\
0.91 \\
1.17 \\
0.73 \\
0.91 \\
0.89 \\
1.25 \\
1.27 \\
1.80\end{array}$ \\
\hline $\begin{array}{r}\text { Mar. } \\
\text { Hour } 10 \\
11 \\
12 \\
13 \\
14 \\
15 \\
16 \\
17 \\
18 \\
19 \\
20 \\
21 \\
22 \\
23 \\
24\end{array}$ & $\begin{array}{r}-2.0 \\
-1.0 \\
-3.0 \\
-1.0 \\
0.0 \\
0.0 \\
+1.0 \\
+1.0 \\
+1.0 \\
0.0 \\
0.0 \\
+1.0 \\
+1.0 \\
+1.0 \\
0.0\end{array}$ & $\begin{array}{l}3.8 \\
4.2 \\
4.7 \\
4.7 \\
5.4 \\
4.6 \\
3.2 \\
1.6 \\
1.1 \\
0.6 \\
0.9 \\
1.0 \\
1.4 \\
0.5 \\
0.7\end{array}$ & $\begin{array}{r}5.8 \\
5.2 \\
7.7 \\
5.7 \\
5.4 \\
4.6 \\
2.2 \\
0.6 \\
0.1 \\
0.6 \\
0.9 \\
0.0 \\
0.4 \\
-0.5 \\
0.7\end{array}$ & $\begin{array}{l}1.46 \\
1.53 \\
1.53 \\
1.90 \\
1.75 \\
1.68 \\
1.46 \\
1.39 \\
1.10 \\
1.39 \\
0.51 \\
0.95 \\
0.80 \\
0.80 \\
0.73\end{array}$ & $\begin{array}{l}3.45 \\
3.82 \\
4.27 \\
4.27 \\
4.91 \\
4.18 \\
2.91 \\
1.45 \\
1.00 \\
0.55 \\
0.82 \\
0.91 \\
1.27 \\
0.45 \\
0.64\end{array}$ & $\begin{array}{l}5.27 \\
4.73 \\
7.00 \\
5.18 \\
4.91 \\
4.18 \\
2.00 \\
0.55 \\
0.09 \\
0.55 \\
0.82 \\
0.00 \\
0.36 \\
0.00 \\
0.64\end{array}$ & $\begin{array}{l}3.04 \\
3.19 \\
3.19 \\
3.96 \\
3.65 \\
3.50 \\
3.04 \\
2.90 \\
2.29 \\
2.90 \\
1.06 \\
1.98 \\
1.67 \\
1.67 \\
1.52\end{array}$ & $\begin{array}{l}1.73 \\
1.48 \\
2.19 \\
1.31 \\
1.35 \\
1.19 \\
0.66 \\
0.19 \\
0.04 \\
0.19 \\
0.77 \\
0.00 \\
0.22 \\
0.00 \\
0.42\end{array}$ & $\begin{array}{r}10.49 \\
12.19 \\
13.62 \\
16.91 \\
17.92 \\
14.63 \\
8.85 \\
4.21 \\
2.29 \\
1.60 \\
0.87 \\
1.80 \\
2.12 \\
0.75 \\
0.97\end{array}$ \\
\hline $\begin{array}{rr}\text { Mor. } & 4 \\
1 & 1 \\
2 \\
3 \\
4 \\
4 \\
5 \\
6 \\
7 \\
8 \\
9 \\
10 \\
11 \\
12 \\
13 \\
14 \\
15 \\
16 \\
17\end{array}$ & $\begin{array}{r}0.0 \\
+1.0 \\
+1.0 \\
0.0 \\
+0.5 \\
0.0 \\
-0.5 \\
0.0 \\
-2.0 \\
-1.0 \\
0.0 \\
-2.0 \\
-2.0 \\
-2.0 \\
-1.0 \\
+2.0 \\
0.0\end{array}$ & $\begin{array}{l}0.7 \\
0.6 \\
0.7 \\
0.6 \\
0.7 \\
0.9 \\
1.3 \\
2.3 \\
3.0 \\
3.7 \\
3.9 \\
4.8 \\
4.9 \\
4.9 \\
4.9 \\
3.4 \\
2.2\end{array}$ & $\begin{array}{r}0.7 \\
-0.4 \\
-0.3 \\
0.6 \\
0.2 \\
0.9 \\
1.8 \\
2.3 \\
5.0 \\
4.7 \\
3.9 \\
6.8 \\
6.9 \\
6.9 \\
5.9 \\
1.4 \\
2.2\end{array}$ & $\begin{array}{l}0.73 \\
0.58 \\
0.73 \\
0.66 \\
0.73 \\
0.58 \\
0.66 \\
0.80 \\
0.95 \\
1.17 \\
1.02 \\
0.95 \\
1.24 \\
1.61 \\
1.31 \\
1.17 \\
1.17\end{array}$ & $\begin{array}{l}0.64 \\
0.55 \\
0.64 \\
0.55 \\
0.64 \\
0.82 \\
1.18 \\
2.09 \\
2.73 \\
3.36 \\
3.55 \\
4.36 \\
4.45 \\
4.45 \\
4.45 \\
3.09 \\
2.00\end{array}$ & $\begin{array}{l}0.64 \\
0.00 \\
0.00 \\
0.55 \\
0.18 \\
0.82 \\
1.64 \\
2.09 \\
4.55 \\
4.27 \\
3.55 \\
6.18 \\
6.27 \\
6.27 \\
5.36 \\
1.27 \\
2.00\end{array}$ & $\begin{array}{l}1.52 \\
1.21 \\
1.52 \\
1.38 \\
1.52 \\
1.21 \\
1.38 \\
1.67 \\
1.98 \\
2.44 \\
2.13 \\
1.98 \\
2.58 \\
3.35 \\
2.73 \\
2.44 \\
2.44\end{array}$ & $\begin{array}{l}0.42 \\
0.00 \\
0.00 \\
0.40 \\
0.12 \\
0.68 \\
1.19 \\
1.25 \\
2.30 \\
1.75 \\
1.67 \\
3.12 \\
2.43 \\
1.87 \\
1.96 \\
0.52 \\
0.82\end{array}$ & $\begin{array}{r}0.97 \\
0.67 \\
0.97 \\
0.76 \\
0.97 \\
0.99 \\
1.63 \\
3.49 \\
5.41 \\
8.20 \\
7.56 \\
8.63 \\
11.48 \\
14.91 \\
12.15 \\
7.54 \\
4.88\end{array}$ \\
\hline \multicolumn{5}{|c|}{ 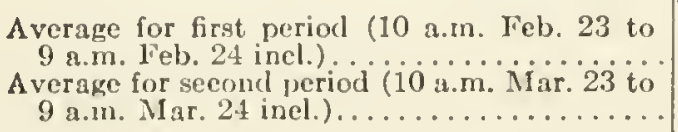 } & $\begin{array}{l}1.74 \\
1.86\end{array}$ & $\begin{array}{l}2.27 \\
1.95\end{array}$ & $\begin{array}{l}1.59 \\
2.21\end{array}$ & $\begin{array}{l}1.07 \\
0.71\end{array}$ & $\begin{array}{l}3.05 \\
5.21\end{array}$ \\
\hline
\end{tabular}

1rrigator column $50 \mathrm{~cm}$. high in first scries, $100 \mathrm{~cm}$. in sceond.

2 Atmorneter readings have been eorrected to tho Livingston standard atmometer and are thus comparable to other published readings obtained with his standardized cylindrical instrument. 
of actually disconnecting the reservoir at each weighing, there occur in the columns for absolute transpiration several cases where there was an apparent negative transpiration, as though the plant had absorbed water out of the air. These are to be regarded as resulting from accumulated errors of weighing, changes in the rubber tube, etc. The discrepancies which would thus be introduced in the derived series have been avoided by considering these values as zero, such assumed values being indicated in the tables by italics. Thus, for example, in table 2 the observed value of the transpiration rate for hour 24, February 23 , is -0.9 , so that no satisfactory data are available for this hour in the columns for $T$ and $\frac{T}{E}$, and these latter data are assumed to be 0.0 . Since the rates with which we are dealing are all low during the night hours when such discrepancies occur, and since only approximate accuracy is here attempted, the errors thus introduced are regarded as negligible in the present preliminary study. The minima and maxima, for the 24-hour period, in the derived columns are indicated by full-face type. At the end of each series are given the respective average deduced values for the 24-hour period beginning with hour 10 and ending with hour 9 of the next day.

\section{DISCUSSION.}

Since attention is to be directed to the daily fluctuations in the various values given in the preceding tables, it will be advantageous to study the graphs ${ }^{1}$ of relative and derived data, which are shown in figures 1,2 , and 3 , instead of studying the tables 2,3 , and 4 themselves. These figures show the five different double graphs, placed one above another, it being obviously impossible clearly to present them all as plotted from the same horizontal line. It is to be borne in mind, however, that all five double graphs for the same plant are comparable as to their relative forms. The horizontal line below each double graph represents the common axis of abscissas for both component graphs. The vertical lines continuing through all five graphs in each figure represent hourly increments of time (marking the middle of the hour represented), and on them have been laid off (upward from the respective horizontal axes) the various ordinate values, taken directly from the tables. Thus, each graph represents the rate of increase or decrease of the particular power or rate to which it refers, with respect to time. The time period is 24 hours in each case, beginning with hour 10 of one day and ending with hour 9 of the day following, the hours of the day being simply numbered from 1 to 24 , without resorting to the conventional repetition after hour 12. Each double graph consists of two single ones, one for the February period of study and the other for the

${ }^{1}$ These graphs have been prepared by Mrs. Grace J. Livingston. 
March period, the former drawn as a full line, the latter as a broken one. The data for the second day of the March period, for hours later than the ninth, have not been included in the graphs. The lowest of the five axes of abscissas, at the base of each figure, is represented by a broad line for the night period, from hour 19 of one day to hour 6 of the next, inclusive; for the remainder of the day, from hour 7 to hour 18 , this line is double, with the same total width as the broad one.

The lowest double graph shows the march of the evaporating power of the air $(E)$, the second shows that of the rate of loss from the irrigator $(I)$, the third is for absolute transpiration $(T)$, the fourth is for transpiring power or relative transpiration $(T \div E)$, and the fifth is for what we have termed environmental desiccating power or aridity $(E \times I)$. It is to be noted that the evaporating power of the air was assumed to be the same for all three plants, hence the lowest double graph of figure 1 is simply repeated for figures 2 and 3 . All values for Coleus and Vicia (figs. 1 and 2) are stated in terms of the corresponding value for hour 3, February 24, considered as unity. For Pelargonium (fig. 3) the basis for comparison is the datum for hour 23, February 23.

The three plants will be considered in the order of the tables. In each case the five double graphs will be given attention in the order in which they have just been characterized. Only the most obvious points will be mentioned.

\section{COLEUS.}

(See table 2 and fig. 1.)

\section{EVAPORATING POWER OF THE AIR $(E)$.}

As is usual, the evaporation rates were generally relatively high during the day hours and much lower during those of the night. The rise in this rate began about hour 8 and attained a maximum (3.17 and 3.96) with hour 13 , for both periods of observation. The low rates characteristic of the night hours were first clearly attained with hour 20 for both periods. The pronounced temporary rise for hour 19 on both these graphs is almost certainly due to some manipulation of the general ennditions of the greenhouse, though this matter was not investigated. The mean rate of water loss from the atmometer was 1.59 for the earlier period and 2.21 for the later one (relative to the rate for hour 3, February 24), and the graph for the March day is seen to be placed generally a little higher or farther from the horizontal axis than is that for February.

The minima for these graphs are not to be satisfactorily located, but we may average the rates for the night period, from hour 20 to hour 7 , in each case, thus obtaining 1.11 and 1.47 for the February and March series, respectively. Using these average night rates we find that the maximum is 2.9 times the night average for the earlier series and 4.6 times the corresponding average for the later series. This state of 
affairs is in agreement with what might be expected from the seasonal difference between the two periods. There appears to be nothing remarkable about the behavior of this rate for either day; these graphs are fairly representative of the conditions obtaining in a rather dry greenhouse, on sunny days when some artificial heat is applied.

\section{ABSORBING POWER OF THE SOIL (I).}

For the February period the maximum (4.72) occurred with hour 16, but nearly as high a rate was maintained till hour 18 . The low night rate was not here attained till hour 23 , but it was maintained from hour

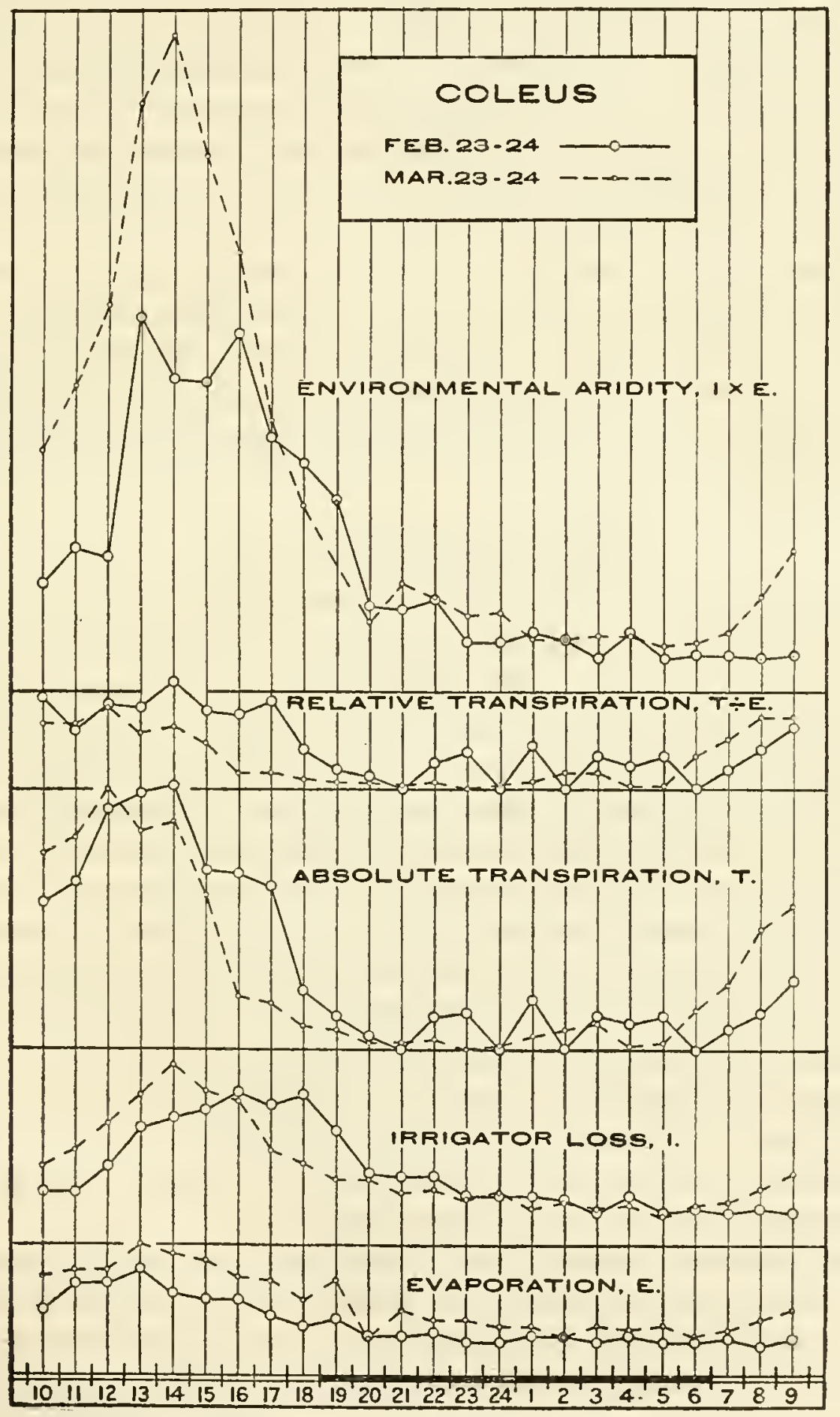

Fro. 1.-Graphs for Coleus. 
23 to hour 9 of the following day. The average value for this period is 1.23 and the maximum is 3.8 times this.

For the later series of observations the maximum (5.54) occurred with hour 14 and the fall was rather uniform thereafter, the night rate being again attained with hour 23 . The average night rate (hour 23 to hour 7 in this case) is 1.23 and the maximum is 4.5 times this.

It is noticeable that the first maximum occurred three hours and the second, one hour later than the corresponding maximum in the evaporating power of the air; also that the low rate for the night hours was not attained in the rate of irrigator loss until 2 or 3 hours later than in the case of evaporation, at least for the February period. These conditions surely have to do with a lag in the chain of cause and effect, from the evaporating power of the air to the absorbing power of the soil; some time must elapse before an increased desiccating power of the air becomes effective, through the plant and soil, upon the irrigator cup. Alteration in transpiring power (due to stomatal movement, etc.) must influence the form of this lag.

It is likewise to be remarked that the maximum in rate of irrigator loss for the second series occurred two or more hours earlier than that for the first. This appears to mean that the effective power of the aerial environment to tax the water-retaining and water-supplying power of the plant was greater during the morning and early afternoon hours of the second period.

\section{ABSOLUTE TRANSPIRATION $(T)$.}

The transpiration rate is the prime controlling condition for the rate of water absorption from the almost uniformly moist soil of our experiments, provided no marked alteration occurs in the state of the absorbing surfaces, aside from the change in their water content conditioned by fluctuation in the tensile stress transmitted from the leaves above. The graphs of transpiration rate thus furnish a picture of the propagation into the plant body of the envirommental disturbance of altered evaporating power of the air. In physiological terms, the rate of transpiration is a measure of the intensity of the effective stimulus which tends to alter the state of saturation deficit within the plant. This first response (which might be paralleled by perception in such unanalyzed processes as tropistic bendings) becomes a condition determining the propagation, inward and downward, in the plant body, of a wave of tension which ultimately results in an alteration in the rate of absorption from the soil. The latter may be paralleled by the process of bending itself, in the case of tropisms.

The transpiration maxima for the two series of observations occurred with hour 14 (8.14) and hour 12 (8.00), respectively. Both graphs show low rates for the night period, from hour 19 in both series to hour 7 in the first and to hour 5 in the second. The two average night rates 
are 0.65 and 0.32 . The maximum for the February series is 12.5 times and that for the March series is 25.0 times the corresponding night average. The great discrepancies between these ratios, on the one hand, and the corresponding ones for evaporation and irrigator loss on the other, are apparently related to alterations in transpiring power brought about by changes within the plant. These two maxima are followed by approximately parallel declines.

In the earlier series of measurements, the occurrence of the maximum transpiration rate an hour later than the occurrence of the maximum in the evaporating power of the air may be related to the fact that the position and surroundings of the atmometer could not be actually identical with those of any single culture; the evaporating power measured may have been somewhat lower than that really effective about the group of plants in question. Or, it may be due to the particular times at which observations were taken. At any rate, the failure of the transpiration rate (and also that of relative transpiration, as will be seen later) to exhibit a maximum earlier in the day than the maximum of evaporating power of the air makes it appear that transpirational water loss was not retarded by incipient drying in this earlier series. In the later series transpiration attains its maximum (hour 12) an hour earlier than does evaporation. The latter seems to be the typical condition of affairs (Livingston and Brown, 1912, and Edith B. Shreve, 1914) with plants taxed by environmental aridity. The points just brought out constitute additional evidence that the effective aridity of the surroundings was more intense during the forenoon hours of the March experiment than during the hours of forenoon and early afternoon of the February series.

\section{TRANSPIRING POWER $(T \div E)$.}

This involves the rate of absolute transpiration, and its graphs therefore show characters somewhat similar to those just considered. The maximum of the earlier graph (3.25) occurs with hour 14, the same hour as was seen to show the transpiration maximum. In the later graph the maximum (2.51) occurs with hour 12, which also agrees with the occurrence of the corresponding maximum in absolute transpiration.

The periods from hour 18 to hour 7 in the first series and to hour 6 in the second (the night hours) were characterized by very low magnitudes of the relative transpiration index. The average night value is 0.61 for the February series and 0.27 for the March series, and the corresponding maxima are 5.3 and 9.3 times their respective night averages. It thus appears that the internal variation in transpiring power, from night to day, is considerably greater than the corresponding environmental variation either in evaporating power of the air or absorbing power of the soil. In this connection it should be remembered that both these environmental variations were relatively small in our experiments. 
In the February series of observations, as has been noted, the transpiring power appears to have attained its maximum only at a time an hour later than that marked by the maximum of evaporation. In the March series, however, the maximum in calculated transpiring power occurred an hour earlier than did that of the evaporating power of the air. In the latter case incipient drying appears to have occurred.

\section{ENVIRONMENTAL ARIDITY $(I \times E)$.}

The two graphs of the value $I E$ differ mainly in two respects: the second series shows a much higher maximum (20.2, hour 14) than does the first (11.54, hour 13), and the second shows a more rapid ascent during the early hours of the forenoon. The period of low aridity extends from hour 23 to hour 9 for the first series and from hour 1 to hour 6 for the second. This last observation is to be taken in connection with the fact that the evaporating power of the air was seen to exhibit a much longer period of low values, beginning with hour 20 . This tardy development of the night condition, in environmental aridity, is no doubt due to the feature already emphasized, that the evening fall in evaporating power and the nearly simultaneous and pronounced fall in transpiring power (the latter probably caused mainly by closure of stomata) do not immediately bring about a corresponding decrease in the rate of absorption by the roots. Thus, the resistance to root absorption remains relatively high for several hours after the aerial desiccating conditions and the internal transpiring power have attained the low values characteristic for the night. The downward slope of the $I E$ graph, from hour 20 to hour 1, is gentle and prolonged, since it is affected by the lag in the fall of irrigator loss for the early night hours, above mentioned.

The average night value of this index is 1.31 for the 11 hours of the first series and 1.58 for the 6 hours of the second. The corresponding maxima are 8.8 and 12.8 times the respective night averages.

\section{DAILY MEAN CONDITIONS COMPARED.}

If we scrutinize the daily averages given at the base of table 1 , it appears that the evaporating power of the air was 1.39 times as great for the March as for the February period. Similarly, the corresponding ratio for the resistance offered by the soil to water absorption by the roots was 1.04, and for the general environmental aridity it was 1.53. On the other hand, transpiring power and absolute transpiration show greater average values for the earlier series, the ratios corresponding to those just given being 0.68 and 0.92 , respectively. It thus seems to be indicated that the plants had lower transpiring power as they became older (they were not very much larger at the second period than at the first, but the percentage of young leaves was much lower) and that this actually decreased the transpirational loss, although 
at the same time the aerial desiccating power was 39 per cent, the subterranean was 4 per cent, and the general environmental aridity was 53 per cent greater during the second period. It appears probable that the absorbing power of the roots may also have been greater during the later period, as might be the case if the absorbing surface were larger. These values illustrate the manner in which external and internal conditions may be expected to influence the plant in its general water-relations.

\section{VICIA.}

(See table 3 and fig. 2.)

\section{EVAPORATING POWER OF THE AIR $(E)$.}

These data are the same as those used for Coleus (table 2, fig. 1). They are simply repeated for Vicia (table 3, fig. 2).

\section{ABSORBING POWER OF THE SOIL (I).}

For the February period the maximum of this rate (6.65) occurred with hour 13 , but nearly as high a rate was maintained till hour 15 . The period of low night values began with hour 22 and continued to hour 7 of the next day. The average value for this period is 1.22 and the maximum is 5.5 times this.

For the March series the maximum (4.75) occurred with hour 14, but the value for hour 13 was almost as large. The fall after hour 14 was more rapid than in the earlier series and the night period began with hour 19. It continued till hour 7 , as in the February series, and the night average was 0.94 . The maximum is 5.1 times this average.

Both maxima may be said practically to have occurred with the same hour as the maximum in the evaporating power of the air, but the high rate was continued, two hours in the first series and one hour in the second, later than in the case of evaporation. This corresponds with the still more pronounced lag in this feature which was noted for Coleus. It is also noticeable that the February graph for Vicia agrees with the corresponding graphs of this feature for Coleus in that the low night rate in soil-absorbing power is not attained till 3 hours later than in the case of atmospheric evaporating power. In the March graph for Vicia the soil-absorbing power attains its night rate even an hour earlier than does the evaporation rate, which suggests that the general low position of the March graph is not due to drying of the soil immediately about the roots, but to low absorbing power of these organs. It is also possible that this difference between the two series is due to the alteration in the height of the irrigator water column, which occurred between the two periods.

Apparently the power of the plant to transmit the disturbance of high evaporation to the soil about the roots and that of these soil layers to transmit it to the irrigator cup were not greatly taxed in either 
series; otherwise a more pronounced lag behind evaporation would have been here exhibited. The later graph falls more rapidly than the earlier one, however, which suggests, as in the case of Coleus, that incipient drying was more pronounced in the second series. The lower maximum for the second series may denote lower transpiring power, perhaps partly due to hardening, etc., of the older leaves and partly to incipient drying and actual wilting, which occurred with hours 12 to 16 , as shown in table 2 .

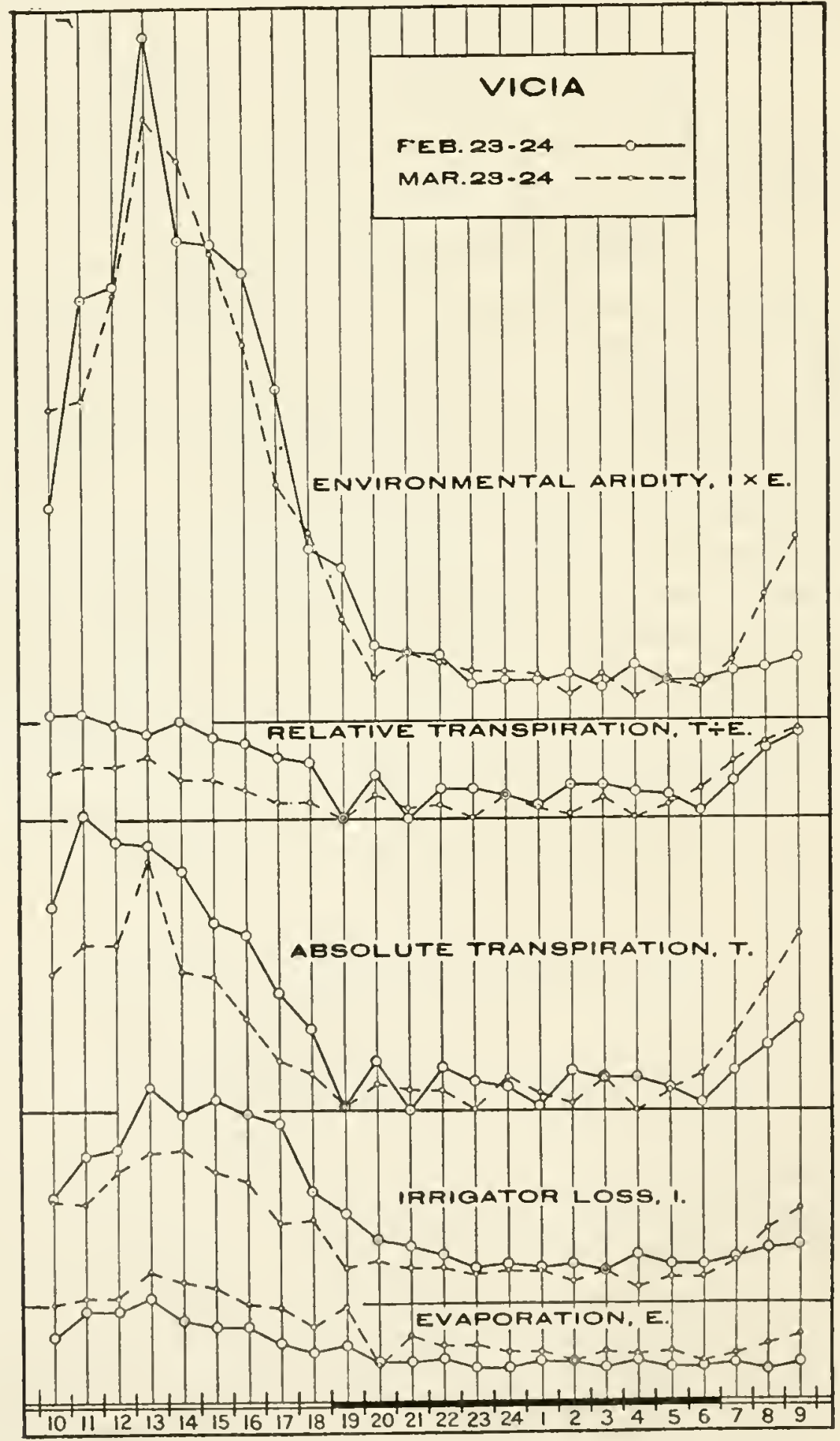

Fig. 2.-Graphs for Vicin. 


\section{ABSOLUTE TRANSPIRATION $(T)$.}

The transpiration maximum (9.10) occurred with hour 11 of the first series of observations and the low night rate was attained with hour 19, continuing to hour 6 of the following day. This occurrence of the February maximum of absolute transpiration two hours before that of the evaporating power of the air is (according to Livingston and Brown, 1912) evidence of pronounced incipient drying in the leaves. That this condition was here pronounced during the hours 12 to 15 is clearly shown by the fact-noted in table 3-that foliar wilting was observed for these hours. The night average (for hours 19 to 6) is 0.69 , and the maximum is 13.2 times this value.

Turning to the March series, the transpiration maximum (7.70) occurred with hour 13, the same hour as exhibited the maximum in the evaporating power of the air. The failure of this transpiration maximum to occur earlier than that of evaporation, in spite of the fact that wilting set in an hour earlier (hour 12) in the second series than in the first, and lasted an hour longer (till hour 16), may be related to some unexamined internal difference between the plants at the two times of study, or possibly to the actual times at which the observations were taken. No adequate data appear to be at hand for an investigation of this discrepancy. The rapid decrease in rate, after the attainment of the maximum in the second series, seems to denote more pronounced incipient drying here.

In this March series the low night rate of transpiration was attained with hour 18, an hour earlier than in the February series, and the low rate persisted till the sixth hour of the next day. The average night rate is 0.55 and the maximum is 14.0 times this value.

TRANSPIRING POWER $(T \div E)$.

The graph of transpiring power, or relative transpiration, for the February series exhibits an unusual form for this kind of graph. Its maximum (3.22) is attained with the eleventh hour, closely approached with the tenth, and the fall to the low night value is remarkably uniform and gradual. The low night rate is attained with hour 19 and maintained till hour 7 , with unsatisfactory fluctuation related to inaccuracies of weighing. The night average is 0.68 and the maximum is 4.7 times this value. The early occurrence of the maximum, two hours before the maximum of evaporation, agrees with the similar behavior of the graph of absolute transpiration for this February series, seeming to indicate pronounced incipient drying early in this day.

The relative transpiration graph for the March series of observations shows a maximum (1.94) with hour 13 , simultaneously with the maximum of the atmometric rate and with that of absolute transpiration. The period of low night values begins with hour 17 and extends to hour 6 of the next day. The average night rate is 0.38 and the maximum is 5.1 times this. This ratio value is similar to that given for the earlier 
series (4.7). These ratios are greater than the corresponding ones for evaporation $(2.9,4.6)$ and not markedly below those $(5.5,5.1)$ for irrigator loss.

Comparing these two graphs, it is apparent that transpiring power was generally lower in the second series than in the first, a feature probably to be related, as in the case of Coleus, to a maturing of the leaves between the times of the two series.

\section{ENVIRONMENTAL ARIDITY $(I \times E)$.}

These two graphs agree fairly well. Both show maxima at the hour of the greatest evaporation intensity, as should be expected from the nature of the conditions, and both show about the same night values. It is probably safe to infer that the low night value was not really attained in either case until hour 23 and that the night period ended with hour 6 . On such a basis the average night values are 1.24 and 1.20 , for the two series, respectively. The only apparent and considerable differences between the two graphs lie in the facts that the earlier series shows a slightly higher maximum and a somewhat more rapid rise in the early forenoon. The two maxima are 17.0 and 15.5 times the corresponding night averages. In this case, then, the ratio of maximum to night average was greater in the February series, while the opposite held for Coleus.

\section{DAILY MEAN CONDITIONS COMPARED.}

The daily averages at the base of table 2 show that, while the evaporating power of the air was, in general, 39 per cent greater for the March than for the February period, all the other features here considered were greater for the earlier period, a fact almost surely due to lowered transpiring power of the plant. The attraction of the soil for water was 37 per cent and the environmental aridity was 2 per cent, the mean transpiration rate was 32 per cent and the transpiring power was 70 per cent greater in March than in February.

The disagreements between these features and the corresponding ones for Coleus seem to illustrate how the internal conditions of the plant, though appearing - at first thought-quite distinct from the external surroundings, play an important role in determining the quantitative conditions of the latter. The environmental aridity is conceived as a function of the atmospheric water-extracting power and the power of the soil to attract moisture. While the former of these two powers may usually be regarded as independent of the latter, the latter is seldom independent of the former-not at all so in our experiments. The atmospheric evaporating power tends usually, in nature, to dry the soil about the roots in two ways: (1) by direct evaporation from the soil-air surfaces and (2) by increased root absorption. In our cultures the plastiline seal prevented the former action; the only way by which the soil adjacent to the roots became less saturated with water was through increased root absorption. But the latter is largely 
(though not wholly) dependent upon the rate of transpiration, which is, in turn, largely (though not wholly) dependent upon the evaporating power of the aerial surroundings. Thus the internal conditions of the plant (such as transpiring power, conducting power, absorbing power) may greatly influence the effect of altered evaporating power of the air upon the power of the soil to resist or retard absorption of water by roots.

\section{PELARGONIUM.}

(See table 4 and fig. 3.)

EVAPORATING POWER OF THE AIR $(E)$.

The data of this feature are repeated in table 4 and figure 3 , from table 2, figure 1 .

ABSORBING POWER OF THE SOIL (I).

The graph of this power for the February series shows a maximum (3.27) with hour 16, 3 hours later than the occurrence of the maximum in evaporation. The period of low night values may be taken as beginning with hour 23 ( 3 hours later than the beginning of the low night rate of evaporation) and ending with hour 7 for both series. The ratio of the maximum value of the earlier series to the night average $(0.92)$ is 3.2. In the case of the later series the maximum (4.91) occurs with hour 14, only a single hour later than the occurrence of the evaporation maximum. The February ratio of the maximum rate of irrigator loss to its average night value $(0.68)$ is 7.2 . It is noticeable that the lag between evaporation and the drying of the soil adjacent to the cup is greater for the earlier series, which is no doubt related to a greater transpiring power and absolute transpiration, possibly also to lower absorbing power of roots in the February series. As is frequent in such graphs, the higher maximum is followed by more rapid fall in this rate, perhaps due to phenomena within the plant as well as to the retardation of root absorption by drying of the adjacent soil, which must accompany high absorption rates. The March graph rises earlier, to a higher maximum, and falls earlier to a lower night rate than does the February one.

\section{ABSOLUTE TRANSPIRATION $(T)$.}

The earlier graph shows a maximum (7.45) with hour 14, an hour later than occurs the maximum of evaporation and 2 hours earlier than occurs that of irrigator loss. Evidently incipient drying of leaves was not effective in this case. The low night rate is attained with hour 18 and is maintained till hour 7 . The ratio of maximum to average night rate $(0.53)$ is 14.1 in this February series.

The March graph shows the maximum (7.00) with hour 12, an hour earlier than the occurrence of the evaporation maximum, thus suggesting some incipient drying in the late forenoon hours. The low night period extends from hour 17 to hour 6 of the next day, its average value being 0.37 . The ratio of the maximum to this average is 18.9 . 
TRANSPIRING POWER $(T \div E)$.

The February graph of this feature shows its maximum (2.98) with hour 14, the same hour as occurs the maximum of absolute transpiration. The period of low night values extends from hour 17 to hour 6 , its aver-

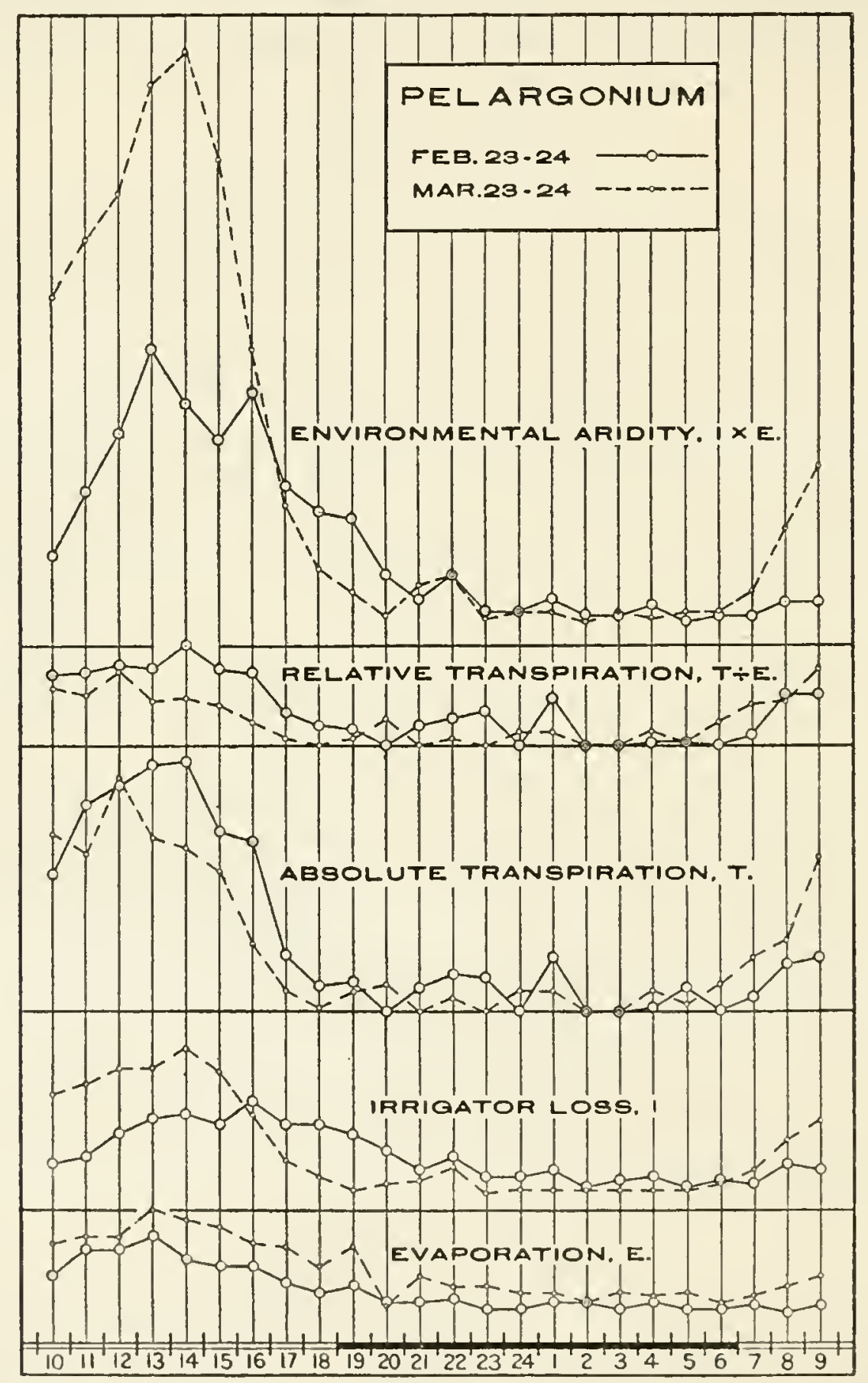

Fra. 3.-Graphs for Pelargonium.

age value being 0.42 and the ratio of the maximum to this being 7.1 . The March graph exhibits its maximum (2.19) with hour 12, also at the same hour as occurs the maximum for absolute transpiration. The March night period extends from hour 16 to hour 6 , with an average value of 0.27 . The maximum is 8.1 times this average. This March graph bears evidence of some incipient drying of the leaves about noon, thus agreeing with the corresponding graph of absolute transpiration. 
ENVIRONMENTAL ARIDITY $(I \times E)$.

The February graph here exhibits its maximum (8.94) with hour 13, the same hour as shows the maximum in evaporation. The February period of low night values extends from hour 23 to hour 7 of the day following, having an average value of 0.98 . The ratio of the maximum to this average is 8.6. The March graph shows a maximum (17.92) an hour later than the first, its night period reaching from hour 23 to hour 6. The night average is here 0.88 and the maximum is 20.4 times this average. The pronounced difference between the two maxima, largely related to the corresponding difference between the two graphs of soil-absorbing power, again illustrates the manner in which internal conditions may indirectly affect external ones; the soil condition in our experiments depended very largely, at any one time, upon the rate of root absorption during the period just past.

\section{DAILY MEAN CONDITIONS COMPARED.}

The daily averages at the base of table 3 show a general condition of affairs resembling that shown for Coleus but differing from that for Vicia. The evaporating power of the air (39 per cent greater in the March series than in the February one), the resistance of the soil to root absorption ( 7 per cent greater in the March series), and the envirorimental product (71 per cent greater in March), agree in the direction of their differences. On the other hand, the two remaining powers here considered possessed higher magnitudes in the February period. Absolute transpiration shows a daily average 16 per cent greater in February, and transpiring power shows an average 65 per cent greater in the earlier period.

\section{GENERAL RESULTS.}

From the foregoing presentation of some of the more outstanding details for the three plants a few general points are fairly well brought out, though the tentative nature of conclusions drawn from a first study of such a complex inter-relation of factors as is here involved must be clearly recognized, and anything like a reliable interpretation of many of the features of the experimental data is quite impossible at present. It appears, in the first place, that the study of the diurnal march of the rate of loss from the irrigator, in connection with simultaneous study of the corresponding march of transpiration and of the evaporating power of the air, promises to throw considerable light on the general problem of the dynamics of the water-relations of plants. The method here employed is susceptible of improvement in many ways, but it appears to look in a promising direction, at least. The value of this measure of the resistance offered by the soil to root absorption, when employed in cultures where the soil-moisture content is not maintained nearly constant, but is directly influenced by external 
conditions (such as evaporation from the soil surface, precipitation and the rise and fall of the subterranean water table), is of course a matter for future determination. In our studies the only immediate conditions markedly altering the soil-moisture content (and therefore its resistance to root intake) were those furnished by the plant itself. These conditions acted through the actual rate of root absorption, which tends to dry the soil layers adjacent to the absorbing surfaces and hence to lower the possible rate of water supply to the roots, by the formation of a drier layer of soil between the roots, and the more distant and more moist soil layers. Aside from growth and other water-consuming processes of the plants themselves, the actual rate of absorption by our roots was controlled by the evaporation rate, which was partly controlled, in turn, by internal conditions, and partly by the evaporating power of the aerial surroundings. But this external influence was not direct, for the disturbance of altered evaporating power never affected the absorptive rate directly, but always through a propagated disturbance in moisture equilibrium traversing the plant body. Internal variations altering the resistance to this propagation of Renner's "suction wave" apparently play an important role in determining the amount of work performed in the actual transfer of water from soil to plant. Thus the rate of irrigator loss is not as purely an environmental factor as is usually that of atmometer loss. It is considerations of this sort which render satisfactory interpretation of many of the phenomena above recorded quite out of the question at the present time. The unexplained phenomena depicted by our graphs appear at present to be related mainly to fluctuations in the internal conditions of the plants.

The data from our measurements bring out one general and possibly important feature of the daily march of the conditions considered. All of the graphs exhibit a high region for the day and a low one for the night, although there is a shifting, by a few hours, backward and forward, of the time at which the various maxima occur and of the beginning and end of the night period of low values. Although we have not been able to study minimal values, we have found it possible to compare the magnitude of each daily maximum with the corresponding average value for the night period. The ratios of maximum to mean night value have been given in the preceding section, and are here brought together in table 5 .

The data of table 5 show that in all cases but two the ratio value is greater for the March than for the February period. That is, outside of the two exceptions, the degree of diurnal fluctuation in the magnitudes of the various conditions is shown to be greater at the later time. The two exceptions are both for Vicia, one for irrigator loss and the other for environmental aridity; the difference between the ratio values, by which the February value is greater, is not large in the former case, but is considerable in the latter one. The occurrence of these 
exceptions may be related to special internal conditions in the Vicia plants, which alone wilted in the experiments, or it may be connected with the change in height of the irrigator water column, occurring between the two tests. The general increase in the degree of the daily fluctuation in these powers and rates is probably related to climatic conditions, but the time is not yet ripe for even a tentative interpretation.

TABLE 5.-Daily fluctuations, ratios of maxima to mean values for night hours.

\begin{tabular}{|c|c|c|c|c|}
\hline & Month. & Coleus. & Vicia. & Pelargonium. \\
\hline Evaporation $(E)$. & $\left\{\begin{array}{l}\text { Feb..... } \\
\text { Mar.... }\end{array}\right.$ & $\begin{array}{l}2.9 \\
4.6\end{array}$ & $\begin{array}{l}2.9 \\
4.6\end{array}$ & $\begin{array}{l}2.9 \\
4.6\end{array}$ \\
\hline Irrigator loss $(I)$. & $\left\{\begin{array}{l}\text { Feb..... } \\
\text { Mar.... }\end{array}\right.$ & $\begin{array}{l}3.8 \\
4.5\end{array}$ & $\begin{array}{l}5.5 \\
5.1\end{array}$ & $\begin{array}{l}3.2 \\
7.2\end{array}$ \\
\hline Absolute transpiration $(T)$. & $\left\{\begin{array}{l}\text { Feb...... } \\
\text { Mar.... }\end{array}\right.$ & $\begin{array}{l}12.5 \\
25.0\end{array}$ & $\begin{array}{l}13.2 \\
14.0\end{array}$ & $\begin{array}{l}14.1 \\
18.9\end{array}$ \\
\hline Relative transpiration $\left(\frac{T}{E}\right)$ & $\left\{\begin{array}{l}\text { Feb..... } \\
\text { Mar... }\end{array}\right.$ & $\begin{array}{l}5.3 \\
9.3\end{array}$ & $\begin{array}{l}4.7 \\
5.1\end{array}$ & $\begin{array}{l}7.1 \\
8.1\end{array}$ \\
\hline Environmental aridity $(E \times I$ & $\left\{\begin{array}{l}\text { Feb..... } \\
\text { Mar.... }\end{array}\right.$ & $\begin{array}{r}8.8 \\
12.8\end{array}$ & $\begin{array}{l}17.0 \\
15.5\end{array}$ & $\begin{array}{r}8.6 \\
20.4\end{array}$ \\
\hline
\end{tabular}

It appears, in general, from our measurements, that the soil here employed was dried out appreciably by root absorption, in the neighborhood of the roots, and that this partial desiccation usually lagged considerably behind its primary cause, rise in transpiration rate. This lag rendered the attraction of the soil for water noticeably high for some time after the transpiration rate had attained its low night value. Thus there occurred a sort of after-effect of high transpiration rate, manifested as resistance to root absorption with later hours in the day than those in which the cause was primarily operative.

To what degree the lag just considered occurred in the plant and to what degree in the soil intervening between roots and the irrigator cup can not of course be ascertained at present. That it is partly due to increased saturation deficit in the leaves of the plant may be regarded as probable from what has been shown by earlier work.

If the tendency of the whole environment to extract water from the plant or to retard water entrance be considered as proportional to the product of the evaporating power of the aerial surroundings and the water-attracting power of the soil, then the lag before us operates to maintain a comparatively high environmental aridity for several hours later in the day than would be the case in the absence of the after-effect in the soil.

In the series of relative values given above we have derived comparable magnitudes by calculating all values of each series to the basis, as unity, of the corresponding value for one of the night hours of the earlier period of observations. We have considered, in each case, the fluctuations in these relative magnitudes for two periods of 24 hours or more, these two periods being a month apart. Had full records been made from the beginning of the cultures to their discontinuance the series of relative values which might thus have been obtained might 
have furnished a rather complete history of the march of the water relations for the entire life of the plants. As it is, the introduction of the method of relative values on the same basis, for two days a month apart, has for the first time furnished evidence on the fluctuation in transpiring power (or relative transpiration), and on that in absolute transpiration, which occur during a month in the middle of a plant's life. The transpiring power of all these plants proved thus to be very markedly less for the 24-hour period in March than for a similar period in February. Our plants were practically full grown at the earlier time and the effect of increase in size (with its concomitant increase in leaf surface) was apparently much more than offset by some process of maturation within the plant, as the hardening of the leaves. The question thus suggested, of the march of transpiring power throughout the life history of the plant, is worthy of further study, and this matter will require consideration before the relations of water, salt, and other requirements at different stages or phases of the plant's growth (relations so important to agriculturists) may be placed upon a satisfactory foundation. It seems quite futile, for example, to expend time and energy in the quantitative comparison of the mineral requirements at different ontogenetic stages, so long as the water-relations of soil, air, and plant are ignored, as has been done so frequently.

The last remark is representative of a legion of fundamental inadequacies prevailing in present-day methods of physiological study, inadequacies which want only attention to be very largely removed. What appears to be needed to place physiological and ecological reasoning upon the same logical basis as that on which rest the more fundamental physical sciences seems to be, for the present at least, the application here of what knowledge and methods those sciences have already developed. Sooner or later it may be realized that the behavior of an organism is not to be adequately studied without quantitative knowledge of its surroundings, just as it is now commonly accepted that a physical or chemical determination is without great value until the environmental conditions and the apparatus used have been subjected to at least as penetrating scrutiny as that directed to the phenomenon in question. This paper has aimed to present what appear to be several short steps in this general direction toward a quantitative appreciation of the water-relations between the plant and its surroundings. 


\section{LITERATURE CITED.}

BABINET, J.

1848. Note sur un atmidoscope. Compt. Rend. 27 : 529-30.

Briggs, L. J., F. O. Martin, and J. R. Pearce.

1904. The centrifugal method of mechanical soil analysis. U. S. Dept. Agric., Bur. Soils Bull. 24.

Brigas, L. J., and A. G. McCall.

1904. An artificial root for inducing capillary movement of soil moisture. Science n. s. 20: $566-9$.

Briggs, L. J., and J. W. McLane.

1907. The moisture equivalent of soils. U. S. Dept. Agric., Bur. Soils Bull. 45.

Briggs, L. J., and H. L. Shantz.

1911. A wax seal method for determining the lower limit of available soil moisture. Bot. Gaz. 51: 210-19.

1912. (1) Application of wilting coefficient determinations in agronomic investigations. Proc. Amer. Soc. Agron. 3: 250-60.

(2) The wilting coefficient and its indirect determination. Bot. Gaz. 53: 20-37.

(3) The relative wilting coefficients for different plants. Bot. Gaz. 53: 229-35.

(4) The wilting coefficient for different plants and its indirect determination. U.S. Dept. Agric., Bur. Plant Ind. Bull. 230.

1913. Die relativen Welkungskoeffizienten verschiedener Pflanzen. Flora 105: 224-40.

Caldowelt, J. S.

1913. The relation of environmental conditions to the phenomenon of permanent wilting in plants. Physiol. Res. 1: 1-56.

Cameron, F. K., and F. E. Gallagher.

1908. Moisture content and physical condition of soils. U. S. Dept. Agric., Bur. Soils Bull. 50 .

Crump, W. B.

1913. Notes on water content and the wilting point. Jour. Ecol. 1: 96-100.

DachNowsKi, A.

1914. Transpiration in relation to growth and to the successional and geographic distribu-

Dixon, H. H. tion of plants. Ohio Naturalist 14: 241-51.

1909. Transpiration and the ascent of sap. Prog. Rei Bot. 3: 1-66.

Free, E. E.

1912. Studies in soil physics. Plant World 14: 29-39, 59-66, 110-19, 164-76, 186-90. Also

HaRvey, E. M.

reprinted, repaged. Tucson. 1912

1913. The action of the rain-correcting atmometer. Plant World 16: 89-93.

Hawkins, LoN A.

1910. The porous clay cup for the automatic watering of plants. Plant World 13:220-27.

HiLGaRd, E. W.

1912. Soils, their formation, properties, composition, and relations to climate and plant

Livingston, B. E growth in the humid and arid regions. New York and London

1906. (1) The relation of desert plants to soil moisture and to evaporation. Carnegie Inst. Wash. Pub. 50. Washington.

(2) Note on the relation between growth of roots and of tops in wheat. Bot. Gaz. 41: $139-43$.

1907. Relative transpiration in cacti. Plant World 10: 110-14.

1908. A method for controlling plant moisture. Plant World 11:39-40.

1909. (1) Roles of the soil in limiting plant activities. Plant World 12: 49-53.

(2) Present problems of physiological plant ecology. Amer. Nat. 43: 369-77. The essentials of this paper appeared also, under the same title, in Plant World 12: 41-6. 1909.

1910. (1) A rain-correcting atmometer for ecological instrumentation. Plant World 13: $79-82$.

(2) Operation of the porous cup atmometer. Plant World 13:111-18.

1911. (1) A radio-atmometer for measuring light intensity. Plant World 14: 96-9.

(2) Light intensity and transpiration. Bot. Gaz. 52: 418-38.

(3) The relation of the osmotic pressure of the cell sap in plants to arid habitats. Plant World 14: 153-64.

1912. (1) Present problems in soil physics as related to plant activities. Amer. Nat. 46: 294-301.

(2) A rotating table for standardizing porous cup atmometers. Plant World 15: $157-62$. 
Livingston, B. E.-continued.

1913. (1) The resistance offered by leaves to transpirational water loss. Plant World 16: $1-35$.

(2) Osmotic pressure and related forces as environmental factors. Plant World 16: $165-76$.

1915. Atmometry and the porous cup atmometer. In press. Plant World 18. 1915.

Livingston, B. E., and W. H. Brown.

1912. Relation of the daily march of transpiration to variations in the water content of foliage leaves. Bot. Gaz. 53: 311-30.

MacDougal, D. T.

1913. Department of botanical research. Carnegie Inst. Wash. Year Book 12: 78.

LLOYD, F. E.

1912. The relation of transpiration and stomatal movements to the water content of the Marí́-Davy, H. leaves of Fouquieria splendens. Plant World 15: 1-14.

1869. Atmidomètre a vàse poreux de Babinet. Nouv. Mét. 2: 253-4.

MAYer, A.

1905. Die Bodenkunde. Heidelberg.

Mitscherlich, E. A.

1904. Ein Verdunstungsmesser. Landw. Versuchsst. 60: 63-72.

1905. Die Bodenkunde für Land- und Forstwirte. Berlin.

Overton, J. B.

1911. Studies on the relation of the living cells to the transpiration and sap-flow in Cyperus.

Pfeffer, W. Gaz. 51: 28-63, 102-20.

1903. Physiology of plants. Translated by A. J. Ewart 2: 121. Oxford.

Pulling, H. E., and B. E. Livingston.

1915. The water-supplying power of the soil as indicated by osmometers. The second

RENNER, O paper of the present publication.

1910. Beiträge zur Physik der Transpiration. Flora 100: 451-547.

1911. Experimentelle Beiträge zur Kenntnis der Wasserbewegung. Flora 103: 171-247.

1912. (1) Versuche zur Mechanik der Wasserversorgung. 1. Der Druck in den Leitungsbahnen von Freilandpflanzen (Vorläufige Mitteilung). Ber. deutsch.Bot. Ges. 30: $576-80$.

(2) Versuche zur Mechanik der Wasserversorgung. 2. Ueber Wurzeltätigkeit (Vorläufige Mitteilung). Ber. deutsch. Bot. Ges. 30: 642-8.

Shive, J. W., and B. E. Livingston.

1914. The relation of atmospheric evaporating power to soil moisture content at permanent wilting in plants. Plant World 17:81-121.

Shreve, Edith B.

1914. The daily march of transpiration in a desert perennial. Carnegie Inst. Wash. Pub. 194. Washington.

Transeau, E. N.

1911. Apparatus for the study of comparative transpiration. Bot. Gaz. 52: 54-60.

WAHNSCHAFFE, F.

1903. Wissenschaftiche Bodenuntersuchung. Berlin.

Wintney, M., and F. K. Cameron.

1903. The chemistry of the soil as related to crop production. U. S. Dept. Agric., Bur. Soils Bull. 22. 


\section{THE WATER-SUPPLYING POWER OF THE SOIL AS INDICATED BY OSHOMETERS}

BY

HOWARD E. PULLING AND BURTON E. LIVINGSTON. 



\section{THE WATER-SUPPLYING POWER OF THE SOIL AS INDICATED BY OSMOMETERS.}

\section{INTRODUCTION.}

From a review of the literature of the water-relation between ordinary plants and the soil in which they are rooted it appears that researches in this field of plant physiology have thus far been few, and that present knowledge in this regard is very meager. The importance of the water-relations of plants, both in themselves and as a basis for the dynamic study of other plant relations, is not likely to be overestimated. The water-relation appears to play a prime role in the influence of most environmental complexes met with in nature and in agriculture, and among the numerous phases of this general relation the particular phase which has to do with the passage of water from soil to roots is not by any means the least worthy of careful study.

It is somewhat surprising to note with what thoroughness the dynamics of root absorption has been overlooked in plant physiology; only very recently has the physiological ecology of roots begun to receive attention, and the soil has been studied mainly as such rather than as a portion of plant environment. Physiological writers appear usually to suppose that vacuolar osmotic pressure in peripheral cells of roots is in some way directly accountable for the continuous supply of moisture to growing and transpiring parts situated higher up, and the exceedingly complex set of conditions controlling water movement through the root periphery is frequently dismissed with brief and vague reference to osmotic phenomena. With the development of our knowledge following Dixon's ${ }^{1}$ admirable researches on the conditions determining the rate of the rise of water in plant stems it became more and more clear that the moisture condition of the transpiring and otherwise water-consuming parts of the plant body probably exercise the fundamental controlling influence upon the ascent of water. It also became more and more apparent that this influence was exerted through a comparatively simple physical connection between the various portions of the plant. Various vague theories of complex and unanalyzed "vital" pumping action in living cells died very hard and their shadows still frequent the literature, but most students familiar with the older contributions referred to by Dixon and with the rather rigorous and very convincing work of Dixon, of Overton, ${ }^{2}$ and of Renner $^{3}$ have apparently laid "vitalism" aside in this connection.

${ }^{1}$ Dixon, H. H., Transpiration and the ascent of sap. Prog. Rei Bot. 3: 1-66. 1909. [This is a summary of the whole problem and is accompanied by many references to the literature.]

${ }^{2}$ Overton, J, B., Studies on the relation of the living cells to the transpiration and sap-flow in Cyperus. Bot. Gaz. 51:28-63, 102-20. 1911.

${ }^{3}$ Renner, O., Experimentelle Beitrïge zur Kenntnis der Wasserbewegung. Flora 103: 171-247. 1911. 
It now appears that water passes from roots to foliage because there is a progressive tendency towards desiccation in the latter and because tension in a liquid is (like pressure) transmitted equally in all directions. Thus, transpiration or growth appears to produce an increased saturation deficit ("Sättigungsdefizit," Renner, 1911) or incipient drying (Livingston and Brown ${ }^{1}$ ) in the exposed cell walls of the leaves, followed by a corresponding increase in this deficit in all cell walls abutting upon gas. It was Dixon who first pointed out that this, and this alone, is a sufficient explanation for the entrance of water through the root periphery, and his ideas in this connection have been supported and augmented by the ingeniously derived experimental evidence set forth by Renner, ${ }^{2}$ wherein he shows that the water-absorptive power of roots is directly related to the degree of saturation deficit obtaining in the leaves above. As Renner has mentioned, this absorptive power seems, indeed, to be a direct function of the tendency of the exposed cell walls of roots to become less thoroughly saturated or imbibed, through migration of water from these organs to higher parts of the plant.

What may be the importance of vacuolar osmotic pressure in root cells, as far as water absorption is concerned, remains to be determined, but it may be supposed at present that the influence of this pressure is only an indirect one, perhaps being mainly effective in maintaining the form of the roots and their contact with the water films of the surrounding soil. It is already clear that roots do not take up water at rates proportional to their vacuolar osmotic pressures and that the absorbing system may operate equally well with high or low turgidity of roots, so long as these organs are not deformed, as by plasmolysis. ${ }^{3}$

The rate at which water enters a plant is obviously a function of the absorbing power of the roots and of the supplying power of the soil. If the water-supplying power of the soil be low and the absorbing power of the roots be high, the subterranean environment as a whole must act to retard water entrance. Statically, such a resistance may be measured in terms of pressure, and its value might be equated to

${ }^{2}$ Livingston, B. E., and W. H. Brown, Relation of the daily march of transpiration to variations in the water content of foliage leaves. Bot. Gaz. 53:309-30. 1912.

${ }^{2}$ Renner, O., Versuche zur Mechanik der Wasserversorgung. 1. Der Druck in den Leitungsbahnen von Freilandpflanzen (Vorlitufige Mitteilung). Ber, deutsch. Bot. Ges. 30: 576-641. 1912.

—, Versuche zur Mechanik der Wasserversorgung. 2. Ueber Wurzeltätigkeit. Ber. deutsch. Bot. Ges. 30: 642-8. 1912.

${ }^{3}$ The relation of internal osmotic pressure to various forms of external resistance to water absorption has been dealt with in the following paper: Livingston, B. E., Osmotic pressure and related forces as environmental factors. l'lant World 16: 165-S6. 1913.

On some aspects of the relation between the osmotic pressure of roots and water absorption, see: Bovie, W. T., Effects of adding salts to the soil on the amount of nonavailable water. Bull. Torr. Bot. Club. 37: 27:3-92. 1910. Livingston, B. E., The relation of the osmotic pressure of the cell sap in plants to arid liabitats. Plant World 14: 153-64. 1911. Also see: Renner, O., Versuche zur Mechanik der Wasserversorgung, 2. 1912.

On the relation of root plasmolysis to absorption, see: Caldwell, J. S., The relation of environmental conditions to the phenomenon of permanent wilting in plants. Physiol. Res. 1: 1-56. 1913. 
osmotic pressure, as though the soil were an aqueous solution of solutes to which the root periphery were impermeable. Similarly, the internal condition controlling water entrance (absorbing power of the roots) might also be stated in terms of osmotic pressure, the imbibing power of the exposed walls being a force comparable in many respects to the water-attracting force of an aqueous solution, which is one aspect of osmotic pressure.

A preliminary study of some of the relations between transpiration and the resistance offered by the soil to water absorption by roots has been made by Livingston and Hawkins (see the first paper of the present publication), in which these authors present simultaneous graphs of these two features-or at least of the first of them and of what they take to be a measure of the other. While the discussion embodied in that paper is closely related to that in which we are about to engage, it is with a different aspect of the general problem that the present paper has to deal.

Dynamically, the upper limit of the rate at which water may pass from soil to root may be said to be a function of the maximum possible rate of absorption (supposedly to be attained if the roots were to be temporarily placed in pure water) and the maximum possible rate of supply by the soil. These maximum possible rates should be proportional to the corresponding static forces just considered. Of course only very short time intervals may here be thought of, for the effect of any rate, or of a force of any given magnitude, must be to bring about a new set of equilibrium relations between soil and plant, with accompanying alterations in the magnitudes of the forces concerned. However, if the actual rate at which roots absorb water does not exceed the maximum possible rate at which the soil may supply water to the active root surfaces, then the magnitude of the rate of absorption should depend upon internal conditions alone and external resistance to absorption should not arise as a limiting condition.

If the above considerations are reliable, it should follow that, as far as water is concerned, the single soil condition which determines whether a plant may grow or maintain turgor or wilt or die is the maximum possible rate of delivery of water to its root surfaces. As has been emphasized by Livingston, ${ }^{1}$ by Free, ${ }^{2}$ and by Livingston and Hawkins (in the first paper of the present publication), this rate appears to be the one simple soil property by which different soils can be definitely characterized in regard to water-relations. It is, however, a feature which has been accorded practically no serious attention by

${ }^{1}$ Livingston, B. E., Present problems of physiological plant ecology. Amer. Nat. 43: 369-77. 1909.

, Present problems in soil physics as related to plant activities. Amer. Nat.46: 294-301. 1912.

${ }^{2}$ Free, E. E., Studies in soil physics. Plant World 14: 29-39, 59-66, 110-19, 164-76, $186-90$. 1911. Also separately reprinted, repaged. Tucson. 1912. 
either soil physicists or plant physiologists. The only published measurements of this power, so far as we are aware, are a few given by Livingston $^{1}$ in his studies on the soil of Tumamoc Hill, at Tucson, Arizona. This author allowed evaporation to proceed from prepared soil surfaces and considered that when no superficial dry layer formed, the soil was able to transmit moisture to the surface at least as fast as it was lost through evaporation. The dishes of soil were weighed at intervals and the rate of water loss was calculated for unit area of the general soil surface. The soil employed was a clay, having a waterretaining power of 52 per cent of its dry volume, unpacked, or 48 per cent of its dry weight. Livingston reports that this soil, when its water content amounted to 30 per cent of its volume, possessed a water-supplying power of at least 0.0077 gram per hour per square centimeter of surface. With a water content of 20 per cent of its volume the same soil could not transmit moisture to the surface at a rate as great as 0.0055 gram per hour per square centimeter. It thus appears that by varying and controlling the evaporating power of the air it should be possible to determine with some accuracy the watersupplying power of different soils. But Livingston's procedure is of little value when field conditions are to be studied, for the tests involve the handling of the soil and the packing of it into dishes.

What is needed, before physiological ecology can proceed quantitatively to the study of soil-moisture relations, is some method by which the water-supplying power of the soil may be approximated without any disturbance of the soil itself or of plants rooted therein. This need has been emphasized by the writer last mentioned, but the requisite method has not yet been forthcoming. Obviously, the prime desideratum in this connection is some sort of water-absorbing surface, the absorbing power of which does not seriously decrease as absorption progresses, this surface being capable of being placed in the soil of field or pot at any desired depth. In connection with such a surface there must, of course, be some device by means of which its rate of absorption may be determined from time to time. Such a surface might be buried in the soil and left there for an indefinite period, thus allowing the adjacent soil to assume its natural volume and condition of aggregation. Thus the practically insuperable problem of artificial packing might be avoided.

The experiment of Whitney and Cameron ${ }^{2}$ and those of Livingston (1906) with cane-sugar osmometers in the soil suggested to the present writers the possibility of employing, as the required standard water-absorbing surface, an osmotic membrane backed by a suitable solution. This membrane, it seemed, might be appressed to the soil

${ }^{1}$ Livingston, B. E., The relation of desert plants to soil moisture and to evaporation. Caruegie Inst. Wash. Pub. 50. Washington. 1906. Pages 36-7.

${ }^{2}$ Whitney, M., and F. K. Cameron, The chemistry of the soil as related to erop production. U. S. Dept. Agric., Bur. Soils Bull. 22. 1903. 
surface to be studied (at any chosen depth), and the rate at which water was osmotically absorbed might be read on a suitable graduated tube, the latter connected with the cell across one side of which the membrane was stretched. After a number of failures, such a device was obtained, and, while the experimentation was necessarily curtailed by lack of time, the results obtained from its use in connection with several artificial soil mixtures seem to promise so much that they are deemed worthy of presentation here. It is to be remarked that the osmometer method here employed will surely be found susceptible of much improvement; our results are brought forward at this time rather to show the possibility of dealing quantitatively with this muchneglected environmental condition than for any other reason.

The studies here reported were carried out at the Desert Laboratory of the Carnegie Institution, at Tucson, Arizona, during the summer of 1913. The writers are indebted to the Director of the Department of Botanical Research of the Carnegie Institution of Washington for the facilities of the Desert Laboratory.

\section{METHODS.}

\section{PREPARATION OF THE OSMOMETERS.}

The osmometers employed were prepared from ordinary thistle tubes, the large opening closed by a collodion membrane. When properly formed this is found to be practically impermeable to cane-sugar, which was the solute used in our cells. At the same time, these collodion films are permeable enough to water for the present purposes, and they are somewhat readily prepared and arranged for operation. ${ }^{1}$

Our membranes were formed by evaporation of the solvent from a solution of "Schering's celloidin," dissolved in a mixture composed of equal parts (by volume) of ether and alcohol. Absolute alcohol should be used. We employed solutions containing from 7 to 10 grams of collodion per 100 c.c. of the solution. When working at high temperatures, as the summer temperatures of Tucson, it is perhaps advisable to employ solutions as weak as with 7 or 8 grams per 100 c.c., on account of the high evaporation rate. The collodion solution is poured on to the surface of clean mercury in a shallow vessel of considerably greater diameter than that required for the membrane. The solution is not

In connection with the use of collodion membranes in osmotic studies, and on the manipulations required in their preparation, see the following papers:

Bigelow, S. L., and A. Gemberling, Collodion membranes. Jour. Amer. Chem. Soc. 29: 157689. 1907.

Mathews, J. H., Osmotic experiments with collodion membranes. Jour. Phys. Chem. 14: 281-91. 1910.

Smith, G. M., The use of collodion membranes for the demonstration of osmosis. Bot. Gaz. 56: $225-9.1913$.

Abel, J. J., L. G. Rowntree, and B. B. Turner. On the removal of diffusible substances from the circulating blood of living animals by dialysis. Jour. Pharmacol. and Exp. Therap. 5: $275-316.1914$. 
allowed to extend outward as far as the walls of the containing vessel, a result readily attained by limiting the amount of the solution originally poured on the mercury surface. After evaporation of the solvent has progressed to a certain degree the marginal portion of the hardening superficial film rises in an irregular manner so as to exhibit a scalloped appearance. When this occurs it is time to lift the film, which is done by inserting the fingers below it (in the mercury), seizing it by its margin, and stripping the whole semi-hardened membrane from the still liquid solution lying below. It has proved advantageous immediately to draw the lower surface of the membrane over a tightly stretched wire, thus removing most of the liquid which adheres and which otherwise frequently collects locally to produce thickened regions in the finished product.

The "green" membrane thus obtained must be expeditiously attached to a suitable support and it must then be matured. In our work, the film of collodion, still wet with liquid solution on its lower surface, was quickly applied to the slightly enlarged rim of the larger opening of a glass thistle tube, the undried surface being against the glass. The membrane was appressed firmly to the edge of the rim and the outer portion was drawn backward and inward and ligatured against the exterior surface of the flaring portion of the tube by means of several turns of linen thread. At the time of attachment the membrane was loose and its central portion sagged considerably into the tube. If this precaution is not observed ruptures are apt to occur with the later removal of the solvent. Drying was then allowed to occur, by simple exposure to the air, until the membrane tightened to a plane surface across the opening and resounded, in tambourine fashion, on tapping with the finger-nail. Having attained this stage of ripening, the membrane was placed in 85 per cent alcohol ( 85 volumes of alcohol and 15 volumes of water), the alcohol solution bathing its external surface only, and was thus allowed to remain for about 12 hours. This procedure was found markedly to decrease its permeability to cane-sugar, though it also lessened that to water. If this alcohol treatment were omitted in our tests the resulting membranes were sensibly permeable to cane-sugar-too much so for the work in hand. After the alcohol treatment, which appears to diminish the degree of dispersion in the coagulating water-collodion emulsion, the membrane, on its mounting, was transferred to water. After a few hours in this liquid the osmometer was ready for use. When not employed the membrane was always kept in water.

Each osmometer was first tested by filling bulb and tube with water and suspending for an hour, with the membrane below, to determine whether any molar movement of water ensued. If liquid water appeared on the exterior surface the instrument was discarded. 


\section{ARRANGEMENT OF THE OSMOMETERS TO OPERATE AGAINST WATER, AND THEIR STANDARDIZATION.}

In the experiments so far carried out, the osmometers have usually contained a 5-weight-molecular ${ }^{1}$ solution of sucrose in water, and only experiments so performed will be here presented. What may be the order of magnitude of the water-absorbing force effective at the peripheries of plant roots we have as yet no means of knowing, but it is surely safe to suppose that the intensity of the osmotic force employed in our osmometers (that of a 5-weight-molecular solution of cane-sugar) very far exceeds that of the corresponding force usually occurring at active plant surfaces. If such studies as the present ones are carried farther it will be desirable to employ lower concentrations, but to accomplish that it will be necessary to improve the apparatus so as to allow the determination of smaller absorption increments than could be read with our instruments. So concentrated a solution was used simply to produce relatively high rates, thus allowing the use of our crude apparatus and avoiding further delay in the preliminary attack upon the important problem before us. It was our idea that the principles involved may probably be much the same when a force of great magnitude is employed as when one of less intensity produces the water movement.

Preliminary tests showed that the passage of cane-sugar through our membranes was practically negligible. Not so unimportant, but still probably negligible here, is the apparent hydrolysis of cane-sugar in aqueous solution; no matter how pure may be the sucrose used, there seems always to be some glucose present, and the amount of this seems to increase (as would be expected) with the age of the solution. This matter, though investigated to some extent, does not require attention in this publication; it was found that a good quality of "granulated sugar" furnished as satisfactory and consistent results in our work as did thoroughly washed "rock candy." On this account the former variety of cane-sugar was used in the tests about to be reported. Freshly made solutions were always employed.

\footnotetext{
${ }^{1}$ This means 5 gram-molecules of cane-sugar dissolved in 1,000 grams of water, following the elaborate and beautiful work of Morse and his collcagues on the osmotic pressures obtainable with cane-sugar solutions and membranes impermeable to this solute, as related to the concentration of the solution and to the temperature. This work has indicated that the diffusion tension of the solute, or the attraction of the solution for water (the osmotic pressure of the solution, as it is usually termed-though osmotic pressure is as much a function of the membrane employed as it is of the diffusion tension of the solute) is proportional to the so-called molar fraction, the ratio of the number of molecules of solute to that of solvent. In this connection, see Morse, H. N., W. W. Holland, E. G. Zies, C. N. Myers, W. M. Clark, and E. E. Gill. The relation of osmotic pressure to temperature, Part V. The measurements. Amer. Chem. Jour. 45: 554-603. 1911. Also see: Earl of Berkeley and E. G. J. Hartley. On the osmotic pressure of some concentrated aqueous solutions. Trans. Roy. Soc. London 206A: 481-507. 1906. The whole matter is briefly but rather clearly discussed by Findlay: Findlay, A., Osmotic Pressure. London, 1913. [Pages 1-84.] The crying need for an appreciation by biologists of this important advance in physical chemistry has been well emphasized by Renner: Renner, $O$., Ueber die Berechnung des osmotischen Druckes. Biol. Centralbl. 32: 486-504. 1912.
} 
One of the most serious difficulties met with in osmometric experimentation arises from the fact that entrance of water through the osmotic membrane into the solution produces, ipso facto, a dilution of the latter, a dilution which, when of considerable amount, can not be readily dealt with mathematically on account of the non-uniformity of dilution throughout the mass of solution. In our studies it was necessary that water be allowed continously to enter the osmotic solution, for the rate of such entrance was just what it was desired to measure. The immediate effect of such entrance should be, of course, to dilute the layer of sugar solution lying against the membrane, thus decreasing the attraction of the instrument for water and seriously complicating the results. The total volume of water entering the osmometer during a test was always exceedingly small, however, as compared to the volume of the entire contents. It appears, then, that if the solution in the cell might be mechanically stirred during the operation of the instrument, the dilution in question would probably be quite negligible, at least in such crude measurements as are here contemplated. No mechanical method for stirring the solution was tried, although one may, no doubt, be somewhat readily devised.

In our earlier experiments the thistle-tube osmometers were erected vertically in water, with the collodion membrane horizontal and below the mass of sugar solution in the bulb. It was thought that this arrangement might promote a continuous convection current in the solution, which might act as a stirrer. Tests indicated that such convection did indeed take place, the more concentrated (heavier) solution apparently passing downward along the glass walls and flowing out upon the collodion film below, thus forcing the more dilute (lighter) solution lying against the membrane to pass toward the center of the latter and thence upward. But the viseosity of the sugar solution used was so great and the form of the thistle bulb is so poorly adapted to the maintenance of uniform convection within, that the eurrent set up was far from continuous. Rather did it appear that the heavier and more concentrated solution from above moved downward only spasmodically; it slumped down in relatively large masses, at somewhat regular intervals, and between the periodic slumps the whole contents of the bulb seemed to remain practically static, excepting for the gradual entrance of water through the membrane below. This condition of affairs was clearly indicated by a curious periodic fluctuation in the rate of water entrance into osmometers thus arranged. An initially high rate of intake gradually fell during a time period and then suddenly increased to a value approximately the original one, after which a decrease again occurred, the variation in rate being thus cyclically continued.

These disconcerting fluctuations in the rate of water intake were at length avoided, simply by altering the position of the osmometer 
through an angle of 90 degrees. The instrument was erected horizontally with the collodion membrane vertical. In such a position the thistle-tube osmometers, operating against water, showed consistently uniform rates of water entrance, at least after the lapse of an initial time period. It appears that there is an initial dilution of the layer of solution abutting against the vertical membrane. This dilution does not proceed far, however, before it inaugurates a rising convection current along the membrane's inner surface, a current which of course brings new and practically undiluted solution into the osmotically active region of the instrument. There seems soon to be established a dynamic equilibrium, and for long periods of time this convection appears to remain nearly continuous and practically uniform, as is clearly indicated by the longcontinued maintenance of nearly uniform rates of water intake. It seems probable that there is established and held a rather definite gradient in solution concentration, from the nearly undiluted concentration at the lower margin of the membrane to the perhaps considerable dilution at the upper margin. The bulge of the thistle bulb is adapted to keep the diluted solution above from a rapid mixing with the main mass, so that it is not surprising that uniform rates of water entrance may be long maintained. Eventually, of course, the diluted solution above will extend downward far enough to decrease seriously the intake rate.

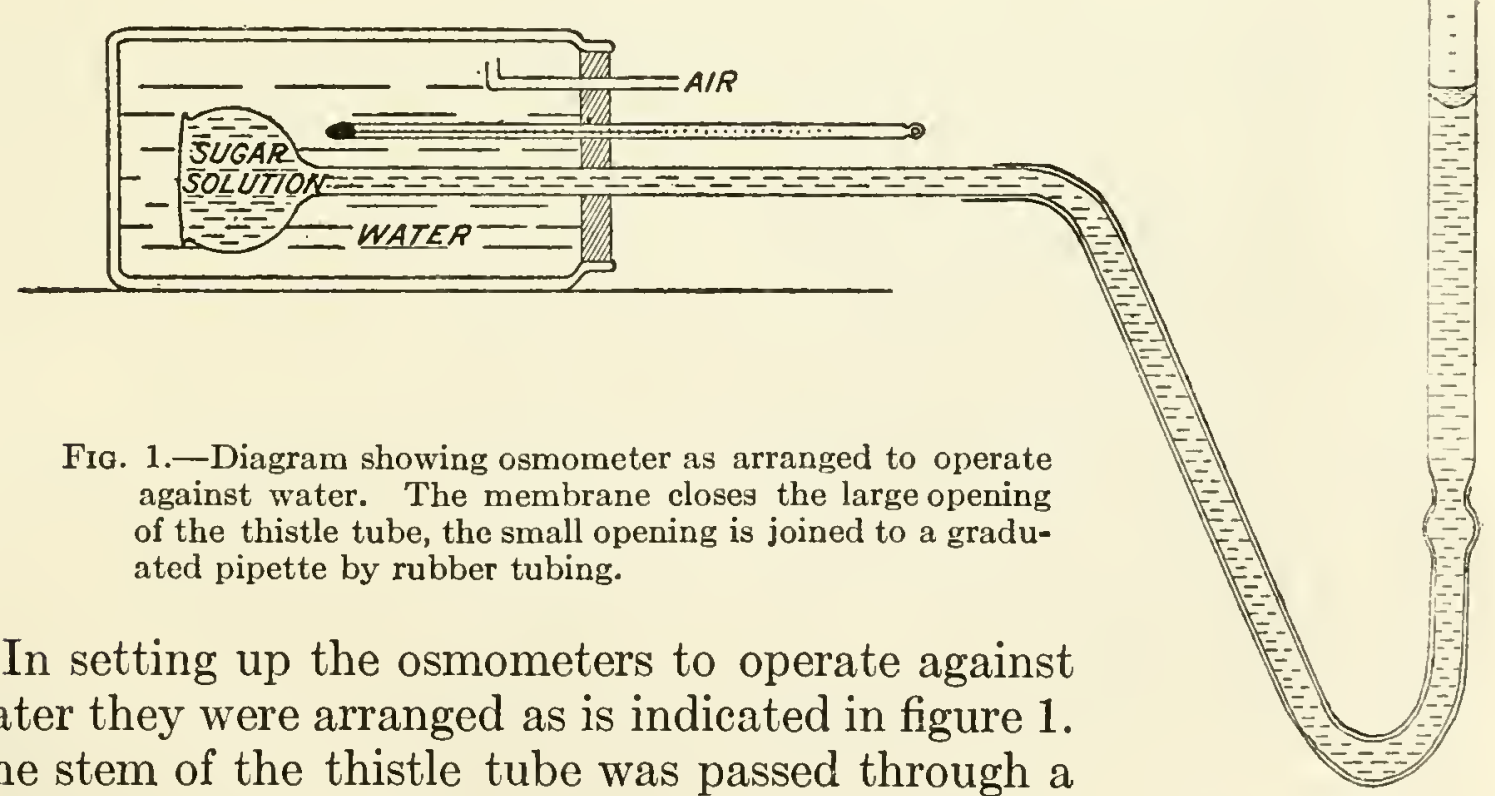
The stem of the thistle tube was passed through a flat cork stopper closing the opening of a horizontal jar, the bulb of the instrument lying within the jar. The latter was nearly filled with water, the atmosphere being allowed access to the upper surface of the water through a small opening near the upper edge of the stopper. The small, external end of the osmometer was connected, by a loop of heavy-walled rubber tubing, to the lower extremity 
of a pipette graduated so as to be read to hundredths of a cubic centimeter. The pipette contained water, its meniscus covered by a layer of oil to retard evaporation. The looped rubber tube allowed the water level in the pipette to be kept approximately constant (with reference to the water level in the horizontal jar) during a series of observations, thus insuring a practically constant and low hydrostatic pressure upon the membrane.

The osmometer was filled, in the erect position, with freshly prepared sugar solution, by means of a small glass tube reaching from its open end nearly to the membrane. It was emptied, after an experiment, by placing the bulb upward and then forcing air into it through the same small tube. Between tests the osmometers were rinsed out and kept in distilled water, the bulbs also filled with water.

In order that different osmometers might be used and that their data might be rendered comparable, it was necessary for each instrument to be calibrated or standardized. The area of each membrane was accordingly determined as accurately as possible, the membrane surface being treated (with its slight bulge when supporting a few centimeters of water column) as a portion of either a spherical or ellipsoid surface of revolution (the openings of the thistle tubes were elliptical in some cases). From the actual area of the osmotic membrane was obtained, in each case (by dividing by 10), a correction coefficient by which each actual reading was to be multiplied in order to give approximately the reading which should have been shown had the area in question been just $10 \mathrm{sq} . \mathrm{cm}$. All rates given below have been thus corrected, and all refer to the hour as time period, so that each of these rates represents the number of cubic centimeters of water passing in onehour through a surface with an area of $10 \mathrm{sq} . \mathrm{cm}$. Every osmometer was tested several times, operating against distilled water, and any considerable leakage of sugar or unusual behavior of the rate of water intake thus detected was considered sufficient reason for discarding.

In both water tests and soil tests temperature readings (upon water or soil) were made whenever the osmometers were read. For this purpose a thermometer was inserted in the jar, alongside the osmometer, its stem (and the portion of the scale used) extending out horizontally through the cork stopper or cotton packing. It would have been much more efficient and generally satisfactory if the temperature had been maintained constant throughout each series, but a constant-temperature room was not available for this work. As will appear later, and as was to be expected, temperature seems to be a very important variable in the soil complex that determines the possible rate of water supply, and this feature should receive careful attention if this sort of study is pushed forward. 


\section{ARRANGEMENT OF OSMOMETERS TO OPERATE AGAINST THE SOIL.}

Since the work in hand was merely of a preliminary character, the aim being primarily to find out whether such methods as these may be regarded as promising, no attempt was made to study any but artificial soil mixtures, and the packing of these soils was always really uncontrolled. The adaptation of the collodion or other similar membrane to actual use in the field and among the roots of growing plants has yet to be accomplished, and may well make several studies for students who sufficiently realize the importance of this general problem to undertake this work. The method, as we have employed it, was devised only for testing the availability of the collodion membrane and is not at all suited to actual use in the field. This point is emphasized to warn the reader against the supposition that we intend to offer here anything approaching a practical arrangement for field work.

Such being the case, the application of our membranes to the soil were made in an exceedingly crude manner. A sample of the soil to be tested was more or less closely packed into the basal half of a jar (about $8 \mathrm{~cm}$. in diameter and $12 \mathrm{~cm}$. high), such as was employed for the water tests, the free soil surface was rendered as smooth and uniform as possible, and the osmometer membrane was gently appressed against this surface. The jar and osmometer tube were again horizontal, as in the water tests, the soil surface to be tested and the membrane in contact therewith being approximately vertical. Evaporation from the soil around the instrument was nearly prevented, and rendered negligible in amount, by filling the remaining portion of the jar with dry cotton, pressed somewhat firmly into place.

It was soon found that the osmometer membrane failed to maintain adequate contact with the soil, which frequently tended to shrink away from the film. To obviate this difficulty an arrangement of a lever, cord, and suspended weight was added, the pressure of the weight being transmitted through cord and lever so as to tend continuously to press the osmometer against the soil. Since the thistle tube could slide rather freely through the cotton packing, any shrinkage of the soil or other serious disturbance of the contact between membrane and soil surface was thus automatically and satisfactorily adjusted. Figure 2 presents the arrangement as actually used. It will be noted that the essential members of the osmometer are disposed quite as in the water tests.

In both water and soil tests, readings on the graduated tube were obtained at 15-minute intervals, and these, after correction to give the rate for the standard area of $10 \mathrm{sq}$. cm., have been reduced to hourly rates-cubic centimeters in all cases.

The soil employed was a mixture of three-fourths sand and onefourth heavy loam, the same mixture as one of those employed by 
Shive and Livingston. ${ }^{1}$ The proportions of the two soils were measured by dry volume, without packing. Sand similar to that here used has, according to Caldwell, ${ }^{2}$ a moisture-holding capacity of 30.86 per cent of its dry weight. The corresponding percentage for the loam used by Shive and Livingston was 57.32, and that for the mixture as here used was 32.02 , the last two data being taken from the paper of Shive and Livingston.

A further characterization of the soil, suggested by Livingston (1906) and based on its volume when allowed to settle under water, as compared to its dry weight, may be employed here. The soil was

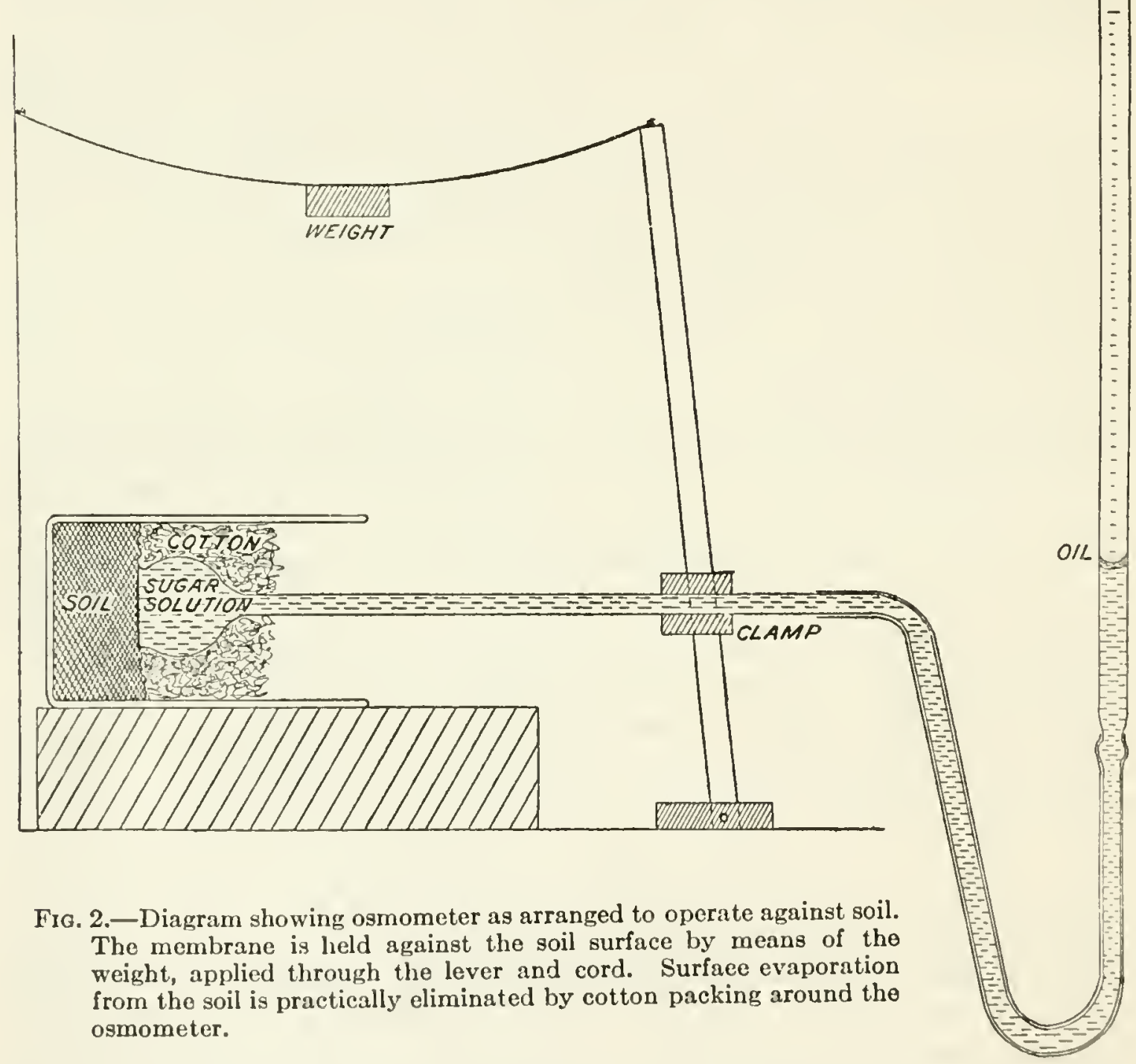

poured into a cylindrical graduate flask, stirred to a thin paste with water, and then allowed to settle, when the volume was read upon the graduate scale. 100 grams of the soil here used had a water-settled volume of 74.7 c.c. The same weight of soil when poured into a graduate in the dry condition had a volume of 72 c.c.

${ }^{1}$ Shive, J. W., and B. E. Livingston, The relation of atmospheric evaporating power to soilmoisture eontent at permanont wilting in plants. Plant World 17: 81-121. 1914.

${ }^{2}$ Caldwell, J. S. 1913. 
With this soil mixture, measured by volume in its dry state, was thoroughly mixed the requisite amount of water, giving the volume per cent of soil water required. The soil was then placed in the container as described above.

The numerical data presented in the following section show that the packing of the soil is a matter of the greatest importance in such studies as this, and means must be devised for obtaining several soil samples packed in the same way. Such means were not available in the present work and their lack is undoubtedly our most prominent source of unknown causation. With this feature of soil conditions future researches will eventually have seriously to deal. 


\section{EXPERIMENTATION.}

\section{GENERAL.}

Data from our osmometric tests will now be presented. Three different osmometers will be considered, and the results obtained with each instrument will be set forth together. The osmometers will be designated as A, B, and C; these were all essentially alike, but their absorbing surfaces were of different extent, which necessitates the use of a different coefficient of correction in each case.

\section{OSMOMETER A.}

\section{WATER TESTS WITH OSMOMETER A.}

Osmometer A had an effective area of $12.8 \mathrm{sq} . \mathrm{cm}$. and a coefficient of correction of 0.781 . It was operated against water three times, twice with somewhat similar temperature ranges and once with a markedly different range. Readings were obtained at intervals of 15 minutes for a period of 5 hours in each of the first two operations and for one of 8 hours in the last. The numerical data from these tests, after application of the calibration coefficient and reduction to hour rates, are presented in table 1. The first column of the table shows the number of the hour, beginning with the placing of the osmometer. The first column under each test gives the hourly rate of water absorption for each 15-minute period within each hour. The average rate for each hour is then given, followed by the average temperature for each hour, the latter derived as the mean of two temperature readings made at the beginning and at the end of the hour, respectively.

In the first and third tests, as shown in table 1, the initial rate for the first 15 minutes is markedly higher than any succeeding rate. This feature may indicate that some time needs to elapse before the membrane comes into dynamic equilibrium with the water on one side and the solution on the other. In the soil tests, as will appear, it is of pronounced importance, but it may be neglected here; the average hourly rates for the first hour are not in any case very much higher than those for succeeding hours. The striking general uniformity of the average rates throughout the first 5 hours for the first two tests, and throughout the first 8 hours for the third, is to be noted.

It is seen at once from table 1 that the average hourly rates obtained in the third test are generally lower than the corresponding ones from the first and second, and that there is no very marked, consistent difference to be observed between the corresponding average rates obtained from the first two tests; it does appear, however, that these averages are slightly lower in the sccond test (with the exception of the average rates for the first hour). After hour 1, the mean average maintained rate for the first two tests is 1.37 . 
There seems to be no reason to doubt, from a comparison of the results of the first two tests with those of the third, that the marked difference in corresponding rates thus evident is due to the different temperature ranges with which the data were obtained. The corresponding rates for the first and second tests may be averaged (since these two experiments were performed under relatively similar temperature conditions) and the means thus obtained may be compared with

TABLE 1.-Numerical data from the operation of osmometer A, against water.

\begin{tabular}{|c|c|c|c|c|c|c|c|c|c|}
\hline \multirow[b]{2}{*}{$\begin{array}{l}\text { No. } \\
\text { of } \\
\text { hour } \\
\text { per- } \\
\text { iod. }\end{array}$} & \multicolumn{3}{|c|}{ First test. } & \multicolumn{3}{|c|}{ Second test. } & \multicolumn{3}{|c|}{ Third test. } \\
\hline & $\begin{array}{c}\text { Hourly } \\
\text { rates per } \\
10 \text { sq. } \mathrm{cm} . \\
\text { for } 15- \\
\text { minute } \\
\text { periods. }\end{array}$ & $\begin{array}{c}\text { Average } \\
\text { hourly } \\
\text { rates. }\end{array}$ & $\begin{array}{l}\text { Average } \\
\text { hourly } \\
\text { temper- } \\
\text { ature. }\end{array}$ & $\begin{array}{c}\text { Hourly } \\
\text { rates per } \\
10 \text { sq. cm. } \\
\text { for } 15- \\
\text { minute } \\
\text { periods. }\end{array}$ & $\begin{array}{c}\text { Average } \\
\text { hourly } \\
\text { rates. }\end{array}$ & $\begin{array}{c}\text { Average } \\
\text { hourly } \\
\text { temper- } \\
\text { ature. }\end{array}$ & $\begin{array}{c}\text { Hourly } \\
\text { rates per } \\
10 \text { sq. } \mathrm{cm} \text {. } \\
\text { for } 15- \\
\text { minute } \\
\text { periods. }\end{array}$ & $\begin{array}{c}\text { Average } \\
\text { hourly } \\
\text { rates. }\end{array}$ & $\begin{array}{l}\text { Average } \\
\text { hourly } \\
\text { temper- } \\
\text { ature. }\end{array}$ \\
\hline 1 & $\left\{\begin{array}{c}c . c . \\
1.54 \\
1.35 \\
1.16 \\
1.41\end{array}\right.$ & $\begin{array}{l}\text { c.c. } \\
1.37\end{array}$ & $\begin{array}{l}{ }^{\circ} C . \\
31.3\end{array}$ & $\begin{array}{c}c . c . \\
1.32 \\
1.47 \\
1.32 \\
1.54\end{array}$ & $\begin{array}{l}\text { c.c. } \\
1.41\end{array}$ & $\begin{array}{l}\circ C . \\
29.1\end{array}$ & $\left\{\begin{array}{c}c . c . \\
1.54 \\
1.28 \\
1.06 \\
1.10\end{array}\right.$ & $\begin{array}{l}\text { c.c. } \\
1.25\end{array}$ & $\begin{array}{l}{ }^{\circ} C . \\
25.1\end{array}$ \\
\hline 2 & $\left\{\begin{array}{l}1.41 \\
1.41 \\
1.41 \\
1.41\end{array}\right.$ & 1.41 & 31.6 & $\left\{\begin{array}{l}1.25 \\
1.47 \\
1.25 \\
1.47\end{array}\right.$ & 1.36 & 29.6 & $\begin{array}{l}1.25 \\
1.25 \\
1.10 \\
1.10\end{array}$ & 1.18 & 25.5 \\
\hline 3 & $\left\{\begin{array}{l}1.41 \\
1.25 \\
1.41 \\
1.41\end{array}\right.$ & 1.37 & 32.1 & $\begin{array}{l}1.28 \\
1.32 \\
1.41 \\
1.47\end{array}$ & 1.37 & 30.4 & $\left\{\begin{array}{l}1.25 \\
1.10 \\
1.10 \\
1.25\end{array}\right.$ & 1.18 & 25.9 \\
\hline 4 & $\left\{\begin{array}{l}1.25 \\
1.41 \\
1.41 \\
1.41\end{array}\right.$ & 1.37 & 32.6 & $\left\{\begin{array}{l}1.44 \\
1.38 \\
1.44 \\
1.06\end{array}\right.$ & 1.33 & 31.0 & $\left\{\begin{array}{l}1.10 \\
1.03 \\
1.00 \\
1.25\end{array}\right.$ & 1.10 & 26.1 \\
\hline 5 & $\left\{\begin{array}{l}1.41 \\
1.25 \\
1.41 \\
1.41\end{array}\right.$ & 1.37 & 33.0 & $\left\{\begin{array}{l}1.38 \\
1.25 \\
1.47 \\
1.35\end{array}\right.$ & 1.36 & 31.6 & $\left\{\begin{array}{l}1.06 \\
1.22 \\
1.00 \\
1.10\end{array}\right.$ & 1.10 & 26.3 \\
\hline 6 & $\left\{\begin{array}{l}\cdots \\
\cdots \\
\cdots \\
\cdots\end{array}\right.$ & $\cdots$ & $\cdots$ & $\begin{array}{l}\ldots \\
\ldots \\
\ldots \\
\ldots\end{array}$ & $\cdots$ & . & $\left\{\begin{array}{l}1.10 \\
1.16 \\
1.00 \\
1.00\end{array}\right.$ & 1.07 & 26.8 \\
\hline 7 & $\begin{array}{l}\cdots \\
\cdots \\
\cdots \\
\cdots\end{array}$ & $\cdots$ & $\cdots$ & $\begin{array}{l}\ldots \\
\ldots \\
\ldots \\
\ldots\end{array}$ & $\cdots$ & $\cdots$ & $\left\{\begin{array}{l}1.16 \\
1.25 \\
1.00 \\
0.94\end{array}\right.$ & 1.09 & 26.9 \\
\hline 8 & $\left\{\begin{array}{l}\cdots \\
\cdots \\
\cdots \\
\cdots\end{array}\right.$ & $\cdots$ & $\cdots$ & $\begin{array}{l}\ldots \\
\ldots \\
\ldots \\
\ldots\end{array}$ & $\cdots$ & $\cdots \cdot$ & $\left\{\begin{array}{c}1.10 \\
1.10 \\
1.10 \\
\ldots \ldots\end{array}\right.$ & 1.10 & 27.0 \\
\hline $\begin{array}{r}\text { Avera } \\
\text { tair }\end{array}$ & $\begin{array}{l}\text { ge main- } \\
\text { aed rate*.. }\end{array}$ & 1.38 & $\ldots$ & $\ldots$ & 1.36 & $\ldots$ & . & 1.12 & \\
\hline
\end{tabular}

*After hour 1. 
the rates of the third test. The essential data for such a consideration are given in table 2 , where the last column is devoted to the approximated increments in hourly rate, per degree rise in temperature. With the exception of the first hour, during which it may be assumed that adjustments of the membrane were in progress, it is apparent that each rise of one degree in temperature is accompanied by an increase in absorption rate of about 0.04 c.c. per hour, per 10 sq. cm. of active surface. It is clear at once that this increment value is far too large to be primarily related to the simple operation of the principle of GayLussac as applied to the diffusion tension of the solute in a solution. If the higher rates shown at higher temperatures were simply related to the temperature effect on the diffusion tension of the sugar, we should expect an increment equal to about $\frac{1}{300}$ of the rate observed with the lower temperature range. Such an increment would have

TABLE 2.-Osmometer A, operating against water. Means of data from first and second tests, compared with data from third test.

\begin{tabular}{|c|c|c|c|c|c|}
\hline \multirow{2}{*}{$\begin{array}{l}\text { No. of } \\
\text { hour } \\
\text { period. }\end{array}$} & \multicolumn{2}{|c|}{$\begin{array}{l}\text { Means from first and } \\
\text { second tests. }\end{array}$} & \multicolumn{2}{|c|}{ Data from third test. } & \multirow{2}{*}{$\begin{array}{l}\text { Approximate } \\
\text { increment in } \\
\text { hourly rate, } \\
\text { per degree } \\
\text { rise in tem- } \\
\text { perature. }\end{array}$} \\
\hline & $\begin{array}{l}\text { Hourly } \\
\text { rate. }\end{array}$ & $\begin{array}{l}\text { Tempera- } \\
\text { ture. }\end{array}$ & $\begin{array}{l}\text { Hourly } \\
\text { rate. }\end{array}$ & $\begin{array}{l}\text { Tempera- } \\
\text { ture. }\end{array}$ & \\
\hline 1 & $\begin{array}{l}\text { c.c. } \\
1.390\end{array}$ & $\begin{array}{l}{ }^{\circ} C . \\
30.2\end{array}$ & $\begin{array}{l}\text { c.c. } \\
1.25\end{array}$ & $\begin{array}{l}{ }^{\circ} C . \\
25.1\end{array}$ & $\begin{array}{l}c . c . \\
0.027\end{array}$ \\
\hline 2 & 1.385 & 30.6 & 1.18 & 25.5 & 0.040 \\
\hline 3 & 1.370 & 31.2 & 1.18 & 25.9 & 0.036 \\
\hline 4 & 1.350 & 31.8 & 1.10 & 26.1 & 0.044 \\
\hline 5 & 1.365 & 32.3 & 1.10 & 26.3 & 0.044 \\
\hline
\end{tabular}

only about one-tenth of the magnitude here experimentally indicated. It appears possible that temperature alterations in the state of the colloidal membrane may contribute something to the great temperature variation in question, but no information is available on this point.

Decrease in the viscosity of the sugar solution with increasing temperature, however, appears to be much more significant than the features just mentioned, and this is, perhaps, the major factor in producing the variations in the rate of water intake of our osmometers. This rate is conditioned by the degree of concentration of the layer of solution next the membrane. The factors tending to maintain this at constant value are the gravitational downward movement of the sugar solution distant from the membrane and the corresponding rise along the membrane surface, the diffusion of the sugar molecules into the diluted region next the membrane, and, opposed to these, the diffusion of the sugar outward through the membrane. Increase in temperature should increase diffusion into the diluted region and outward from the osmometer. However, as is well known, the diffusion of cane-sugar from concentrated to weak solutions is extremely small for 
such periods of time as are here considered, and, in comparison with the great changes induced in the viscosity of such solutions by temperature variation, this minor effect may safely be neglected. Powell ${ }^{1}$ states that the viscosity of a 40 per cent cane-sugar solution (40 grams in 100 c.c. of water) decreases about 3 per cent with each degree of temperature rise. In a 50 per cent solution the corresponding decrement is 3.5 per cent. The concentration of the solutions here used, computed upon the same basis as the above, is about 117 per cent. Some rough observations with an Ostwald viscosimeter indicate that the viscosity decrement of our solution, per degree rise in temperature, may be well above 7 per cent, and table 2 shows that the increase in water intake of our osmometers per degree rise in temperature was about 3 per cent. Powell's observation that the viscosity decrement increases by 0.5 per cent between solution concentrations of 40 and 50 per cent supports our own rough observation upon the higher concentrations used. These considerations make it reasonable to conclude that the decrease in viscosity of the sugar solution, with higher temperature, is alone sufficient to account for the observed variations in the water intake of our osmometers.

On account of the preliminary nature of the present studies, and because of the inadequacy of the experimental data for such treatment, we shall here make no attempt to utilize the temperature increments just mentioned, as in attempting to approximate by calculation the absorption rates from water with other temperature ranges. The range of temperatures for the soil tests to be presented below was generally not far from that employed for the first and second water tests. Thus, the mean data from these two tests should be roughly applicable for comparison of the rates of absorption from water with those from soil.

\section{SOIL TESTS WITH OSMOMETER A.}

Osmometer A was operated in soil mixtures containing 25, 20, 15, 10 , and 5 per cent of water, on the basis of dry volume, unpacked. After thorough mixing by hand, the soil sample to be studied was placed in the jar with as uniform (usually medium) firming as possible, the surface was smoothed, and the osmometer was placed. The cotton packing above the soil and around the instrument was applied immediately and the device for constant pressure upon the osmometer was then attached. Readings were obtained at 15-minute intervals, as in the water tests.

The data to be presented below refer to a test with each one of the five soil mixtures just mentioned, to a second test with the 20 per cent soil (much more firmly packed than usual), and to a duplicate test with the 10 per cent soil.

${ }^{1}$ Powell, C. W. R. Viscosity of sugar solutions. Jour. Chem. Soc. 105: 1-23. 1914. 
The 15 per cent soil was such as would be regarded as having about optimum moisture content for pot cultures. The 25 per cent soil was decidedly wet and the 20 per cent was more moist than would ordinarily be used by gardeners. The soils containing 5 and 10 per cent of moisture were evidently too dry for most plant cultures.

The numerical data referring to these soil tests are set forth in tables 3 to 9 . They are arranged as those of table 1 .

TABLE 3.-Numerical data for osmometer $A$, operating against soil mixture with 25 per cent of moisture, on basis of dry volume (18.75 per cent on dry weight basis).

\begin{tabular}{|c|c|c|c|c|c|c|c|}
\hline $\begin{array}{c}\text { No. of } \\
\text { hour } \\
\text { period. }\end{array}$ & $\begin{array}{c}\text { Hourly } \\
\text { rates per } \\
10 \text { sq. } \mathrm{cm} ., \\
\text { for } 15 \text {-min. } \\
\text { periods. }\end{array}$ & $\begin{array}{l}\text { Average } \\
\text { hourly } \\
\text { rates. }\end{array}$ & $\begin{array}{l}\text { Average } \\
\text { hourly } \\
\text { temper- } \\
\text { ature. }\end{array}$ & $\begin{array}{l}\text { No. of } \\
\text { hour } \\
\text { period. }\end{array}$ & $\begin{array}{l}\text { Hourly } \\
\text { rates per } \\
10 \text { sq. cm., } \\
\text { for } 15 \text {-miu. } \\
\text { periods. }\end{array}$ & $\begin{array}{c}\text { Average } \\
\text { hourly } \\
\text { rates. }\end{array}$ & $\begin{array}{l}\text { Average } \\
\text { hourly } \\
\text { temper- } \\
\text { ature. }\end{array}$ \\
\hline 1 & $\left\{\begin{array}{c}c . c . \\
1.10 \\
0.41 \\
0.53 \\
0.47\end{array}\right.$ & $\begin{array}{l}c . c . \\
0.63\end{array}$ & $\begin{array}{l}{ }^{\circ} C . \\
28.2\end{array}$ & 4 & $\left\{\begin{array}{c}c . c . \\
0.28 \\
0.28 \\
0.19 \\
0.19\end{array}\right.$ & $\begin{array}{l}\text { c.c. } \\
0.24\end{array}$ & $\begin{array}{l}\circ C . \\
29.2\end{array}$ \\
\hline 2 & $\left\{\begin{array}{l}0.69 \\
0.28 \\
0.28 \\
0.31\end{array}\right.$ & 0.39 & 28.5 & 5 & $\begin{array}{l}0.22 \\
0.12 \\
0.19 \\
0.12\end{array}$ & 0.16 & 29.7 \\
\hline 3 & $\begin{array}{l}0.31 \\
0.24 \\
0.31 \\
0.28\end{array}$ & 0.31 & 28.9 & 6 & $\left\{\begin{array}{l}0.12 \\
0.16\end{array}\right.$ & 0.14 & 30.0 \\
\hline
\end{tabular}

TABLE 4.-Numerical data for osmometer $A$, operating against soil mixture (usual packing) with 20 per cent of moisture, on basis of dry volume (14.47 per cent on dry weight basis.)

\begin{tabular}{|c|c|c|c|c|c|c|c|}
\hline $\begin{array}{l}\text { No. of } \\
\text { hour } \\
\text { period. }\end{array}$ & $\begin{array}{c}\text { Hourly } \\
\text { rates per } \\
10 \text { sq. em., } \\
\text { for } 15 \text {-min. } \\
\text { periods. }\end{array}$ & $\begin{array}{c}\text { Average } \\
\text { hourly } \\
\text { rates. }\end{array}$ & $\begin{array}{c}\text { Average } \\
\text { hourly } \\
\text { temper- } \\
\text { ature. }\end{array}$ & $\begin{array}{c}\text { No. of } \\
\text { hour } \\
\text { period. }\end{array}$ & $\begin{array}{c}\text { Hourly } \\
\text { rates per } \\
10 \text { sq. } \mathrm{cm} ., \\
\text { for } 15 \text {-min. } \\
\text { periods. }\end{array}$ & $\begin{array}{c}\text { Average } \\
\text { hourly } \\
\text { rates. }\end{array}$ & $\begin{array}{l}\text { Average } \\
\text { hourly } \\
\text { temper- } \\
\text { ature. }\end{array}$ \\
\hline 1 & $\begin{array}{l}c . c . \\
0.41 \\
0.31 \\
0.31 \\
0.31\end{array}$ & 0.34 & $\begin{array}{l}{ }^{\circ} C . \\
27.9\end{array}$ & 5 & $\begin{array}{l}c . c . \\
0.09 \\
0.09 \\
0.19 \\
0.12\end{array}$ & $\begin{array}{l}\text { c.c. } \\
0.12\end{array}$ & $\begin{array}{l}{ }^{\circ} C . \\
28.3\end{array}$ \\
\hline 2 & $\begin{array}{l}0.31 \\
0.31 \\
0.25 \\
0.25\end{array}$ & 0.28 & 28.0 & 6 & $\begin{array}{l}0.09 \\
0.22 \\
0.09 \\
0.09\end{array}$ & 0.12 & 28.4 \\
\hline 3 & $\begin{array}{l}0.19 \\
0.16 \\
0.16 \\
0.16\end{array}$ & 0.17 & 28.0 & 7 & $\begin{array}{l}0.06 \\
0.06 \\
0.03 \\
0.06\end{array}$ & 0.05 & 28.1 \\
\hline 4 & $\begin{array}{l}0.16 \\
0.16 \\
0.12 \\
0.09\end{array}$ & 0.13 & 28.0 & 8 & $\begin{array}{l}0.16 \\
0.09 \\
0.06 \\
0.09\end{array}$ & 0.10 & 28.1 \\
\hline
\end{tabular}


TABLE 5.-Numerical data for osmometer A, operating against soil mixiure (firm packing) with 20 per cent of moisture, on basis of dry volume (15.3 per cent on dry weight basis).

\begin{tabular}{|c|c|c|c|c|c|c|c|}
\hline $\begin{array}{l}\text { No. of } \\
\text { hour } \\
\text { period. }\end{array}$ & $\begin{array}{l}\text { Hourly } \\
\text { rates per } \\
10 \text { sq. cm., } \\
\text { for } 15 \text {-min. } \\
\text { periods. }\end{array}$ & $\begin{array}{c}\text { Average } \\
\text { hourly } \\
\text { rates. }\end{array}$ & $\begin{array}{l}\text { Average } \\
\text { hourly } \\
\text { temper- } \\
\text { ature. }\end{array}$ & $\begin{array}{l}\text { No. of } \\
\text { hour } \\
\text { period. }\end{array}$ & $\begin{array}{l}\text { Hourly } \\
\text { rates per } \\
10 \text { sq. cm., } \\
\text { for } 15 \text {-min. } \\
\text { periods. }\end{array}$ & $\begin{array}{c}\text { Average } \\
\text { hourly } \\
\text { rates. }\end{array}$ & $\begin{array}{l}\text { Average } \\
\text { hourly } \\
\text { temper- } \\
\text { ature. }\end{array}$ \\
\hline 1 & $\left\{\begin{array}{c}c . c . \\
0.38 \\
0.41 \\
0.34 \\
0.25\end{array}\right.$ & $\begin{array}{l}\text { c.s. } \\
0.35\end{array}$ & $\begin{array}{l}\circ C . \\
24.0\end{array}$ & 6 & $\left\{\begin{array}{l}\text { c.c. } \\
0.12 \\
0.12 \\
0.12 \\
0.12\end{array}\right.$ & $\begin{array}{l}c . c . \\
0.12\end{array}$ & $\begin{array}{l}{ }^{\circ} C . \\
25.2\end{array}$ \\
\hline 2 & $\begin{array}{l}0.22 \\
0.16 \\
0.16 \\
0.19\end{array}$ & 0.18 & 24.4 & 7 & $\left\{\begin{array}{l}0.09 \\
0.09 \\
0.12 \\
0.12\end{array}\right.$ & 0.13 & 25.2 \\
\hline 3 & $\left\{\begin{array}{l}0.19 \\
0.16 \\
0.16 \\
0.16\end{array}\right.$ & 0.17 & 24.9 & 8 & $\left\{\begin{array}{l}0.19 \\
0.12 \\
0.16 \\
0.12\end{array}\right.$ & 0.15 & 25.0 \\
\hline 4 & $\left\{\begin{array}{l}0.12 \\
0.16 \\
0.19 \\
0.16\end{array}\right.$ & 0.16 & 25.0 & 9 & $\left\{\begin{array}{l}0.12 \\
0.19 \\
0.09 \\
0.16\end{array}\right.$ & 0.14 & 25.2 \\
\hline 5 & $\left\{\begin{array}{l}0.16 \\
0.16 \\
0.16 \\
0.09\end{array}\right.$ & 0.14 & 25.0 & & & & \\
\hline
\end{tabular}

TABLE 6.-Numerical data for osmometer A, operating against soil mixture with 15 per cent of moisture, on basis of dry volume (11.92 per cent on dry weight basis).

\begin{tabular}{|c|c|c|c|c|c|c|c|}
\hline $\begin{array}{l}\text { No. of } \\
\text { hour } \\
\text { period. }\end{array}$ & $\begin{array}{l}\text { Hourly } \\
\text { rates per } \\
10 \text { sq. cm., } \\
\text { for } 15 \text {-min } \\
\text { periods. }\end{array}$ & $\begin{array}{c}\text { Average } \\
\text { hourly } \\
\text { rates. }\end{array}$ & $\begin{array}{l}\text { Average } \\
\text { hourly } \\
\text { temper- } \\
\text { ature. }\end{array}$ & $\begin{array}{c}\text { No. of } \\
\text { hour } \\
\text { period. }\end{array}$ & $\begin{array}{l}\text { Hourly } \\
\text { rates per } \\
10 \text { sq. cm., } \\
\text { for } 15 \text {-min. } \\
\text { periods. }\end{array}$ & $\begin{array}{c}\text { Average } \\
\text { hourly } \\
\text { rates. }\end{array}$ & $\begin{array}{l}\text { Average } \\
\text { hourly } \\
\text { temper- } \\
\text { ature. }\end{array}$ \\
\hline 1 & $\left\{\begin{array}{c}c . c . \\
0.22 \\
0.22 \\
0.09 \\
0.16\end{array}\right.$ & $\begin{array}{l}c . c . \\
0.17\end{array}$ & $\begin{array}{l}{ }^{\circ} C . \\
25.0\end{array}$ & 5 & $\left\{\begin{array}{c}c . c . \\
0.16 \\
0.16 \\
0.12 \\
0.12\end{array}\right.$ & $\begin{array}{l}\text { c.c. } \\
0.14\end{array}$ & $\begin{array}{l}{ }^{\circ} C . \\
26.2\end{array}$ \\
\hline 2 & $\left\{\begin{array}{l}0.16 \\
0.22 \\
0.12 \\
0.12\end{array}\right.$ & 0.16 & 25.0 & 6 & $\begin{array}{l}0.12 \\
0.12 \\
0.12 \\
0.12\end{array}$ & 0.12 & 26.4 \\
\hline 3 & $\left\{\begin{array}{l}0.09 \\
0.22 \\
0.09 \\
0.22\end{array}\right.$ & 0.16 & 25.4 & 7 & $\begin{array}{l}0.06 \\
0.12 \\
0.12 \\
0.12\end{array}$ & 0.11 & 26.4 \\
\hline 4 & $\left\{\begin{array}{l}0.09 \\
0.12 \\
0.12 \\
0.16\end{array}\right.$ & 0.12 & 25.9 & 8 & $\left\{\begin{array}{l}0.09 \\
0.09 \\
0.09 \\
0.09\end{array}\right.$ & 0.09 & 26.5 \\
\hline & & & & 9 & $\left\{\begin{array}{l}0.09 \\
0.09\end{array}\right.$ & 0.09 & 26.5 \\
\hline
\end{tabular}


Examination of tables 3 to 8 brings to light several apparently important points. In the first place, it should be remarked that there are much wider variations in temperature in these experiments than is to be desired; no doubt the differences in temperature ranges between the several series of observations make up one of the important complexes of uncontrolled and unanalyzed conditions. Nevertheless, as

TABLE 7.-Numerical data for two tests with osmometer $A$, operating against soil mixture with 10 per cent of soil moisture, on basis of dry volume, unpacked (11.4 per cent on dry weight basis in first test and 7.6 per cent in second).

\begin{tabular}{|c|c|c|c|c|c|c|}
\hline \multirow{2}{*}{$\begin{array}{l}\text { No. of } \\
\text { hour } \\
\text { period. }\end{array}$} & \multicolumn{2}{|c|}{$\begin{array}{l}\text { Hourly rates per } \\
10 \text { sq. cm., for } \\
15 \text {-min. periods. }\end{array}$} & \multicolumn{2}{|c|}{$\begin{array}{l}\text { Average hourly } \\
\text { rates. }\end{array}$} & \multicolumn{2}{|c|}{$\begin{array}{l}\text { Average hourly } \\
\text { temperature. }\end{array}$} \\
\hline & $\begin{array}{l}\text { First } \\
\text { test. }\end{array}$ & $\begin{array}{l}\text { Second } \\
\text { test. }\end{array}$ & $\begin{array}{l}\text { First } \\
\text { test. }\end{array}$ & $\begin{array}{c}\text { Second } \\
\text { test. }\end{array}$ & $\begin{array}{l}\text { First } \\
\text { test. }\end{array}$ & $\begin{array}{c}\text { Second } \\
\text { test. }\end{array}$ \\
\hline & $\begin{array}{l}\text { c.c. } \\
0.31\end{array}$ & $\begin{array}{l}\text { c.c. } \\
0.16\end{array}$ & c.c. & c.c. & ${ }^{\circ} \mathrm{C}$ & ${ }^{\circ} \mathrm{C}$ \\
\hline 1 & $\begin{array}{l}0.25 \\
0.19 \\
0.16\end{array}$ & $\begin{array}{l}0.19 \\
0.16 \\
0.12\end{array}$ & 0.23 & 0.16 & 24.0 & 26.4 \\
\hline 2 & $\begin{array}{l}0.12 \\
0.09 \\
0.09 \\
0.09\end{array}$ & $\begin{array}{l}0.09 \\
0.06 \\
0.09 \\
0.12\end{array}$ & 0.10 & 0.09 & 23.9 & 26.7 \\
\hline 3 & $\begin{array}{l}0.06 \\
0.09 \\
0.12 \\
0.06\end{array}$ & $\begin{array}{l}0.12 \\
0.06 \\
0.12 \\
0.09\end{array}$ & 0.08 & 0.10 & 24.2 & 27.2 \\
\hline 4 & $\begin{array}{l}0.06 \\
0.09 \\
0.09 \\
0.12\end{array}$ & $\begin{array}{l}0.09 \\
0.09 \\
0.06 \\
0.06\end{array}$ & 0.09 & 0.08 & 24.8 & 27.7 \\
\hline .5 & $\begin{array}{l}0.06 \\
0.06 \\
0.06 \\
0.06\end{array}$ & $\begin{array}{l}0.06 \\
0.16 \\
0.06 \\
0.09\end{array}$ & 0.06 & 0.12 & 25.6 & 28.3 \\
\hline 6 & $\begin{array}{l}0.06 \\
0.09 \\
0.06 \\
0.09\end{array}$ & $\begin{array}{l}0.12 \\
0.09 \\
0.06 \\
0.03\end{array}$ & 0.08 & 0.08 & 26.4 & 28.8 \\
\hline 7 & $\begin{array}{l}0.03 \\
0.09 \\
0.09 \\
0.09\end{array}$ & $\begin{array}{l}0.12 \\
0.09 \\
0.09 \\
0.06\end{array}$ & 0.08 & 0.09 & 27.3 & 29.4 \\
\hline 8 & $\begin{array}{l}0.06 \\
0.09 \\
0.06 \\
0.12\end{array}$ & $\begin{array}{l}0.12 \\
0.06 \\
0.03 \\
0.09\end{array}$ & 0.08 & 0.08 & 28.1 & 29.9 \\
\hline$\theta$ & $\begin{array}{l}0.09 \\
0.09 \\
0.06 \\
0.03\end{array}$ & $\begin{array}{l}0.09 \\
0.03 \\
0.06 \\
0.06\end{array}$ & 0.07 & 0.06 & 28.4 & 29.7 \\
\hline
\end{tabular}


has been already noted, no attempt will here be made to incorporate temperature correction into our considerations.

One of the most striking features of all the series lies in the fact that the initial absorption rate is very high and that it is followed by a rapid decrease, this decrease being most rapid within a short period at the outset of the experiment. For more ready comparison, the average hourly rates for all these series are brought together in table 9 , to which are appended the several means of these series averages, beginning with hour 3.

TABLE 8.-Numerical data for osmometer A, operating against soil mixture with 5 per cent of moisture, on basis of dry volume, unpacked (4.1 per cent on dry weight basis). (As used, 0.071 c.c. of water occupied 1 c.c. of soil.)

\begin{tabular}{|c|c|c|c|c|c|c|c|}
\hline $\begin{array}{l}\text { No. of } \\
\text { hour } \\
\text { period. }\end{array}$ & $\begin{array}{l}\text { Hourly } \\
\text { rates per } \\
10 \text { sq. } \mathrm{cm} ., \\
\text { for } 15 \text {-min. } \\
\text { periods. }\end{array}$ & $\begin{array}{c}\text { Average } \\
\text { hourly } \\
\text { rates. }\end{array}$ & $\begin{array}{l}\text { Average } \\
\text { hourly } \\
\text { temper- } \\
\text { ature. }\end{array}$ & $\begin{array}{l}\text { No. of } \\
\text { hour } \\
\text { period. }\end{array}$ & $\begin{array}{l}\text { Hourly } \\
\text { rates per } \\
10 \mathrm{sq} . \mathrm{cm} ., \\
\text { for } 15-\mathrm{min} . \\
\text { periods. }\end{array}$ & $\begin{array}{l}\text { Average } \\
\text { hourly } \\
\text { rates. }\end{array}$ & $\begin{array}{l}\text { Average } \\
\text { hourly } \\
\text { temper- } \\
\text { ature. }\end{array}$ \\
\hline 1 & $\left\{\begin{array}{l}c . c . \\
0.12 \\
0.06 \\
0.03 \\
0.03\end{array}\right.$ & $\begin{array}{l}c . c . \\
0.06\end{array}$ & $\begin{array}{l}{ }^{\circ} C . \\
26.2\end{array}$ & 4 & $\left\{\begin{array}{c}c . c . \\
0.03 \\
0.03 \\
0.03 \\
0.03\end{array}\right.$ & $\begin{array}{l}c . c . \\
0.03\end{array}$ & $\begin{array}{l}{ }^{\circ} C . \\
27.0\end{array}$ \\
\hline 2 & $\left\{\begin{array}{l}0.03 \\
0.06 \\
0.03 \\
0.03\end{array}\right.$ & 0.04 & 26.3 & 5 & $\left\{\begin{array}{l}0.03 \\
0.03 \\
0.03 \\
0.03\end{array}\right.$ & 0.03 & 27.0 \\
\hline 3 & $\left\{\begin{array}{l}0.03 \\
0.03 \\
0.03 \\
0.03\end{array}\right.$ & 0.03 & 26.7 & 6 & $\left\{\begin{array}{l}0.03 \\
0.03\end{array}\right.$ & 0.03 & 27.0 \\
\hline
\end{tabular}

From table 9 it appears that the 5 and 10 per cent soils exhibited the lowest average hourly rates and also maintained these rates nearly constant after hour 2 . It is also clear that the 25 per cent soil and the 20 per cent soil with usual packing failed to maintain a rate at any time during the period of the test, but showed a generally continued decrease until the end. This observation appears to apply more truly to the former than to the latter of these two soils. Furthermore, although the firmly packed 20 per cent soil presents a fairly uniform rate during the last 7 hours of the test, the 15 per cent soil packed as usual fails to show such uniformity and appears to belong in the category of the 25 and 20 per cent mixtures. From the general appearance and texture of the various soils (but without adequate tests) it was concluded that the soils having 25 and 20 per cent of moisture contained more than their optimum water content (as this term is now understood by soil physicists), while, as has been stated, that with 15 per cent was taken to represent about the optimum. If the optimum moisture content, as judged by touch and appearance, really represents a critical 
state of the soil- -as has been indicated by the studies of Cameron and Gallagher ${ }^{1}$ - and if the optimum for this soil lies in the neighborhood of 15 per cent of soil moisture, it is not surprising to find that the degree of packing of the 20 per cent soil seems to determine in which of our two categories it belongs. Following this suggestion, we may say, tentatively at least, that those of our soils which were at or above the optimum critical point in moisture content and were not firmly packed failed to maintain a rate of supply to the osmometer, those below this point, similarly packed, were able to maintain such a rate, and the

TABLE 9.-Average hourly rates of absorption by osmometer $A$, operating against soi s of various moisture contents, together with corresponding mean rates for third and later hours.

\begin{tabular}{|c|c|c|c|c|c|c|c|}
\hline \multirow{3}{*}{$\begin{array}{l}\text { No. of hour } \\
\text { period. }\end{array}$} & \multicolumn{7}{|c|}{ Percentage of water, on basis of dry volume. } \\
\hline & \multirow{2}{*}{25} & \multicolumn{2}{|c|}{20} & \multirow{2}{*}{15} & \multicolumn{2}{|c|}{10} & \multirow[b]{2}{*}{5} \\
\hline & & $\begin{array}{c}\text { Usual } \\
\text { packing. }\end{array}$ & $\begin{array}{l}\text { Firm } \\
\text { packing. }\end{array}$ & & $\begin{array}{l}\text { First } \\
\text { test. }\end{array}$ & $\begin{array}{l}\text { Second } \\
\text { test. }\end{array}$ & \\
\hline $\begin{array}{l}1 \ldots \ldots \ldots \\
2 \ldots \ldots \\
3 \ldots \ldots \\
4 \ldots \ldots \\
5 \ldots \ldots \\
6 \ldots \ldots \\
7 \ldots \ldots \\
8 \ldots \ldots \\
9 \ldots \ldots \\
9 \ldots \ldots\end{array}$ & $\begin{array}{c}c . c . \\
0.63 \\
0.39 \\
0.31 \\
0.24 \\
0.16 \\
0.14 \\
\ldots \\
\ldots \\
\ldots\end{array}$ & $\begin{array}{l}\text { c.c. } \\
0.34 \\
0.28 \\
0.17 \\
0.13 \\
0.12 \\
0.12 \\
0.05 \\
0.10 \\
\ldots .\end{array}$ & $\begin{array}{l}\text { c.c. } \\
0.35 \\
0.18 \\
0.17 \\
0.16 \\
0.14 \\
0.12 \\
0.13 \\
0.15 \\
0.14\end{array}$ & $\begin{array}{c}c . c . \\
0.17 \\
0.16 \\
0.16 \\
0.12 \\
0.14 \\
0.12 \\
0.11 \\
0.09 \\
0.09\end{array}$ & $\begin{array}{l}c . c . \\
0.23 \\
0.10 \\
0.08 \\
0.09 \\
0.06 \\
0.08 \\
0.08 \\
0.08 \\
0.07\end{array}$ & $\begin{array}{l}c . c . \\
0.16 \\
0.09 \\
0.10 \\
0.08 \\
0.12 \\
0.08 \\
0.09 \\
0.08 \\
0.06\end{array}$ & $\begin{array}{c}\text { c.c. } \\
0.03 \\
0.04 \\
0.03 \\
0.03 \\
0.03 \\
0.03 \\
\ldots . \\
\ldots \\
\ldots\end{array}$ \\
\hline $\begin{array}{l}\text { Average main- } \\
\text { tained rate*. }\end{array}$ & $\dagger 0.21$ & $\uparrow 0.12$ & 0.14 & $\uparrow 0.12$ & 0.08 & 0.09 & 0.03 \\
\hline
\end{tabular}

*After hour 2. $\quad$ But there is a general fall in the rate to the end of the experiment.

well-packed sample of the 20 per cent mixture behaved as though it were below the critical point. How much truth there may be in this generalization, and what may be its importance if true, must remain for future investigation to bring out.

Turning to the relative magnitudes of the absorption rates, as shown in table 9 , the initial average hourly rates are seen to give, generally, an indication of the moisture content, as ought of course to be expected. The peculiarly high initial rate shown by the first test of the 10 per cent soil, as well as the near approach to agreement in the initial rates for the 15 per cent soil and for the second test of the 10 per cent, are not explainable from any information at hand. As shown in the heading of table 7, a marked difference was apparent, as to packing, between the two samples of the last-named soil mixture; but a priori considerations would be out of place in this connection and we are unable otherwise to discuss the matter without further experimentation.

${ }^{1}$ Cameron, F. K., and F. E. Gallagher, Moisture content and physical condition of soils. U. S. Dept. Agric., Bur. Soils Bull. 50. 1908. 
Where absorption rates were maintained, they appear clearly to indicate the moisture content and the water-supplying power. The 5 per cent sample could supply water to the absorbing surface at a rate of 0.03 c.c. per hour per 10 sq. cm. of area; the 10 per cent samples could supply moisture to the osmometer at an hourly rate of 0.08 or 0.09 c.c.; and the firmly packed 20 per cent sample maintained a rate of 0.14 c.c.

On the other hand, the data for the soils which did not exhibit maintained rates fail to give any real indication as to the maximum possible rates at which these soils might supply water; in these cases it appears clearly that a marked and progressive drying of the soil near the absorbing surface has entered into the dynamics of the system, and that this drying might have been wholly or partially avoided had a less concentrated sugar solution been employed. Thus, for example, we dare not assert that the 25 per cent soil sample might not have maintained a rate as high as 0.39 c.c. if the initial rate had been lower, through the use of a weaker solution as absorbent. It is true that this same consideration may apply, in a much less marked degree, to the soil mixtures which did exhibit maintained rates. If the osmometric method here introduced becomes available for physiological and ecological measurements, lower concentrations will need to be studied. To some considerations of the probable nature and effects of the drying out of the soil layer next the absorbing surface we shall turn in a later paragraph.

\section{OSMOMETER B.}

\section{WATER AND SOIL TESTS WITH OSMOMETER B.}

This instrument had an effective area of $8.35 \mathrm{sq} . \mathrm{cm}$. and a coefficient of correction of 1.198. It was tested against water and operated against soil mixtures in a manner quite similar to that used in the case of instrument $\mathrm{A}$. The details of these tests bring out no more than has been shown by the details already presented and they will therefore be suppressed here. It is expedient, also, to present the data for water and soil tests together.

The average hourly rates, together with their means, for two similar tests with water, and for one test with 25 per cent, two tests with 20 per cent, and one test with 15 per cent soil, will be considered. The temperatures for these tests were of similar range, from about $27.5^{\circ}$ to about $31^{\circ} \mathrm{C}$, and all tests will be here regarded as comparable in this regard. The averages for all these experiments are set forth together in table 10. The final means represent the rates after the first hour, instead of after the second, as in the preceding case.

Table 10 shows the results of these water tests to be in good agreement with each other and with those from the first two similar tests with osmometer A. This means that instrument B had practically the same water-absorbing power per unit of area as had instrument A. 
It is to be noted, however, that the initially high rate is much more pronounced here than in the water tests presented in table 2.

The soil sample containing 25 per cent of water (on dry volume basis) exhibits here, again, a prolonged fall in water-supplying power, though the average hourly absorption rates more nearly approach uniformity in the present than in the former case. The two 20 per cent samples here agree very well in supplying power, but give a final mean markedly higher than that obtained in either ease with osmometer $\mathrm{A}$. This is probably mainly due to uncontrolled packing. The 15 per cent mixture exhibits a well-maintained water-supplying power after the first hour, the value of the final mean being somewhat but not markedly higher than in the case of instrument A.

TABLE 10.-Average hourly absorption rates for osmometer B, operating against water and various soil mixtures.

\begin{tabular}{|c|c|c|c|c|c|c|c|c|}
\hline \multirow{4}{*}{$\begin{array}{l}\text { No. of hour } \\
\text { period. }\end{array}$} & \multicolumn{8}{|c|}{ Average hourly rate. } \\
\hline & \multicolumn{3}{|c|}{ Against water. } & \multicolumn{5}{|c|}{ Against soil. } \\
\hline & \multirow{2}{*}{$\begin{array}{l}\text { First } \\
\text { test. }\end{array}$} & \multirow{2}{*}{$\begin{array}{l}\text { Second } \\
\text { test. }\end{array}$} & \multirow[b]{2}{*}{ Mean. } & \multirow[b]{2}{*}{$\begin{array}{l}25 \text { per } \\
\text { cent. }\end{array}$} & \multicolumn{3}{|c|}{20 per cent. } & \multirow[b]{2}{*}{$\begin{array}{l}15 \text { per } \\
\text { cent. }\end{array}$} \\
\hline & & & & & $\begin{array}{l}\text { First } \\
\text { test. }\end{array}$ & $\begin{array}{l}\text { Second } \\
\text { test. }\end{array}$ & Mean. & \\
\hline $\begin{array}{l}1 \ldots \ldots \\
2 \ldots \ldots \\
3 \ldots \ldots \\
4 \ldots \ldots \\
5 \ldots \ldots \\
6 \ldots \ldots \\
7 \ldots \ldots \\
8 \ldots \ldots\end{array}$ & $\begin{array}{c}c . c . \\
1.68 \\
1.32 \\
1.34 \\
1.32 \\
1.25 \\
1.40 \\
1.41 \\
1.39\end{array}$ & $\begin{array}{c}c . c . \\
1.63 \\
1.40 \\
1.49 \\
1.52 \\
1.47 \\
\ldots . \\
\ldots .\end{array}$ & $\begin{array}{c}c . c . \\
1.66 \\
1.36 \\
1.42 \\
1.42 \\
1.36 \\
1.40 \\
1.41 \\
1.39\end{array}$ & $\begin{array}{c}c . c . \\
0.45 \\
0.33 \\
0.30 \\
0.28 \\
0.27 \\
0.29 \\
0.25 \\
0.21\end{array}$ & $\begin{array}{c}\text { c.c. } \\
0.27 \\
0.24 \\
0.24 \\
0.23 \\
0.22 \\
0.23 \\
0.22 \\
0.23\end{array}$ & $\begin{array}{c}c . c . \\
0.34 \\
0.25 \\
0.27 \\
0.23 \\
0.24 \\
0.23 \\
0.19 \\
0.22\end{array}$ & $\begin{array}{c}c . c . \\
0.31 \\
0.25 \\
0.26 \\
0.23 \\
0.23 \\
0.23 \\
0.21 \\
0.23\end{array}$ & $\begin{array}{l}c . c . \\
0.26 \\
0.14 \\
0.16 \\
0.15 \\
0.15 \\
0.15 \\
0.15 \\
0.15\end{array}$ \\
\hline $\begin{array}{l}\text { Average main- } \\
\text { tained rate*... }\end{array}$ & $\ldots$ & $\ldots$ & 1.39 & t0.28 & & $\ldots$ & 0.23 & 0.15 \\
\hline
\end{tabular}

*After hour 1.

†But there appears to be here, as with osmometer A (table 9), a general fall in rate throughout the experiment.

Considering the facts that the packing of our soil samples was inadequately controlled and that constant temperature was not maintained, the results of these tests appear to be in very satisfactory agreement with those already presented.

\section{OSMOMETER C.}

WATER AND SOIL TESTS WITH OSMOMETER C.

This instrument had an effective absorbing area of $13.3 \mathrm{sq} . \mathrm{cm}$. and a calibration coefficient of 0.754 . Below will be presented the results of two water tests with this instrument, together with those obtained by operating it against 5 per eent soil in the usual manner. Also, this instrument was employed for studying the effect of placing a dry soil layer between the absorbing surface and the supplying soil, and 
the results of this study will be presented. Finally, a test of the watersupplying power of a soil in which a plant had become permanently wilted will receive some attention. The experiments with water and those with soil will again be presented together.

For the two experiments where the instrument operated against water, and for one test with 5 per cent soil (on basis of dry volume), the average hourly rates and means are given in table 11, which conforms with table 10 . The 15-minute rates are again suppressed, since they show no new points. The temperature ranges for these tests were approximately comparable within the group and with most of the tests heretofore considered, being from about $27^{\circ}$ to about $31^{\circ} \mathrm{C}$. The final means represent the rates after the first hour.

The results shown in table 11 agree in general with the corresponding ones of the series above presented, and require no special comment. We shall now consider the three special soil tests made with osmometer C.

TABLE 11.-Average hourly absorption rates of osmometer $C$, operating against water and against soil mixture containing 5 per cent of soil moisture (on basis of dry volume).

\begin{tabular}{|c|c|c|c|c|}
\hline \multirow{3}{*}{$\begin{array}{l}\text { No. of hour } \\
\text { period. }\end{array}$} & \multicolumn{4}{|c|}{ Average hourly rate. } \\
\hline & \multicolumn{3}{|c|}{ Against water. } & \multirow{2}{*}{$\begin{array}{l}\text { Against } \\
5 \text { per cent } \\
\text { soil. }\end{array}$} \\
\hline & $\begin{array}{l}\text { First } \\
\text { test. }\end{array}$ & $\begin{array}{l}\text { Second } \\
\text { test. }\end{array}$ & Mean. & \\
\hline & c.c. & c.c. & c.c. & c.c. \\
\hline $1 \ldots \ldots$ & 1.44 & 1.39 & 1.42 & 0.10 \\
\hline & 1.29 & 1.25 & 1.27 & 0.05 \\
\hline & 1.34 & 1.30 & 1.32 & 0.03 \\
\hline & 1.38 & 1.33 & 1.36 & 0.03 \\
\hline & 1.39 & 1.29 & 1.34 & 0.04 \\
\hline & 1.43 & $\ldots$ & 1.43 & $\ldots$ \\
\hline & 1.34 & $\ldots$ & 1.34 & $\ldots$ \\
\hline & 1.43 & .. & 1.43 & $\cdots$ \\
\hline $\begin{array}{c}\text { Average main- } \\
\text { tained rate*... }\end{array}$ & $\ldots$ & $\cdots$ & 1.36 & 0.04 \\
\hline
\end{tabular}

*After first hour.

It has been noted throughout the presentation of experimental results that all soil tests and some water tests agree in showing unusally high initial absorption rates, these rates tending subsequently to decrease with more or less rapidity toward a lower rate, which was long maintained in the case of the drier soils. It appears probable that two sets of conditions may be operative in bringing about this phenomenon. The first of these may be a set of conditions within the osmometer, the second set seems to lie outside.

What may be the causative factors inside the osmometer can not now be determined. They may be related to changes in the membrane in relation to its imbibed water (as through variations in tension between the imbibed water and external water, brought about when the instrument is emptied of distilled water and placed in active use with a sugar solution upon one side). They may be related to some critical limit 
of absorption that must needs be attained before the convection current necessary for the action of the instrument becomes operative. Or, they may be related to maximum sugar concentration in the membrane itself, which might control the intake of water through its action in clogging the water ways.

The fact that the high initial rate and rapid subsequent decrease do frequently occur when the instruments operate against water clearly shows that soil is not essential to this occurrence. It is clear, however, that the phenomenon in question is not nearly so pronounced in the water tests as in most of those with soil. Furthermore, long-continued fall in absorption rate appears to occur only with soils having a moisture content about or above the critical optimum, as has been remarked. This suggests that failure to show a maintained rate (which is accompanied by the exhibition of a very high initial rate) is mainly due to some adjustment which gradually takes place in the wetter soils, but which does not occur either in water or in the drier soils. If we cast about for some possible condition which may be supposed to control this important distinction between soils above their optimum water content, on the one hand, and both water and soils below their optimum, on the other hand, we discover that there is one pronounced feature of wet soils which is not marked in drier ones and not found at all in water itself. This feature is ready variability in the thickness of the water films which surround and lie between the soil particles. There are no such films in water itself and the films of drier soils are not very easily altered in thickness, and the possible amount of such alteration is greatly restricted.

If we consider a wet soil, such as the 25 per cent mixtures dealt with in our experiments, we must suppose that such a soil is, roughly, a three-phase system. The solid particles are each to be conceived as surrounded by a layer of water, these layers completely closing the spaces between the particles where the latter are small, but notcompletely closing them where they are large. The central portions of the larger spaces are filled by gas bubbles. If such a soil is in static equilibrium, as far as water adjustment is concerned, the water layers and air bubbles must remain constant in form and size. The water is held in place through (1) adbesion of water to the solid particles and (2) cohesion of the water itself. This latter force is here mainly manifested as the familiar force of gas-liquid surface tension, which tends to keep the gas bubbles small and thus resists removal of water. It is of much lower magnitude than the force of adhesion. These two forces together make up what is frequently termed capillary force, or simply capillarity.

If, now, we suppose a vertical plane to be passed through our hypothetical soil mass, the portion of the soil lying on one side of this plane being removed, and if we let a water-absorbing membrane (such as 
our collodion one, backed by an osmotic solution) be placed against the new soil surface thus formed, there should then be no alteration in the surface tensions effective at the gas-liquid surfaces, for such a membrane is to be thought of as saturated with imbibed water and covered on its exposed side by a water film. Our system would remain in static equilibrium if no movement of water were to occur through the membrane. But water does migrate from soil to osmometer solution (we need not here complicate the argument by attempting to analyze this process in detail), and the result of such migration, in its incipient stage, must be to decrease the thickness of the soil-moisture films lying nearest to the absorbing surface and to enlarge the gasliquid surfaces. In this process the water-attracting force exerted by our sugar solution is opposed by the tension of the water surfaces abutting upon gas bubbles, the water being held to the soil grains by the greater force of adhesion. Neither sugar nor soil particles can pass the membrane, hence it is clear that the water movement is dynamically dependent upon the relative magnitudes of the diffusion tension of the solution, on the one hand, and of the gas-liquid surface tension on the other. If the attraction of sugar solution for water were not as great as that of the opposed force, then water should move in the opposite direction, and the soil moisture films must thicken. It is not probable that the osmometer ever reduces the adjacent soil films to the hygroscopic state.

With the very inception of water absorption, then, the attraction for water exhibited by the thin layer of soil next to the membrane is more or less markedly increased. Before this occurrence, however, our hypothetical system was supposed to be in static equilibrium, as far as water movement is concerned, and now we find that the slightly dried soil layer is attracting water more strongly than the more distant portions of the soil mass. After such a disturbance equilibrium must tend to recur, which must imply water movement from more distant soil films to those which have been thinned. Thus the drying process is extended outward from the absorbing surface, and our process of absorption has now come to involve not only movement from soil to osmometer, but also movement from soil film to soil film. The latter phenomenon and its dynamics are apparently of fundamental importance to an appreciation of the water relation between plant and soil.

The migration of water from one part of the soil to another-from soil film to soil film-must of course take place through films already more or less thinned, and the thinner are the films involved the greater should be the force requisite to produce such movement at any given rate. This means that such movement must be exceedingly slow when the films are much thinned and, in any event, when its path becomes of considerable length. It must thus soon come about (usually within the first one or two short periods in our tests, apparently) that the 
ultimate controlling force determining the rate of water entrance into our osmometer becomes the capillary resistance just referred to. This control is no longer simply the relation between the water attraction of the sugar solution and that of the soil films adjacent to the membrane, though of course this relation is still the proximate control. The waterattracting force of the first soil layer has been greatly increased through partial drying and can not decrease except by income of water from more distant regions of the soil. Thus, at a certain stage, the rate of intake by the osmometer becomes limited by the rate of arrival of water in the active soil layer against the membrane.

In our experiments it appears that the gradually or rapidly lowered rate of water absorption is brought about on account of this last consideration, and the rates actually recorded, after the first short time interval, are the highest possible rates at which water can move from more distant regions to the actively supplying soil layer. Why does this fall in rate continue for so long a time in the moister soils and for so short a period in the drier ones? For answer to this question we need only to revert to the consideration of the ease with which the first decrement of water is removed from the soil in its assumed static condition. In the drier soils we may suppose that the water films are, at the start, so thin that their capillary force is nearly as great as the force exerted toward absorption by the osmometer. This condition may be supposed to obtain throughout the soil mass. Hence, when absorption begins there can occur but a relatively small amount of thinning of the water films nearest the membrane, and as the wave of movement progresses outward there can arise but little increase in the resistance offered to movement of water from soil film to soil film. Such a soil should very soon come into a state of dynamic equilibrium and its rate of supply should then be long maintained. This is exactly what seems to be exhibited by our soils below the critical point of optimum water content.

With the moister soils, on the other hand, there should be, at the outset, a much greater initial and early change in the thickness of the proximate soil films, and with progressive outward propagation of the disturbance thus inaugurated there should be a long-continued increase in the resistance offered to movement of moisture from more distant regions to the active layer. In the end, no doubt, an absorption rate should be maintained, but much longer time must elapse before this condition might be reached in the wetter soil than is required in the case of the drier one. This, also, is in agreement with the experimental findings set forth above.

From these considerations it was suggested that the initial interposition of a dry soil layer, between the osmotic membrane and the supplying soil, might diminish or remove altogether the phenomenon of high initial rate and prolonged decrease. This was tested in two 
cases, one with a soil of moisture content higher than its retaining capacity, and the other with the 25 per cent mixture already dealt with in some of the preceding tests.

For these two experiments the soil samples were prepared and placed in the jars in the usual manner, but a layer of air-dry soil $1 \mathrm{~cm}$. in thickness was interposed between the moist soil surface and the osmometer when the latter was brought into position. The numerical results are presented in detail in table 12. The temperature ranges here were again from about $28^{\circ}$ to about $31^{\circ} \mathrm{C}$.

TABLE 12.-Average hourly absorption rates for osmometer $C$, operating against moist soil mixtures with interposition of dry soil layer.

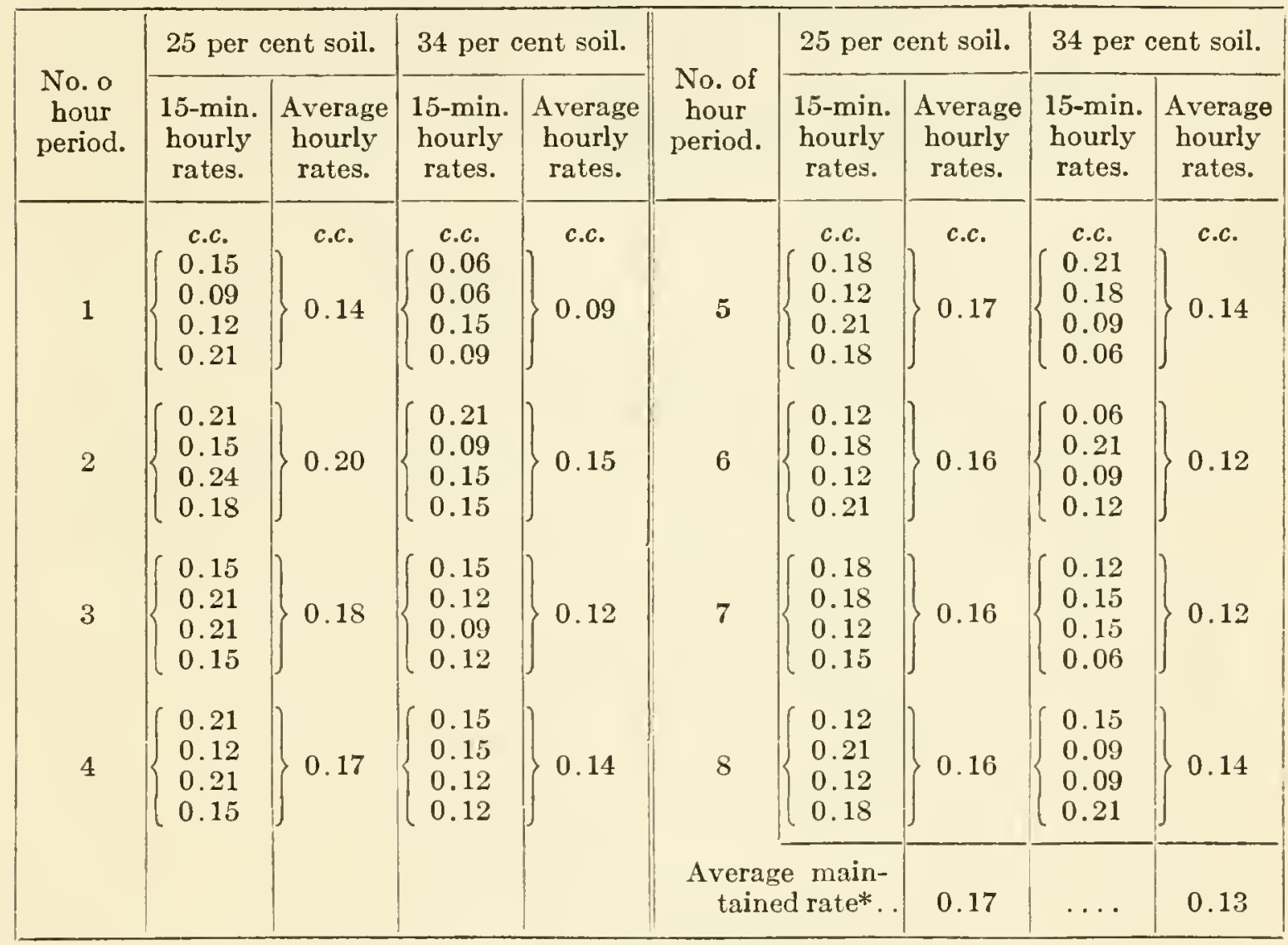

*After hour 1 .

The dry soil layer is seen to have prevented the high initial absorption rates otherwise usually shown. More than that, the initial rates are seen here to be low instead of high. It is also noticeable that both samples show comparatively uniform rates after the first hour, which was not true of the 25 per cent sample as usually arranged. Whether the higher mean rate exhibited by the drier of these two soils is a feature of importance or not can not now be stated. In any event, we may take it as probable that this method of testing may be expected to render the absorption rates from different but very moist soils more nearly alike than does the usual method. These results appear to support the general hypothetical treatment of the whole matter of high initial rate and more or less prolonged decrease, as above given. 
Finally, to obtain a preliminary idea of the moisture-supplying power of soils when they fail to support turgidity in plants rooted therein, osmometer $\mathrm{C}$ was operated against a soil in which a Phaseolus vulgaris plant had just attained the condition of permanent wilting. ${ }^{1}$ The plant, well grown and apparently healthy, had developed from seed in a sheet-metal cylinder. It had been sealed and allowed to wilt thoroughly in the glass box, with high humidity, employed by Shive and Livingston. The plant was lifted, allowing the roots to bring away as much soil as they would. The bottom of the opening thus formed in the soil was smoothed by removing loose soil and the TABLE 13.-Absorption rates of osmometer $C$, operating against soil in which Phaseolus plant had wilted with very low evaporation intensity.

\begin{tabular}{|c|c|c|c|c|c|}
\hline $\begin{array}{l}\text { No. of } \\
\text { hour } \\
\text { period. }\end{array}$ & $\begin{array}{l}\text { Hourly } \\
\text { rates, for } \\
15 \text {-min. } \\
\text { periods. }\end{array}$ & $\begin{array}{c}\text { Average } \\
\text { hourly } \\
\text { rates. }\end{array}$ & $\begin{array}{l}\text { No. of } \\
\text { hour } \\
\text { period. }\end{array}$ & $\begin{array}{l}\text { Hourly } \\
\text { rates, for } \\
15 \text {-min. } \\
\text { periods. }\end{array}$ & $\begin{array}{c}\text { Average } \\
\text { hourly } \\
\text { rates. }\end{array}$ \\
\hline 1 & $\left\{\begin{array}{l}c . c . \\
0.06 \\
0.15 \\
0.06 \\
0.03\end{array}\right.$ & $\begin{array}{l}\text { c.c. } \\
0.08\end{array}$ & 5 & $\begin{array}{l}\text { c.c. } \\
0.03 \\
0.03 \\
0.03 \\
0.00\end{array}$ & $\begin{array}{l}\text { c.c. } \\
0.02\end{array}$ \\
\hline 2 & $\begin{array}{l}0.03 \\
0.06 \\
0.03 \\
0.03\end{array}$ & 0.04 & 6 & $\begin{array}{l}0.03 \\
0.03 \\
0.06 \\
0.03\end{array}$ & 0.04 \\
\hline 3 & $\begin{array}{l}0.03 \\
0.00 \\
0.00 \\
0.03\end{array}$ & 0.02 & 7 & $\left\{\begin{array}{l}0.03 \\
0.03 \\
0.03 \\
0.03\end{array}\right.$ & 0.03 \\
\hline \multirow[t]{2}{*}{4} & $\begin{array}{l}0.06 \\
0.03 \\
0.03 \\
0.06\end{array}$ & \multirow[t]{2}{*}{0.05} & S & $\left\{\begin{array}{l}0.03 \\
0.03 \\
0.03 \\
0.03\end{array}\right.$ & 0.03 \\
\hline & & & $\begin{array}{r}\text { Aver } \\
\text { tai }\end{array}$ & $\begin{array}{l}\text { e main- } \\
\text { d rate*.. }\end{array}$ & 0.03 \\
\hline
\end{tabular}

*After hour 1.

osmometer was appressed against it. Cotton was packed about the instrument in the usual manner and the whole cylinder was then sealed with plastiline. The results of this test are given in table 13. The temperature range during the test was from $27.8^{\circ}$ to $31.0^{\circ}$.

At the end of this experiment the soil directly beneath the osmometer was found to have a moisture content of 4.2 per cent, on the basis of dry weight. It is probably safe to suppose that this soil had as low a water-supplying power $(0.03$ c.c. per hour through $10 \mathrm{sq} . \mathrm{cm}$. of crosssectional area) as any in which ordinary plants can usually maintain foliar turgidity. This single test is sufficient here to show the manner in which such osmometers as were here employed may be used for physiological inquiry.

'Shive and Livingston, 1914. This soil was from one of the wilting experiments of these authors. 


\section{CONCLUSION}

The experiments with which the preceding pages have had to deal have shown that collodion membranes are suitable for the making of osmotic cells to be used in the study of the water-supplying power of soils. The thistle-tube osmometers here used have served their purpose well, though many improving modifications might be suggested, and the instrument, even in its present form, promises to be very useful in the study of the neglected problems of the dynamic water-relation between plant and soil.

Our experiments have had to do with only one soil, aside from various water contents and degrees of packing, this soil being rather light ( 3 parts of sand and 1 part of clay loam, by dry volume). There seems to be no reason for doubt that the method here used may be found adapted to similar studies with other soils.

Packing is here shown to be of prime importance in determining the water-supplying power of the soil, and the lack of suitable methods for obtaining strictly comparable packing of a number of soil samples is one of the main obstacles to a rapid investigation of the field thus opened. There is reason to hope, however, that the requisite methods may soon be devised. In default of a better one, the mechanical method of packing employed by Cameron and Gallagher may be found advantageous, at least in the early stages of this study.

The importance of the degree of packing here emphasized brings again to the front the old question regarding the most satisfactory basis upon which to calculate soil-moisture content, in ecological and agricultural inquiries. It is once more made clear that it is the percentage of contained soil moisture on the basis of actual soil volume, and not at all this percentage calculated on dry weight of the soil, which plays an important part in determining the efficiency of the soil as a source of water supply to growing plants. This point has received emphasis from many writers on soil physics, but few seem yet to have sought to take cognizance of it in actual studies. Weight percentages should soon vanish from serious consideration in regard to soil-moisture relations.

After all, however, it is not the soil-moisture content (even when measured on the basis of actual volume) nor the data of physical analysis, that are directly effective as the subterranean water-relation controlling plant activities. The effective condition is the complex soil property, water-supplying power, which is itself a function of the nature, size, and arrangement of the solid particles and of the water content per unit volume. While the analysis of this water-supplying power into its component elements is very difficult, the whole maze of problems entailed by such analysis may be avoided by studying directly the 
complex property as such. Atmometry made little or no progress, as far as its use in physiology is concerned, so long as interest therein centered mainly in the analysis of evaporation into its component elements, but atmometric measurements became at once valuable in physiological work as soon as this almost futile attempt at analysis was largely replaced by suitable measurements of the evaporating power of the air as such. In a parallel way, it is to be hoped that studies of the water-supplying power of the soil may eventually place the subterranean environment (as far as water is concerned) in as satisfactory a condition for quantitative study as are now the water-relations of the aerial environment.

The influence of temperature upon the water-supplying power of the soil, or at least upon its measurement, appears to be of great importance. This is not seriously considered in the present paper, but should receive attention in later studies along these lines.

Turning now to the actual water-supplying powers which have been dealt with in the preceding pages, it appears that our osmotic solution (5-weight-molecular cane-sugar) was too concentrated to enable us to measure the water-supplying power of our soil mixtures with water content much above their critical optimum. The effect of such high water-absorbing power in the instrument is profoundly to alter the soil condition in the vicinity of the membrane, and thus to introduce a new and disconcerting factor into a problem already very complex. Future work will need to deal with lower osmotic concentrations of the absorbing medium, if apparatus may be devised for their use.

Below the critical moisture content our tests gave quite satisfactory results-for such a preliminary study as the present. The osmometers exhibited rates of water absorption that were maintained nearly constant for many hours. Among other results, it may be here recalled that a soil in which a Phaseolus plant had become strongly wilted, with very low evaporating power of the air, exhibited a measured water-supplying power expressed as 0.03 c.c. per hour through 10 sq. $\mathrm{cm}$. of cross-sectional area, at a temperature ranging from about $28^{\circ}$ to about $31^{\circ}$. This power, measured thus as a rate, may be compared with the water-supplying power of pure water in regard to the same osmometer. It will be remembered that this latter power was found to be about 1.36 to 1.39 c.c. per hour, for approximately the same absorbing area and temperature range. It is therefore possible to define the soil sample just considered as possessing a water-supplying power of about 0.02 , when the supplying power of water is considered as unity This may be taken as an example of the sort of quantitative measurement toward which our studies have been looking, as a goal distant but nevertheless apparently attainable.

For soils with moisture contents higher than the apparent critical optimum, our method, as has been stated, appears generally to fall short 
of furnishing definite maintained rates of absorption. Nevertheless, it demonstrates an apparently important initial absorption rate and also a subsequent fall, the gradient of which promises to be of some value in the quantitative estimation of the soil water-relation. There seems to be reason to expect that the employment of weaker solutions, as water absorbers, will alleviate this difficulty, but the matter has yet to be studied. Of fundamental interest, however, is the fact that the critical point in soil-moisture content, with which we have here to deal, appears to be approximately the same as that emphasized as the critical optimum water content by workers in other lines of soil physics. 


\section{LITERATURE CITED.}

Abel, J. J., L. G. Rowntree, and B. B. Turner.

1914. On the removal of diffusible substances from the circulating blood of living animals by dialysis. Jour. Pharmacol. and Exp. Therap. 5: 275-316.

Berkeley, Earl of, and E. G. Hartley.

1906. On the osmotic pressure of some concentrated aqueous solutions. Trans. Roy. Soc. London 206 A: 481-507.

Bigelow, S. L., and A. Gemberling.

1907. Collodion membranes. Jour. Amer. Chem. Soc. 29 : 1576-89.

Bovie, W. T.

1910. Effects of adding salts to the soil on the amount of nonavailable water. Bull. Torr.

CALDWELL, J. S. Bot. Club 37: 273-92.

1913. The relation of environmental conditions to the phenomenon of permanent wilting in plants. Physiol. Res. 1: 1-56.

Cameron, F. K., and F. E. Gallagher.

1908. Moisture content and physical condition of soils. U. S. Dept. Agric., Bur. Soils

Findiat, A. Bull. 50.

1913. Osmotic pressure. London.

Free, E. E.

1912. Studies in soil physics. Plant World 14:29-39, 59-66, 110-19, 164-76, 186-90. Also reprinted, repaged. Tucson. 1912.

Livingston, B. E.

1906. The relation of desert plants to soil moisture and to evaporation. Carnegie Inst. Wash. Pub. 50. Washington.

1909. Present problems in physiological plant ecology. Amer. Nat. 43: 369-77. The essentials of this paper appeared also, under the same title, in Plant World 12: 41-6. 1909.

1911. The relation of the osmotic pressure of the cell sap in plants to arid habitats. Plant World 14: 153-64.

1912. Present problems in soil physics as related to plant activities. Amer. Nat. 46: 294-301.

1913. Osmotic pressure and related forces as environmental factors. Plant World 16: $165-76$.

Livingston, B. E., and W. H. Brows.

1912. Relation of the daily march of transpiration to variations in the water content of foliage leaves. Bot. Gaz. 53: 311-30.

Livinaston, B. E, and L. A. Hawkins.

1915. The water relation between plant and soil. The first paper of the present publication. MatheWs, J. H.

1910. Osmotic experiments with collodion membranes. Jour. Phys. Chem. 14: 281-91.

Morge, H. N., W. W. Holland, E. G. Zies, C. N. Myens, W. M. Clark, and E. E. Gill.

1911. The relation of osmotic pressure to temperature. Part V. The measurements.

Overton, J. B. Amer. Chem. Jour. 45: 554-603.

1911. Studies on the relation of the living cells to the transpiration and sap-flow in Cyperus. Bot. Gaz. 51: 28-63, 102-20.

Powell, C. WV. R.

1914. Viscosity of sugar solutions. Jour. Chem. Soc. 105: 1-23.

ReNNer, O.

1911. Experimentelle Beiträge zur Kenntnis der Wasserbewegung. Flora 103: 171-247.

1912. (1) Versuche zur Mcchanik der Wasserversorgung. 1. Der Druck in den Leitungsbahnen von Freilandpflanzen (Vorläufigo Mitteilung). Ber. deutsch Bot. Ges. 30: 576-80.

(2) Versuche zur Mechanik der Wasserversorgung. 2. Ueber Wurzeltätigkeit (Vorläufge Mitteilung). Ber. deutsch. Bot. Ges. 30: 642-8.

(3) Ueber die Berechnung des Osmotischen Druckes. Biol. Centralbl. 32: 486-504.

SHive, J. W., and B. E. Livingston.

1914. The relation of atmospheric evaporating power to soil moisture content at permanent wilting in plants. Plant World 17:81-121.

Smith, G. M.

1913. The use of collodion membranes for the demonstration of osmosis. Bot. Gaz. 56 : 225-9.

IVhitney, M., and F. K. Cameron.

1903. The chemistry of the soil as related to crop production. U. S. Dept. Agric., Bur. Soils Bull. 22. 




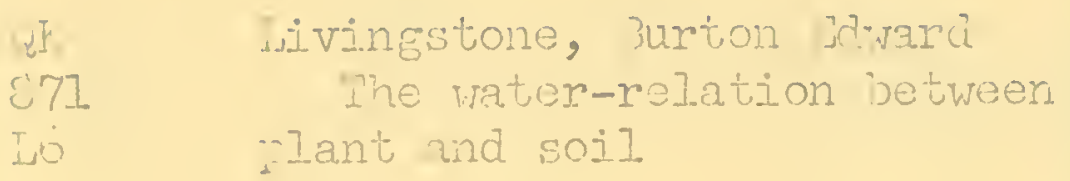

Biolier

PLEASE DO NOT REMOVE CARDS OR SLIPS FROM THIS POCKET UNIVERSITY OF TORONTO LIBRARY 
